\title{
DREAMS OF PARADISE
}

\author{
by \\ Afsaneh F. Asayesh \\ Bachelor of Environmental Design in Architecture \\ North Carolina State University, 1983
}

\author{
A thesis \\ presented to Ryerson University \\ in partial fulfillment of the \\ requirements for the degree of \\ Master of Architecture \\ in the program of \\ Architecture
}

Toronto, Ontario, Canada 2012

(C) Afsaneh F. Asayesh 2012 


\section{AUTHOR'S DECLARATION OF ELECTRONIC SUBMISSION OF A THESIS}

I hereby declare that I am the sole author of this thesis. This is a true copy of the thesis, including any required final revisions, as accepted by my examiners.

I authorize Ryerson University to lend this thesis to other institutions or individuals for the purpose of scholarly research.

I further authorize Ryerson University to reproduce this thesis by photocopying or by other means, in total or in part, at the request of other institutions or individuals for the purpose of scholarly research.

I understand that my thesis may be made electronically available to the public. 


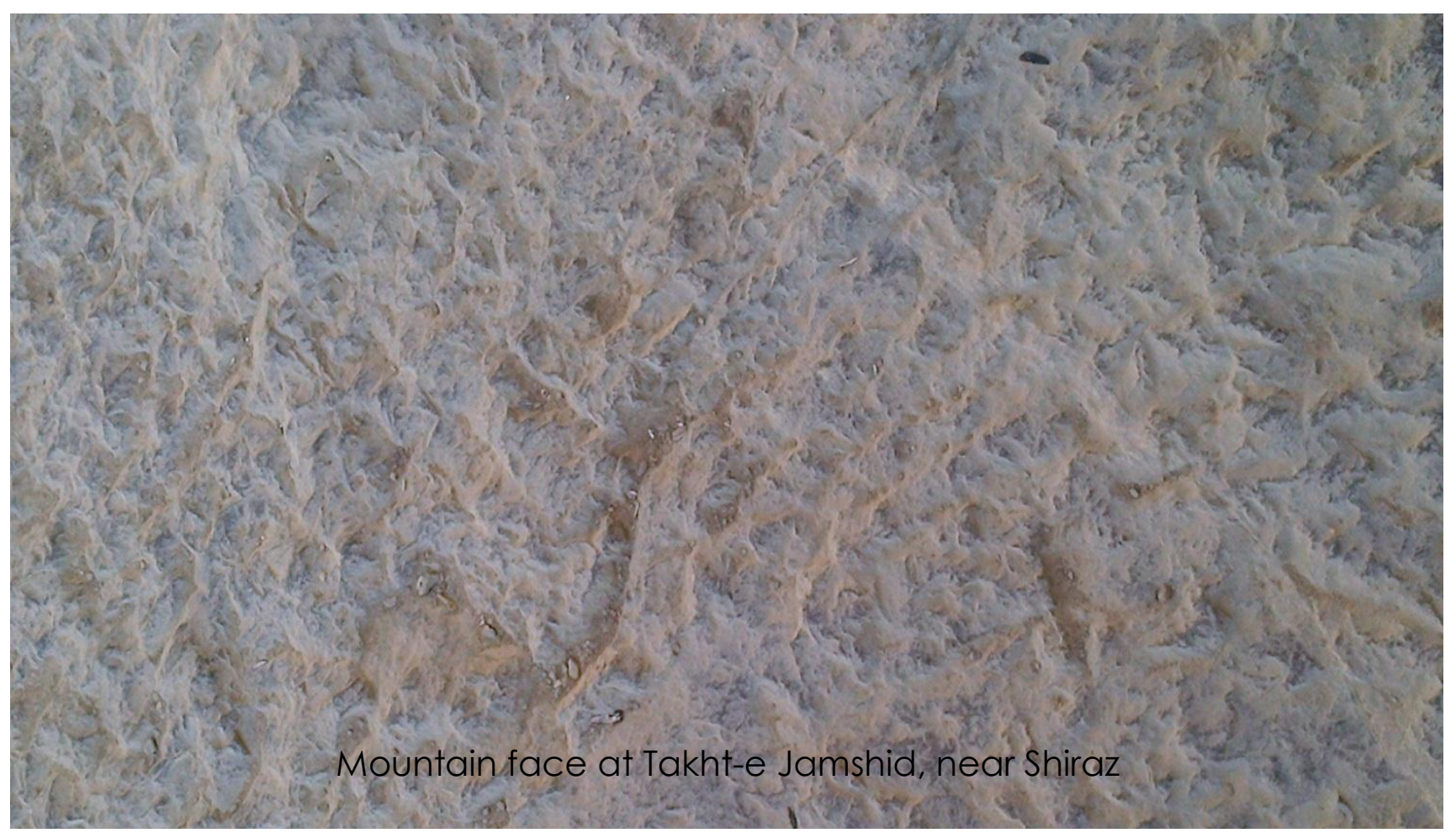




\section{THE PERSISTENCE OF MEMORY}

Memory is what shapes us. Memory drives our aspirations and our search for happiness, for paradise.

This project is situated within the architecture of memory, where it explores issues of journey and migration, reminiscence and desire, and the transformation that results when emotions overlay physical experiences of place. Its structure is the juxtaposition of the journey of paradise with a personal life journey, with memory as the driving force. In explorations and re-formations of paradises, it examines the internalization of place through memory and emotion, and extrapolates the powerful desires thus formed into new expressions of paradise.

Paradise - this powerful construct - has endured millennia, manifesting in painting, pottery, tiles, poetry, stained glass, carpets,.... and in architecture. As a place, Paradise is about contrast and tension : outside versus inside, lush garden versus arid desert, abundance versus desolation, growth versus stasis. It is about the sanctuary of a garden in contrast to the desert. Transformed into concept, it is about the promise of the ultimate sanctuary of happiness, a sanctuary against death and oblivion.

The journey of dissemination and transformation of Paradise is testament to the potency of memory as it propels change, interpreting physical space as we project the dreams of our internal architecture to re-fashion our world. 


\section{ACKNOWLEDGMENTS}

My gratitude extends first and foremost to my family here and in Iran - for understanding and accepting the need and supporting the effort. For all the sacrifices you have made on my behalf.

My father who gave a name to the quest for architecture all those years ago. My mother who reminded me to be kind to myself when things weren't going well. My sister who encouraged my aspirations. My husband who paid the price!, and without whose daily support and encouragement I could not have persevered. Above all, my children, who accepted less of my time and attention than they deserve.

Thanks to all my teachers and mentors - especially to Colin, who first planted the seed. I have benefited from your knowledge, support, enthusiasm, and forbearance in my journey. 
For Daria and Misha 


\title{
TABLE OF CONTENTS
}

The Persistence of Memory

(Abstract)

1.0 Pairi Daeza

\author{
Introduction \\ Thesis \\ Questions and Intentions \\ Background Information \\ Geography and Climate \\ Pairi Daeza \\ The First Garden \\ Before Walls \\ Why Paradise
}

Manifestations

2.0 The First Garden (Literature Review)

Origins of an Idea

Origins of a Place

Significance of Key Elements

Realm of Influence

Passage and re-formation

Memory and Interpretation 
3.0 The Architecture of Memory (Precedent Review)

Gardens (and Parks)

Buildings (Manifesting the Paradise Parti)

Houses

Hotels

Sacred Architecture (Mosque, Shrine, Tomb)

Public Architecture (Square, Bazaar, Museum)

4.0 Architecture of the Heart

A Journey

Intentions

Site \& Program

Parti

Materiality

5.0 The Persistence of Memory (Project)

6.0 The Medium is the Message

Bibliography

Images 


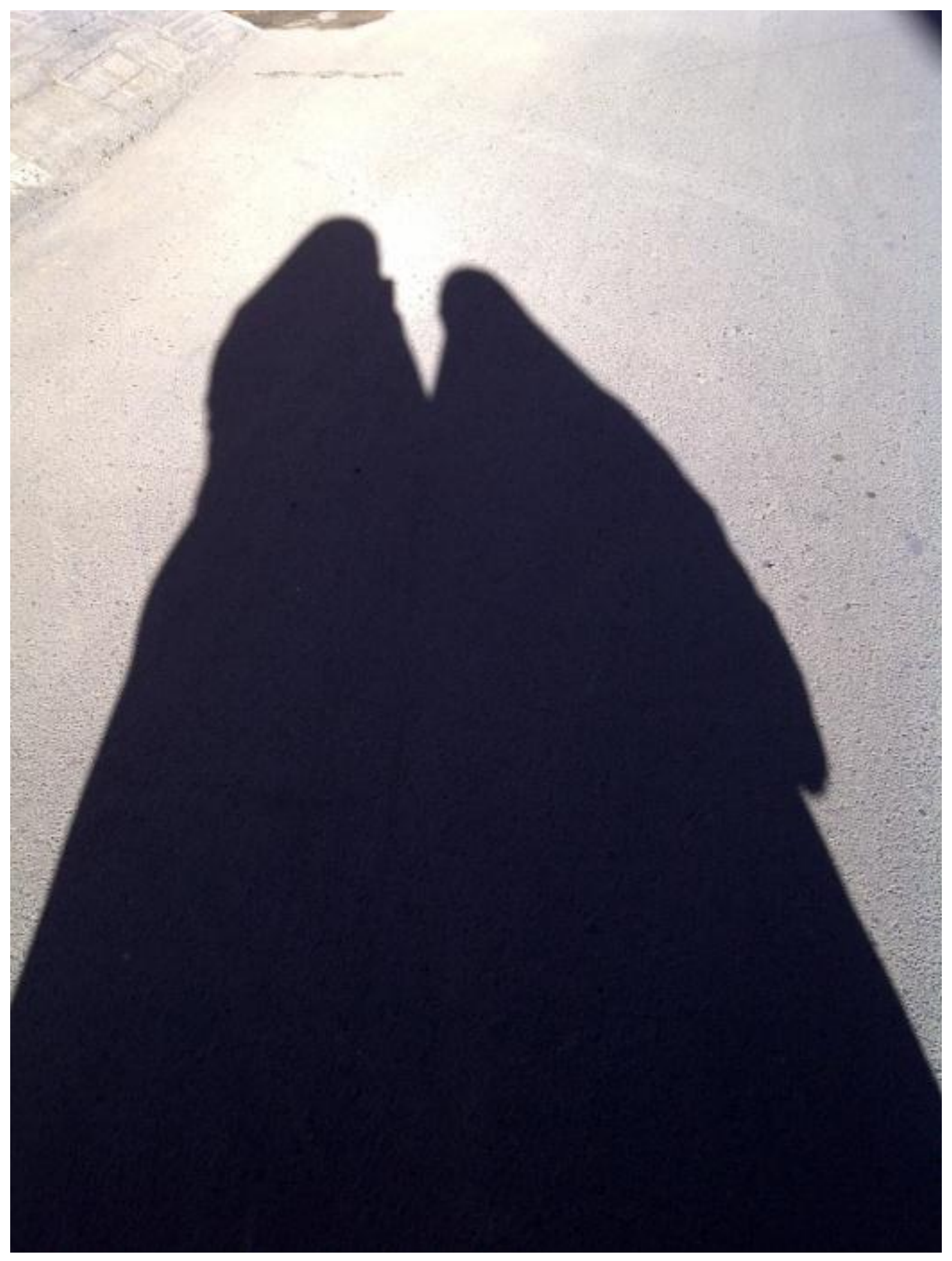


1. PAIR DAEZA

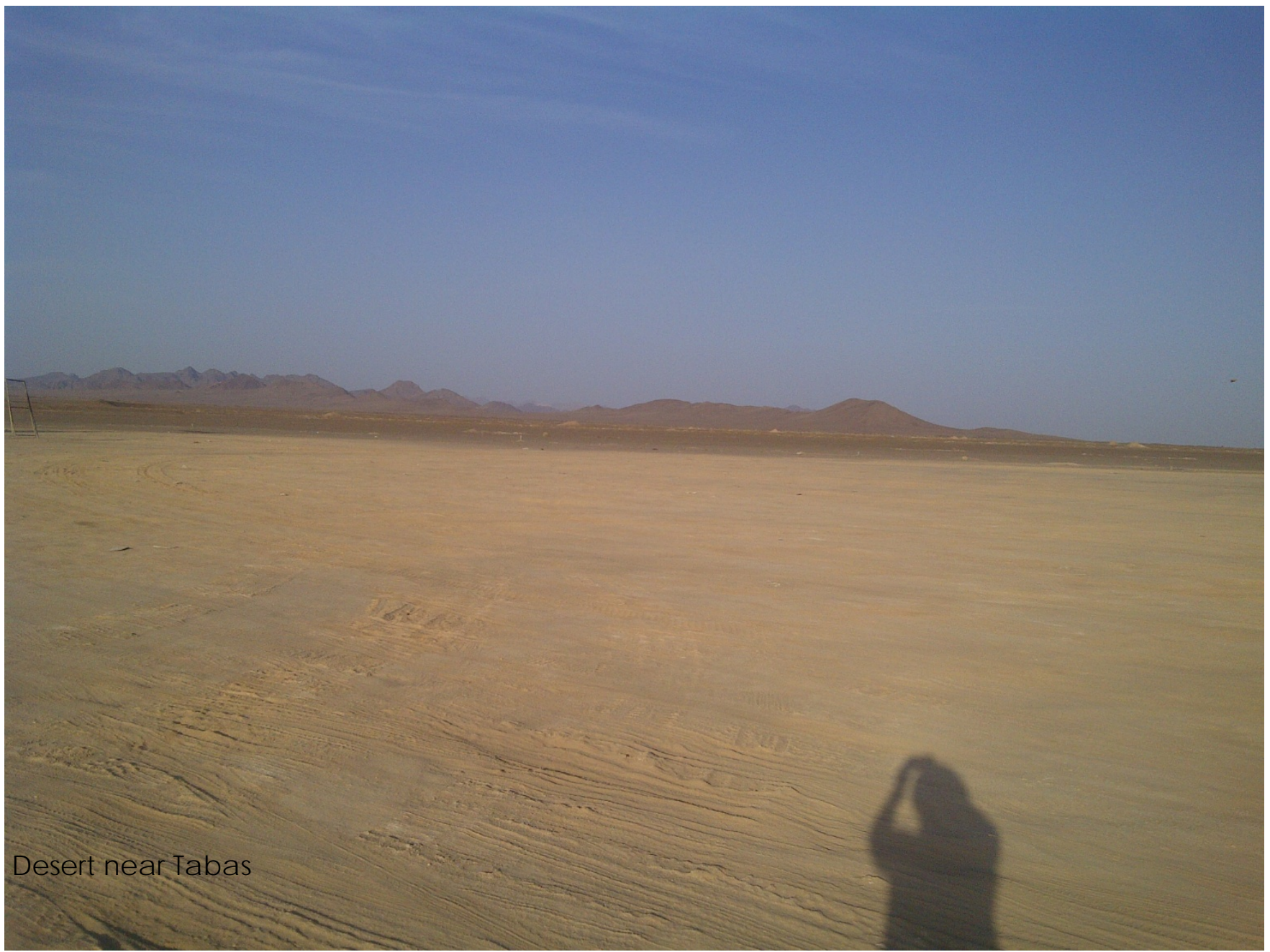




\section{INTRODUCTION}

"Architecture exists as a physical entity and therefore registers as a place that we come to remember... architecture, whether or not it still stands, can exist or be found beyond the physic al site itself in our recollection of it. We function always with what I call, an 'architecture of the heart', or a place within us that holds on to the emoting memory of a place. That is the symbolic construction that connects our idea or image of a place to its physicality." (Homstein, 2011. P.3)

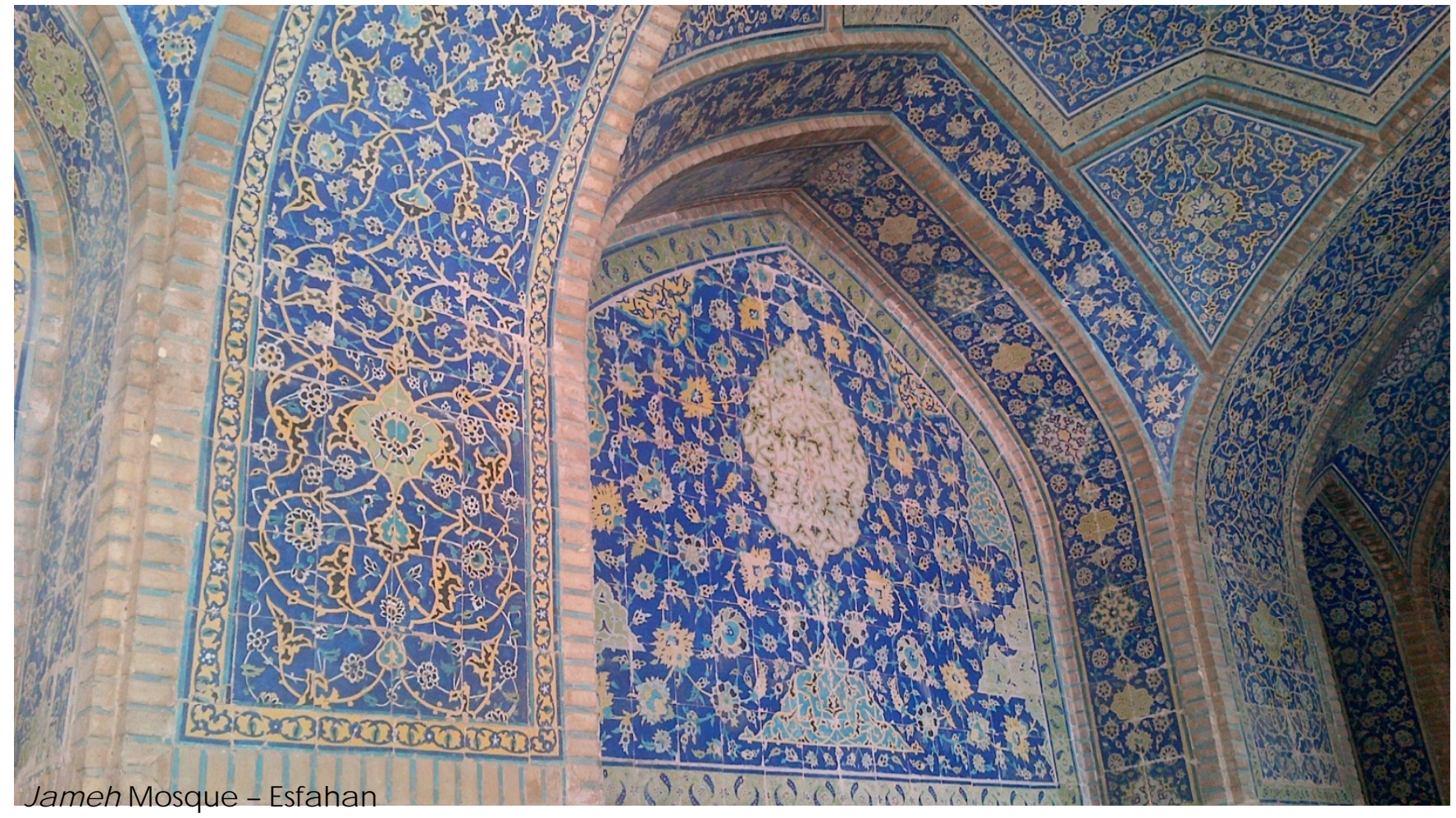




\section{Thesis}

Memory is what sha pes us. Memory drives our aspirations, and our search for happiness - for paradise.

Pain Daeza - a garden enclosed by walls - was a simple response to a harsh desert climate and the need for the respite of shelter. The passing of millennia, and encounters through joumey, memory, re-telling, and re-creating refracted this simple notion and manifested it in many locations and through multiple media. This process ultimately transformed "Paradise" into a potent aspirational concept overlaid with powerful emotions and desires for redemption and reward. Today, the word conjures images of peace and happiness, of etemal sanctuary.

In this thesis, I intend to look at how the forc es of joumey, migration, memory and desire transform a place into a powerful concept. Paralleling a personal joumey with that of Paradise, I will examine a reading of the paradises encountered along my travels, coalescing the memories into an intemal dream garden of visions.

As an immigrant, I face the challenge of reconciling the rupture at the core of continued existence, of bringing into a lignment memories of the conflicting worlds I inhabit. For this reason, the project is positioned in the realm of memory as it seeks to honour the past while illuminating the possibility of future paradises.

\section{Questions and Intentions}

In the beginning, there are only questions - spanning miles and millennia.

What is Paradise? Where and why did it originate? What was Paradise intended to be, and what did it transform into? What are the joumeys it has taken as a concept as well as a place? And most important - is there still paradise - and what does it look like now?

There is also a paradox: a place that originated as a climatic response in a moment of triumph hundreds of yea rs before the advent of J uda ism, Christia nity, or Islam has transformed into a potent dream to which all souls a spire, a universal concept overlaid with desire and passion. Disseminated through gardens, architecture, art, poetry and 
the interactions of the two most influential courts (Canepa, 2009) of the ancient world, the Paradise Garden was a major influence not only within Iran and the conquening Isla mic dynasties, but also throughout Asia and Europe.

My intention is to understand Paradise at its origins as well as through its joumey of transformation and myriad manifestations. To explore its essence as place as well as promise. Along the way, I will examine its current meaning through a search for personal relevance. Ultimately, I will und ertake to translate a construct originating 2600 years ago in an arid plateau to the lush lakeside of Toronto now.

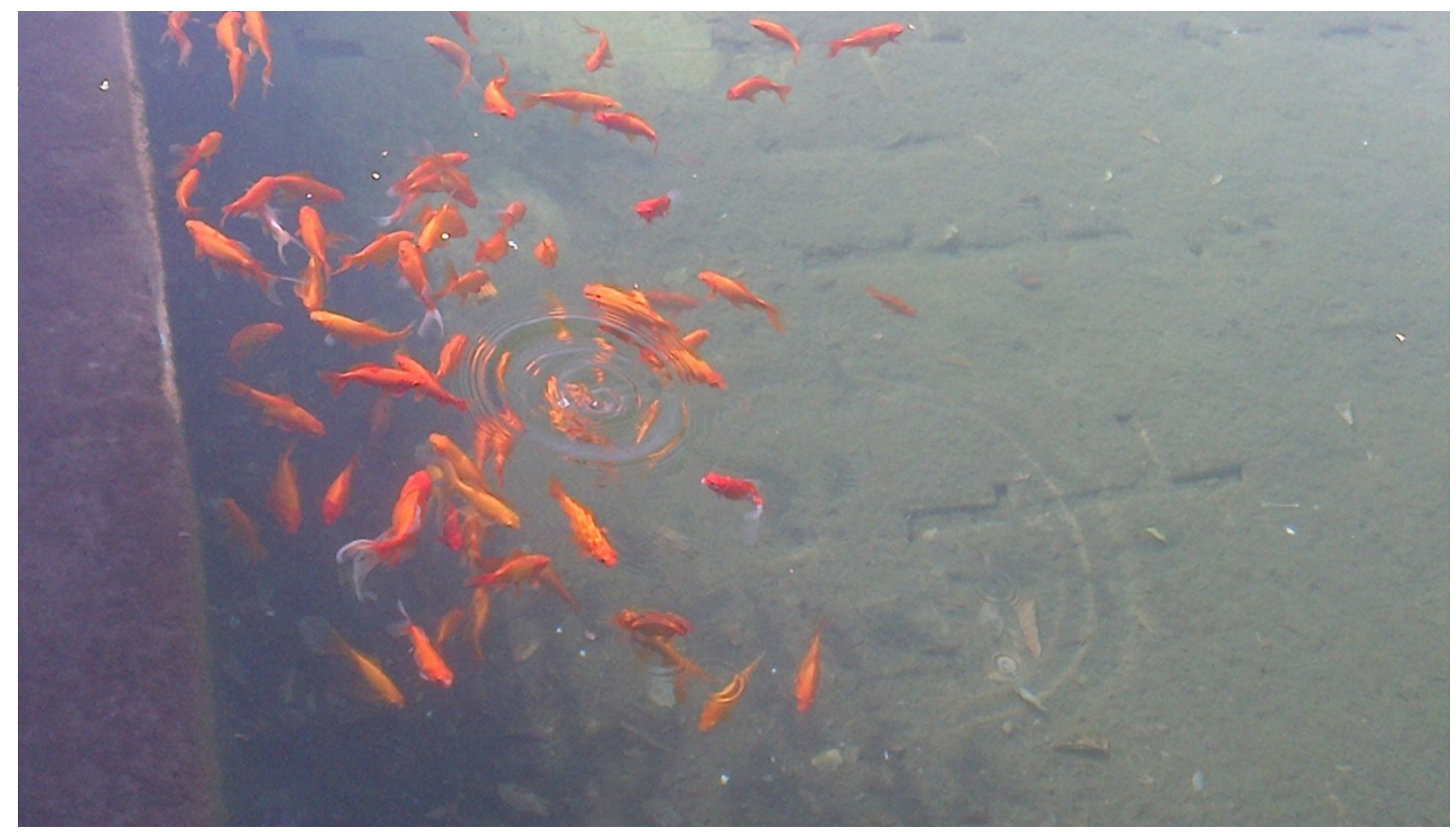

Some of the forces at play are ancient, having to do with pomp and pageantry, the rituals and privileges of roya Ity, expressions of power and circ umstance. Others deal with adaptation and transformation, resilience and resourcefulness in the face of invasion. The trajectory of transformation is tied to the history of a nation and its interactions as conquerors and under occupation, and thus, tied to the advent of globalization. All is propelled by memory - the stories we tell to and of ourselves - and 
the overlay of desires and projections. The nebulous and disjointed realm of memory, its mysterious operations and formidable power, is the language through which the joumey is narrated.

Secondary questions concem themselves with the signific ance of a number. Why seven? It is a number believed to represent perfection and plenty by the ancient Greeks(Wikipedia, 2012). Seven is a signific ant number throughout history and theology and in numerous other fields. (In fact, a search for book titles using the number yields 2339 results in the Ryerson Library catalogue!) There are seven days of the week - the number of days it took to create the universe. There are seven seas, seven heavens, seven virtues, and seven deadly sins. Seven is a prominent number in Zoroastria nism, Judaism, Christianity and Islam. There is a seven year itch, seven dwarves, seven wonders of the world, and even seven lamps of a rchitecture. So, seven it shall be. 


\section{BACKGROUND INFORMATION}

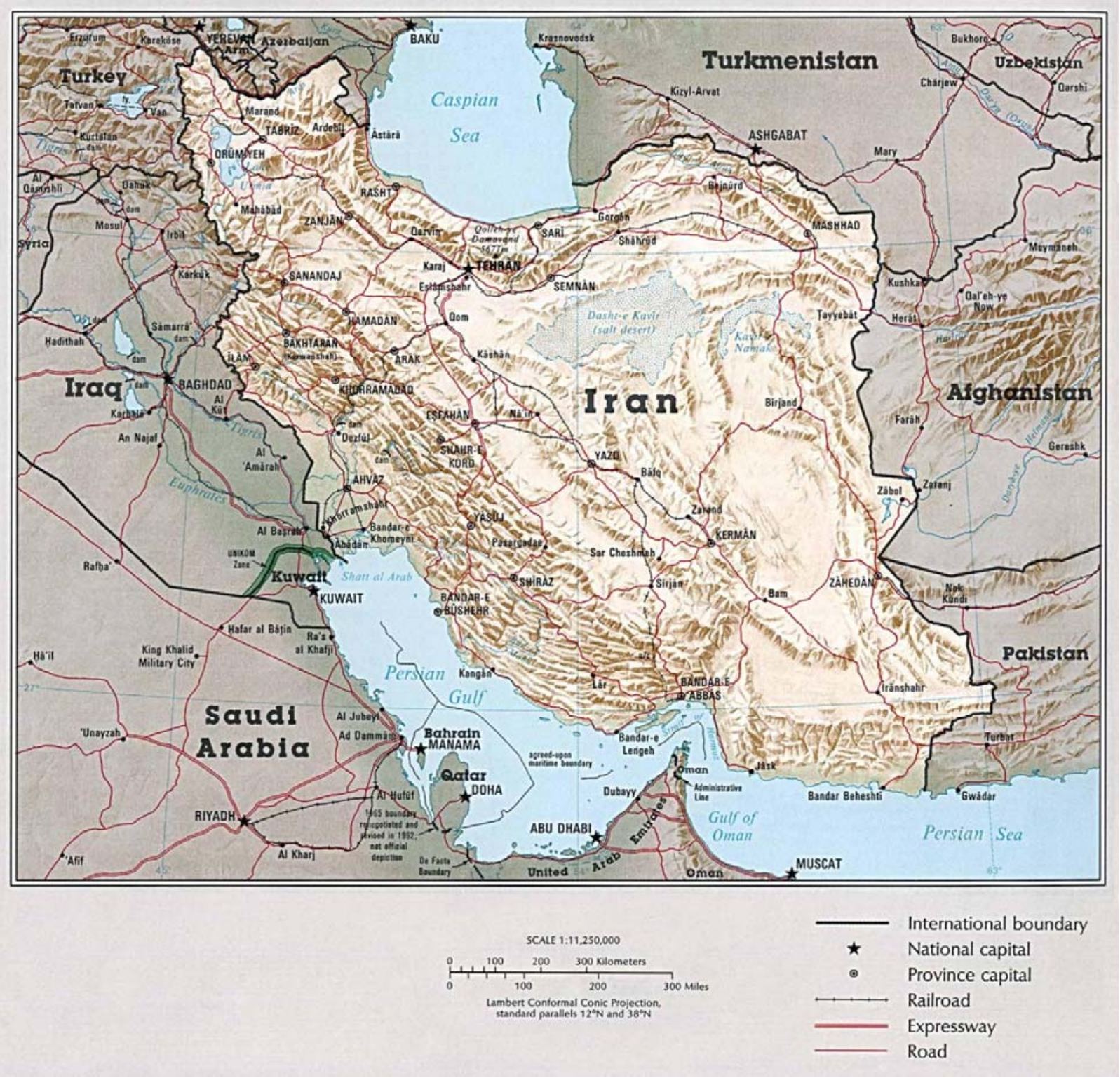

Map of Iran

(The Circle of Ancient Iranian Studies, 2011)

\section{Geography and Climate}

"The Iranian platea $u$ is not an auspicious place for a garden." (Moynihan, 1979. p.14)

Contrary to the popular conception of Iran as all desert, it is a land of innumerable mountains. The geography of present-day Iran is comprised of plenteous mounta in ranges surrounding an interior plateau which is primarily salt desert. Roughly two-thirds 
of this ancient plateau constitutes Iran (Pimia \& Ashtiani, 2007), with the balance extending into Afghanistan and Pakistan.

Iran is also a land of complex climates spanning everything from arid desert to humid gulf seasoned with snow-clad mounta ins and misty sea-side villages. Its c limatic complexity notwithstanding, the development of habitation and civilization has been primarily concentrated in and around the arid interior. Mounta in ranges which extend a long the Caspian to the north and much of the Persian Gulf to the south cut off the moisture traveling inland from these bodies of water, creating na row zones of green on the water side of the Alborz range in the north and the Zagros range to the south. Thus, while annual rainfall on the Caspian coast a verages $1355 \mathrm{~mm}$ (53 inches), rainfall on the plateau a verages around $126 \mathrm{~mm}$ (5 inches) a year (Beazley \& Harverson, 1982). In contrast, annual precipitation in Toronto averages $830 \mathrm{~mm}$ (32.7 inches)(Wikipedia, 2012).

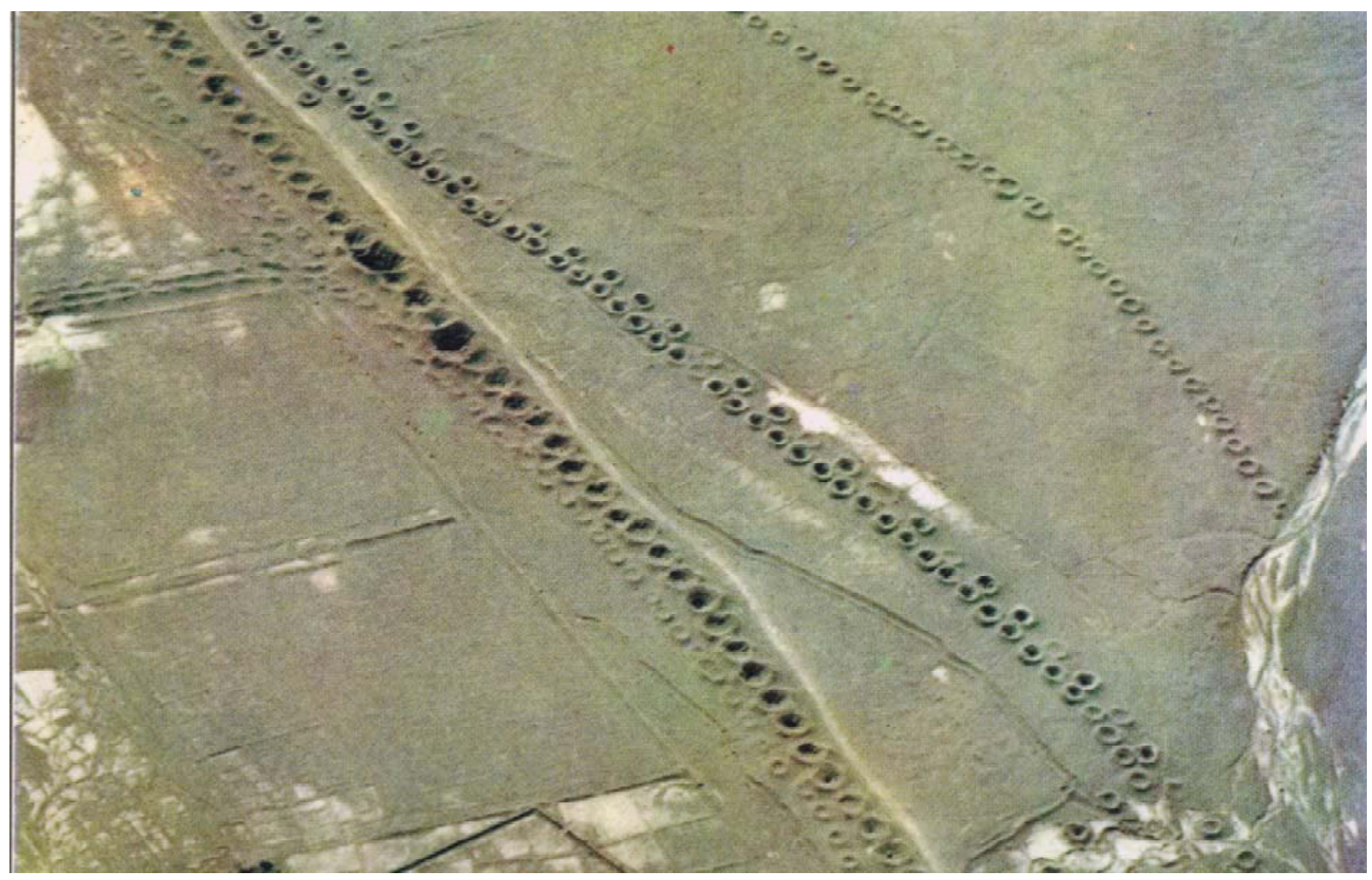

Aerial view of qanat (Ba sta ni Pa rizi, 1978. c over) 
The development of an ancient civilization in co-existence with the desert was enabled by ingenuous c limate management solutions. These included the qanat (hand-dug underground channels) to bring water from the foothills into the desert, ab-anbar (cistems) to store the hard-won water in, bad-gir (wind catcher) system for cooling often combined with underground streams or pools - along with the use of the plentiful dust to make bricks and thick walls with a high themal insulation value(Beazley \& Harverson, 1982).

The development of qa nat was the single most decisive factor in the settlement of the Iranian Plateau. Around 1,000 B.C., the ancient Persians and Medes created a pa instaking system to bring snow melt from the mounta ins to the dry interior. They first excavated a shaft or mother well (which could be as deep as 150 feet) into an underground stream at the base of a mountain, whence they tunneled outward on a shallow gradient to direct the water towards the plains. At regular intervals, vertic al shafts were dug to excavate the dirt displaced along the route of the qanat(Beazley \& Harverson, 1982). The rhythm of these mound s of earth is a reverse foot-print of sorts, marking the hidden joumey of water below the desert floor as it flows to enable life.

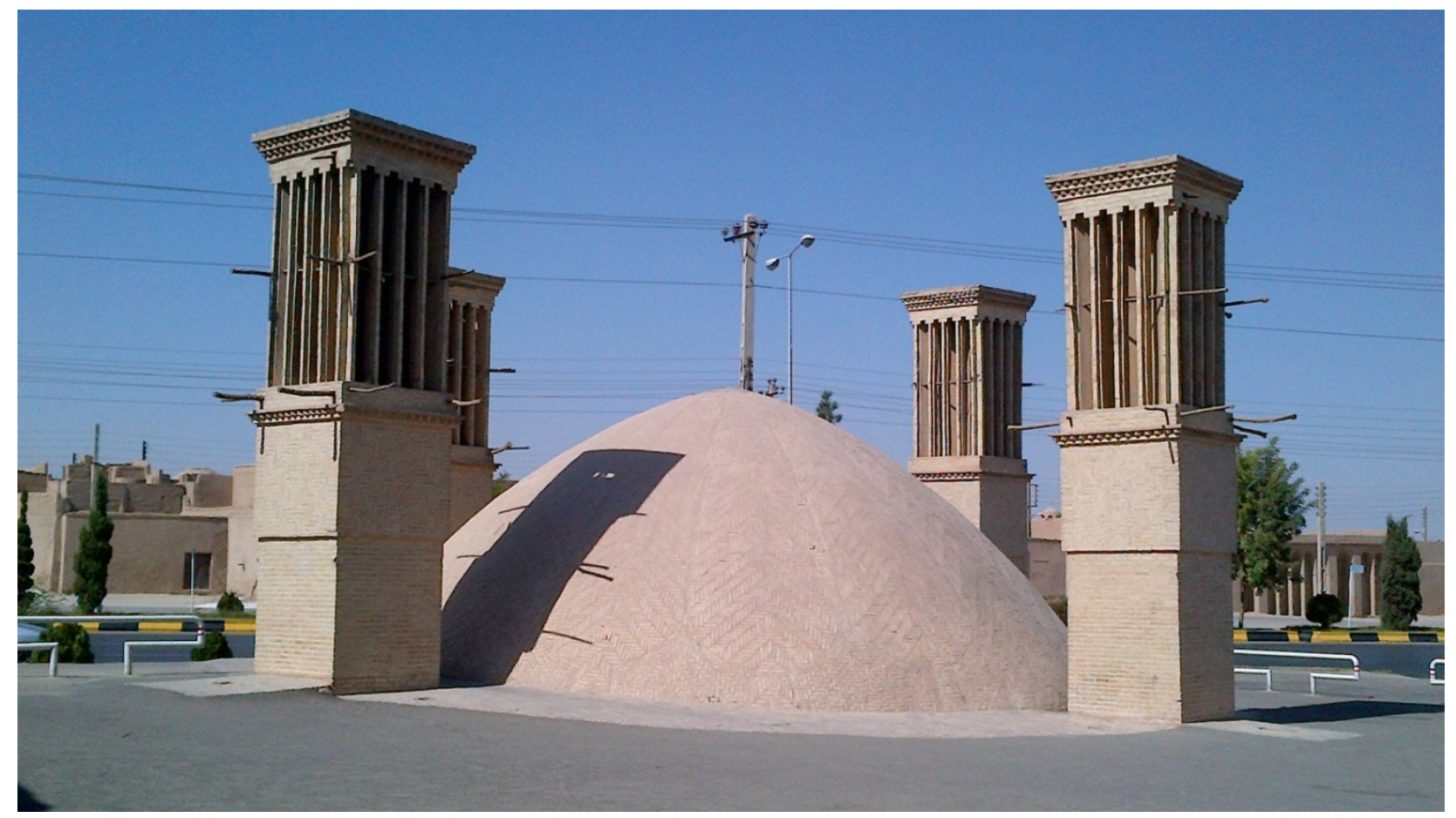

Char-Badgir Water Cistem - Yazd, depic ting an ab-anbar surrounded by four cooling bad-gir 


\section{Pain Daeza}

"Garden of Eden" and "Heaven" are two first (and for our purposes most signific ant) definitions of "Paradise" listed in The Concise Oxford dictionary of English etymology. These are followed by additional meanings such as "park", "pleasure ground", and the explanation that the word was "first used of the parks of Persian kings and nobles..."(Hoad, 1986. p.335).

The "Etymonline" website entry also begins with "Garden of Eden" as the first definition, refeming the origins of the Old French "paradis", Late Latin "paradisus", and Greek "paradeisos" (meaning park, paradise) to Iran and derived from the Avestan "painidaeza" (Etymonline, 2011). The entry indicates the word to be a "compound of pair"around" + diz "to make, form (a wall)", and proceeds to note that Modem Farsi and Arabic both contain the word "firdaus" (again meaning "garden, paradise"). The entry closes by stating that the Greek word "was used in Septua gint (ancient Greek translation of the Hebrew Bible (Wikipedia, 2011) ) to mean "Garden of Eden," and in New Testa ment translations of Luke xxiii.43 to mean "heaven"(Etymonline, 2011) . Modem Farsi a lso conta ins the word piramoon - meaning perimeter - whose roots may likely be traced to the ancient Avestan word pair. Nasr dates the origins of the word to 3,000 years ago, when it denoted the gardens surrounding - forming the perimeter - of many Iranian houses(Nasr, 2010). 


\section{The First Garden}

"On the great pla in of Marvdasht east of the Zagros mounta ins lie the scattered remains of the earliest garden of which we have a record." (Hobhouse, 2004. p.7)

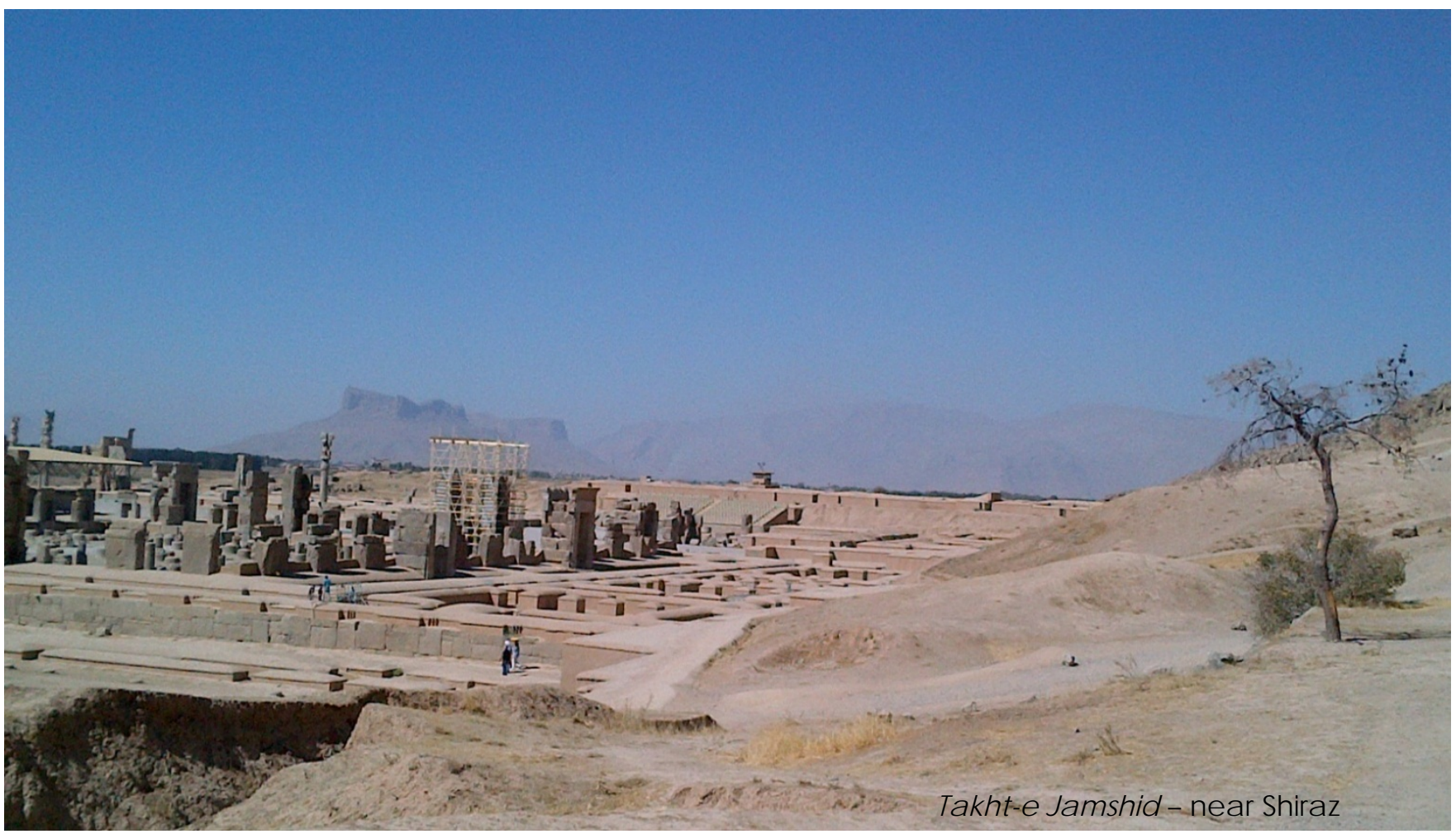

The origins of Paradise as a place date back to $550 \mathrm{BC}$, when Achaemenid king Cyrus the Great ruled over ancient Iran. Cyrus had overthrown the Medes and united the various regions and dynasties of the Iranian Plateau to create an Empire - which would grow to include much of Asia and parts of Europe at its peak (Hobhouse, 2004).

Following defeat of the Medesnear Pasargad in central Iran, Cyrus proceeded to build his capital at the location where he had triumphed (Hobhouse, 2004). During this period of prosperity and potential, there was time for the enjoyment of gardens- enclosed gardens which served not only as respite but also as pageantry. Some of these paradise gardens were expansive enough to be stocked with and serve as sites for royal hunts(Allsen, 2006). Such a menities were essential components of the majestic setting aga inst which the ritual and grandeur of the Achaemenian Dynasty would be staged (Shahbazi, 2005). 
While there are no remains of these first gardens (Hobhouse, 2004), the a ncient ruins of Persepolis still beat against the barren expanse of Marvdasht. The massive columns and fantastic relief carvings simulta neously evidence the grandeur of aspiration while they manifest the dust from which paradise was wrested. Thus, it is perhaps ironic that those endeavours of which no material evidence remains should have had such lasting and far-reaching influence :

"These first ideas of a garden as a paradise were to be as vital in the history of the spintual Muslim garden and the Indian gardens of the Mughal Empire as they have been influential in the gardens of Rena issance Europe and Westem civilization." (Hobhouse, 2004. p.7)

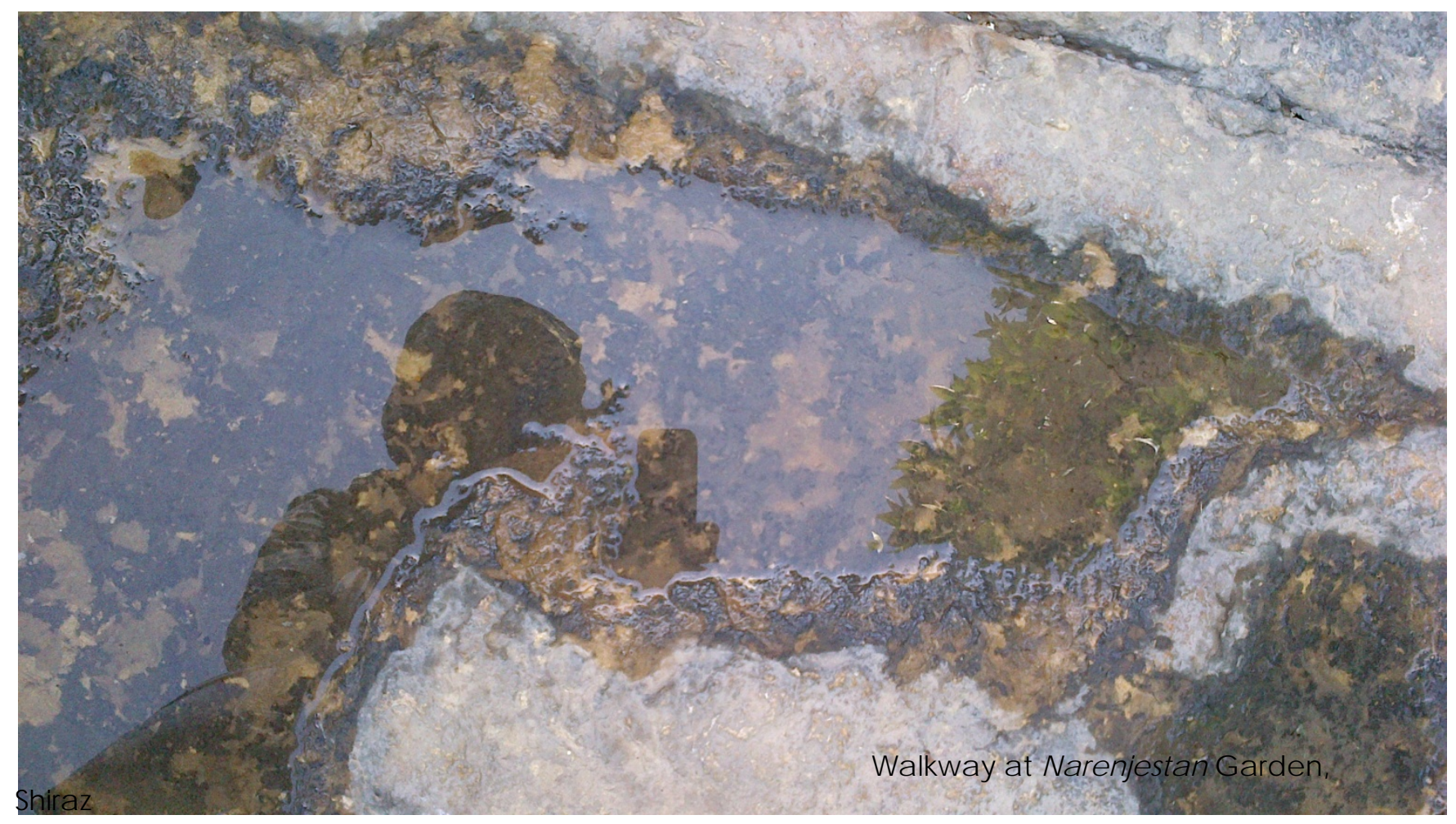

These walled gardens combined architecture with plantings, and were organized a round water for practic al as well as symbolic purposes. The geometric organization of the layout originated in part from the need to conduct water throughout the garden, leading to a four-part plan which could be adapted according to the scale and extent of the garden. Animals were often added to the abundant plantings with profusions of 
flowers and trees- especially fruit bearing trees. Many of the plant and a nimal specimens were collected during crusades in other temitories (Moynihan, 1979). Therefore, in these places of sanctuary, "The space inside the enclosure was deliberately glorified in contrast to the hostile world without, confiming the Persians' inbuilt attitude toward nature in a land where habitation depends on the availability of water." (Hobhouse, 2004. p.9)

\section{Before Walls}

“The earliest gardens were desert oases, fenced to keep out drifting sands, as well a shuman and animal ma rauders."

(Hobhouse, 2004. p.45)

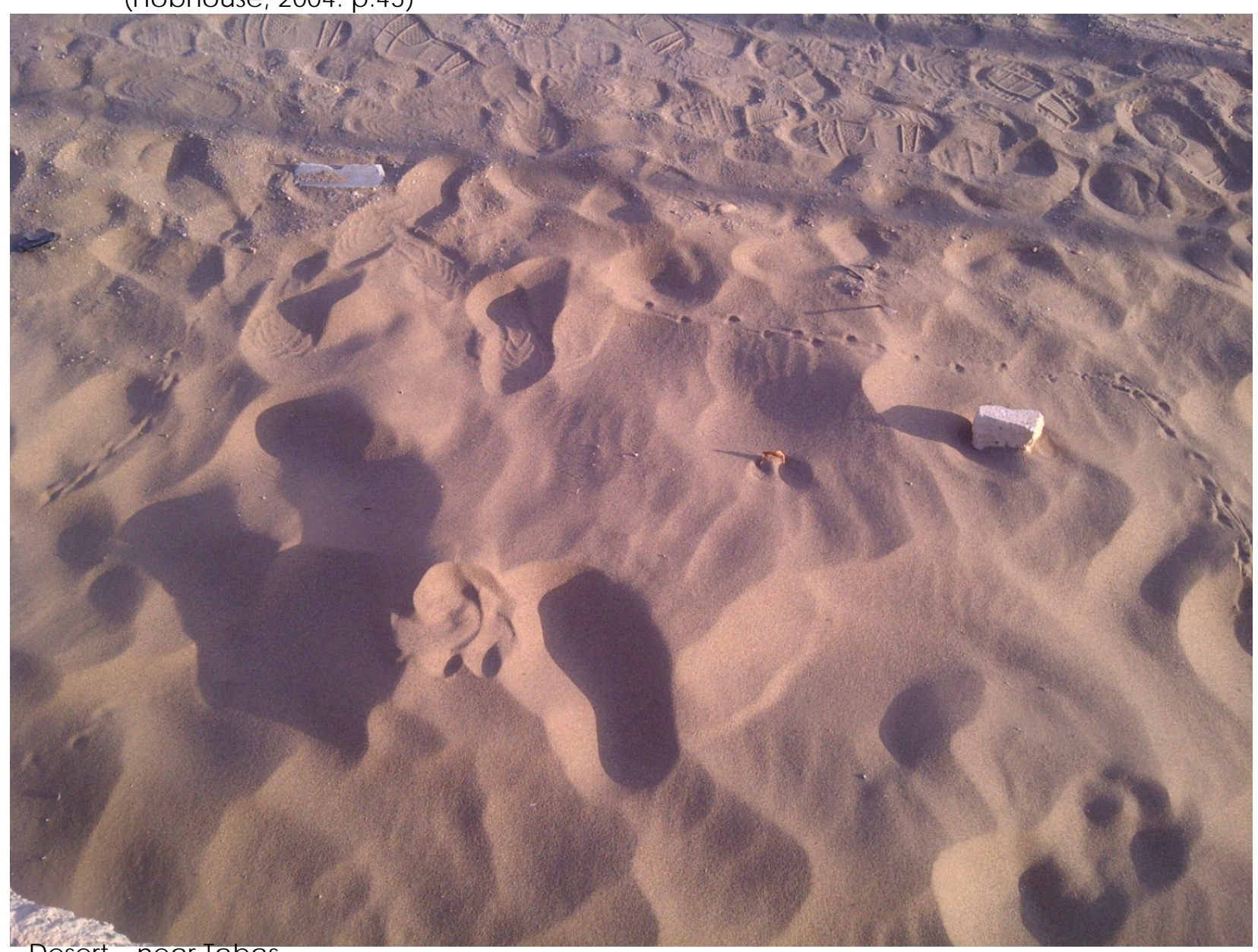

Desert-nearTabas

Long before the conquest of kings occasioned the creation of formal grandeur in the form of palaces and walled-in gardens, oases sprung from the desert floor, nourished by 
natural springs (Hobhouse, 2004). A chance encounter by a delighted nomad roaming for the next stop, or dusty caravans of travelers looking for respite led to a camp being struck and the beginnings of settlement. It follows that walls would be erected to safeguard the oasis from sand and predators a nimal and human (Hobhouse, 2004).

The desert which was capable of producing these inspirational oases also dictated the often harsh terms of survival. The necessity of co-existing with the desert led to the development of ingenuous imigation, construction, and a ir c irc ulation methods which have endured for centuries (Beazley \& Harverson, 1982). These techniques a re what enabled the transformation of the chance oasis into the planned paradise. Some of these natural c limate control systems and approaches, such asbad-gir (wind catcher) have been adapted for use in westem buildings in recent decades (in the form of wind towers and the growing emphasis on natural and cross-ventilation).

\section{Why Paradise?}

A Paradise Garden is a sanctuary. A place of respite, a break from the world outside its walls. It is a chance to contemplate and marvel at the abundance of nature, a passive reverie of contemplation. According to poet and a uthor Vita Sackville-West who visited Iran in the early part of the twentieth century, for an Iranian the garden

“... is not a place where he wants to stroll; it is a place where he wants to sit and enterta in his friends with conversation, music, philosophic al discourse, and poetry; and if he can watch the spring rain pouring down, so much the better, for he knows it will not come again for months and months and months."(Moynihan, 1979. p.18)

The layout is simple, and unvariable. The "Char Bagh" (Four Gardens) standard layout for Persian Gardens is comprised of two axes, one longer than other (Khansan, Moghtader, \& Yavari, 1998). Depending on the size and complexity of the garden, this essential parti can be repeated multiple times, resulting in a very rectilinear and geometric layout. 


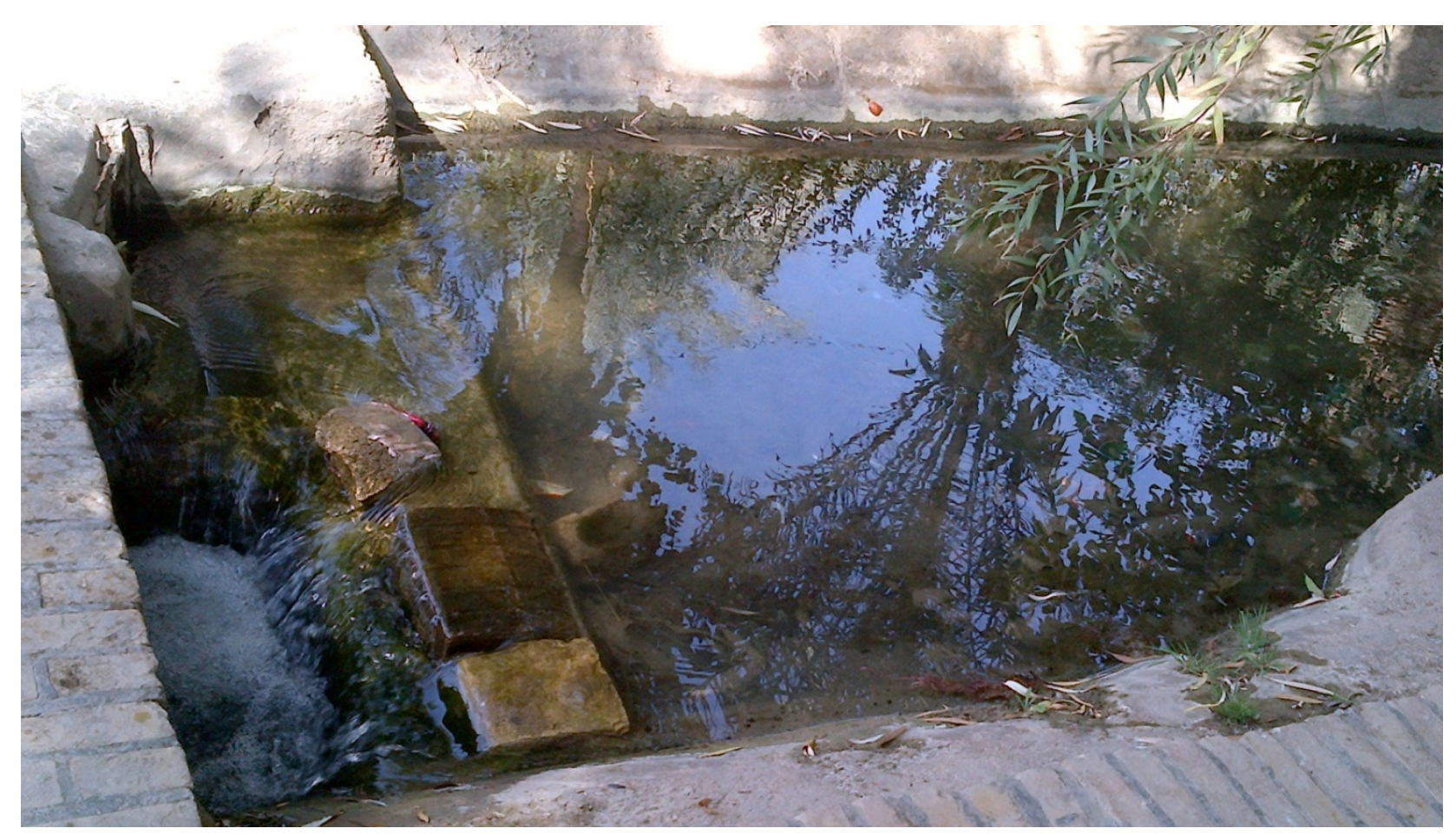

Golshan Garden - Tabas

\section{Manifestations}

In addition to gardens, Paradise has been manifested in a multitude of other constructs. There were the sizeable gardens during the Achaemenid and Sassanian dynasties which were stocked with a nima ls encountered during wars or travel and served as parks for royal hunts (Khansari et al, 1998). There was the public architecture of the squaresand caravanserai (such as in Esfahan during the Safavid Dynasty), the numerous mosques and shrines throughout the Islamic world, and of course residential a rc hitecture - of which early $20^{\text {th }}$ century Qajar houses a re a prime example. All of these typologies use the Paradise parti of a perimeter encircling an intemal event. 


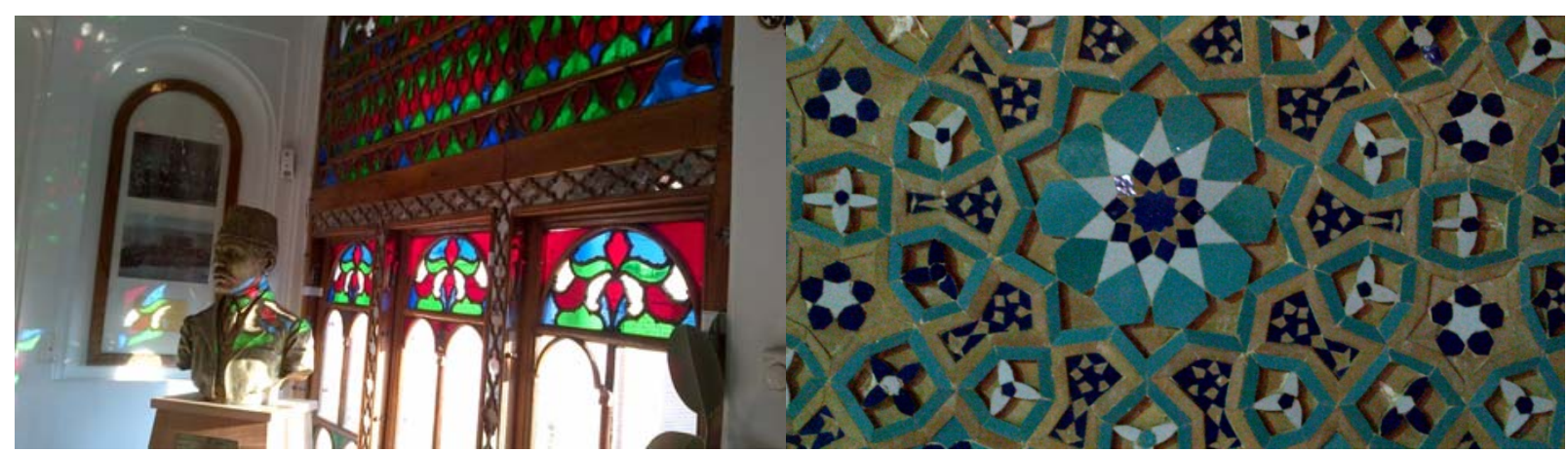

Sta ined glass windows, Qajar House-Ta briz

Tile work, Seyed Roknoldin Mausoleum-Yazd

Beyond architecture, Paradise has manifested itself in the beautiful hand painted tile work which adoms mosques, mausoleums, palaces, and shrines. The glories of Paradise are represented in rich niots of colour - the turquoise blue of the sky, the lapis lazuli of water, the green of spring leaves, the bright yellow of the sun, and all the colours of plants and flowers. Due to the Islamic belief that representation of the human figure is a sin against God beca use it promotes idolatry (Wikipedia, 2012), tiles, mirrors, and stained glass in mosques and shrines often employ stylized geometries and a rabesques which emulate the natural world. Elsewhere, plants and flowers predominate, with the occasional a nimal figure, and the very ra re human.

Carpets are a thousand and one stories again, each the handiwork of years of painstaking effort, each relating a tale of joy through dancing a rabesques and bea utiful colours. Kasraian and Naderi speak of the simila rities between Iranian Gardens and rugs (Kasraian \& Naderi, 2003), and Curatola and Scarcia describe Persian carpets as "Flowers of wool" (Curatola \& Scarcia, 2007. p.217) - veritable gardens, riotous with plant forms, a nimals, and colour. Then there is the brightly hued stained glass of Qajar era architecture which uses colour and sinuous lines to represent nature. The multifaceted brilliance of glass and mirrors in shrines with their geometric abstractions of garden themes and colours da zzle visitors as they create otherworld ly visions of refraction. 


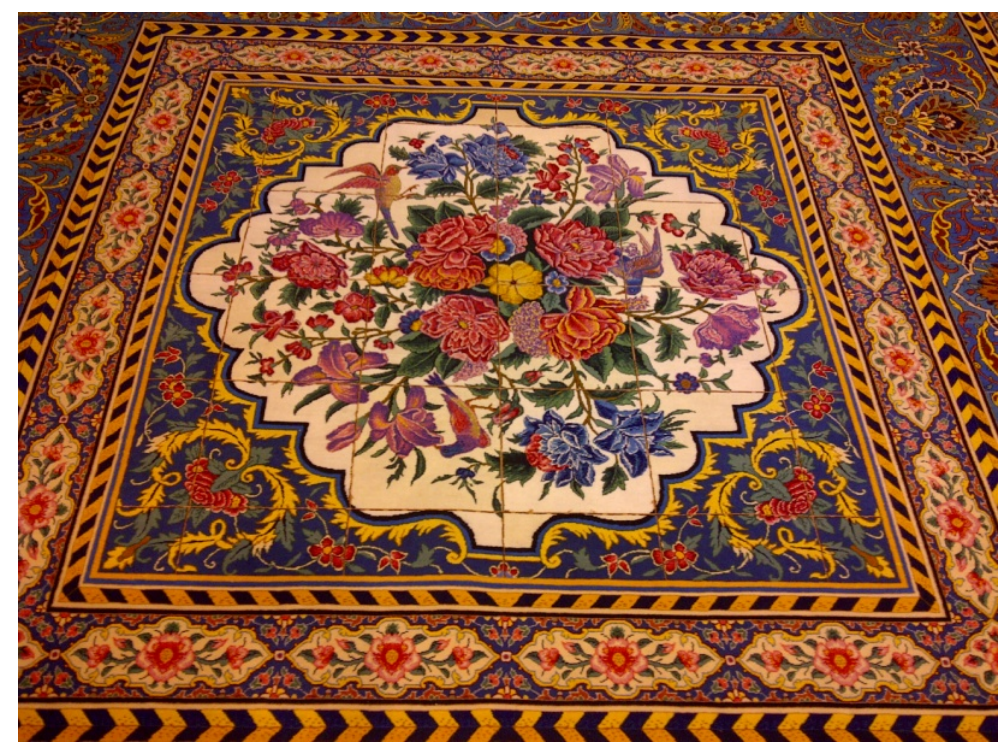

Wool and Silk Carpets - Esfahan

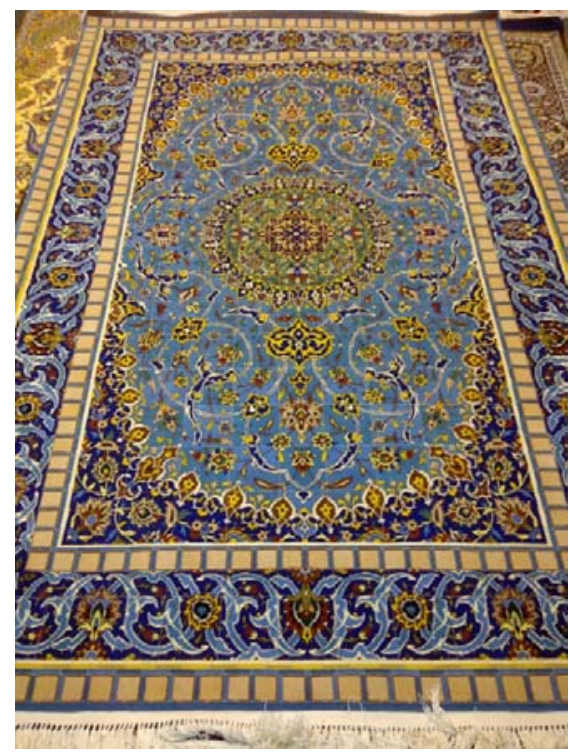

In the arts, poetry and painting both abound with representations of Pa radise. Images of gardens, flowers, water, and nightingales prolifera te in centuries of Irania n poetry. A prime example is Ferdowsi's epic Shahnameh (book of kings). This epic is one of the best known, loved, and widely read books in Iran since its creation in the early $11^{\text {th }}$ century. It ranks a longside Hafez's volume of poetry (he was called Hafez - the keeper - for his memorization of the Koran in its entirety), and the holy Koran. Shahnameh was a masterpiece, influential in mythologizing and celebrating Iran's ancient royal history and traditions. Overa period of 30 years, Ferdowsi collected primeval legends and epic tales passed from one generation to the next, and set the exploits and battles of preIslam royalty in verse. In re-telling the stories of kings and wars and conquest - often in lush settings and parks - Ferdowsi documented and ma de vivid a way of life, reinforcing the connection between paradise and royalty through his vivid depictions of palaces and gardens. And as an interesting aside - Firdowsi's name means "of pa radise", being derived from the word "Firdaus" discussed ea rlier.

Ferdowsi's Shahnameh is a vivid example of what Gianroberto Scarcia was refeming to when he spoke of finding “....in the "“"perennia lly Persian" features of Isla mic culture an historical reconquest of Muhammad by Zoroaster." (Curatola \& Scarcia, 2007. p.8) Later printings of the Shahnameh incorporated intric ate "miniatures" - a style of pa inting 
which employed a flattened perspective, vivid colours, and gold leaf - executed in intricate detail. These small illustrations created a n entireuniverse within a few centimeters of drawing by depicting gardens, palaces, lovers, wa miors, jinns, and hunters in metic ulous and elaborate detail. This style of painting was popular in Iran and India, used primarily for the illustrations of text (Ka sraian \& Naderi, 2003). Wood carving, plaster and glass reliefs, stone work, and metal grilles are some of the other instances of joyful expressions of paradise incorporated into a variety of building types. 


\section{THE RRSTGARDEN}

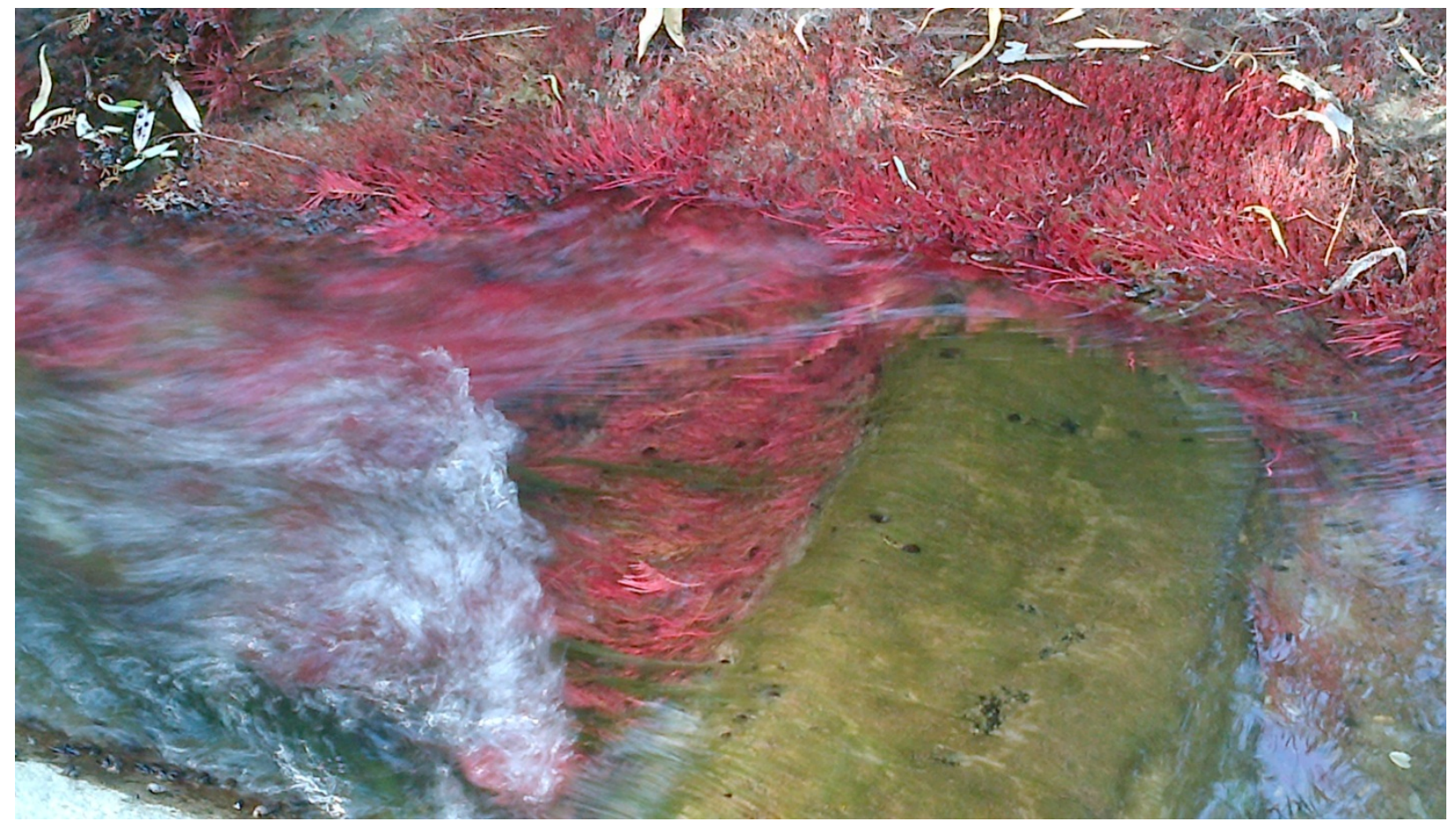

Golshan Garden - Tabas 
Because this project occ upies the rea Im of dreams - memory, interpretations, and parallel rea lities appear to be suitable topics of inquiry. Accordingly, while the literature surveyed includes writings on Paradise - as a spinitual and theologic al concept and later as a n earthly rea lity in the form of gardens - there is emphasis on research on the significance of memory in shaping our identity and the intemal architecture of our dreams(Homstein, 2011), in sparking the act of c reation (Bastéa, 2004).

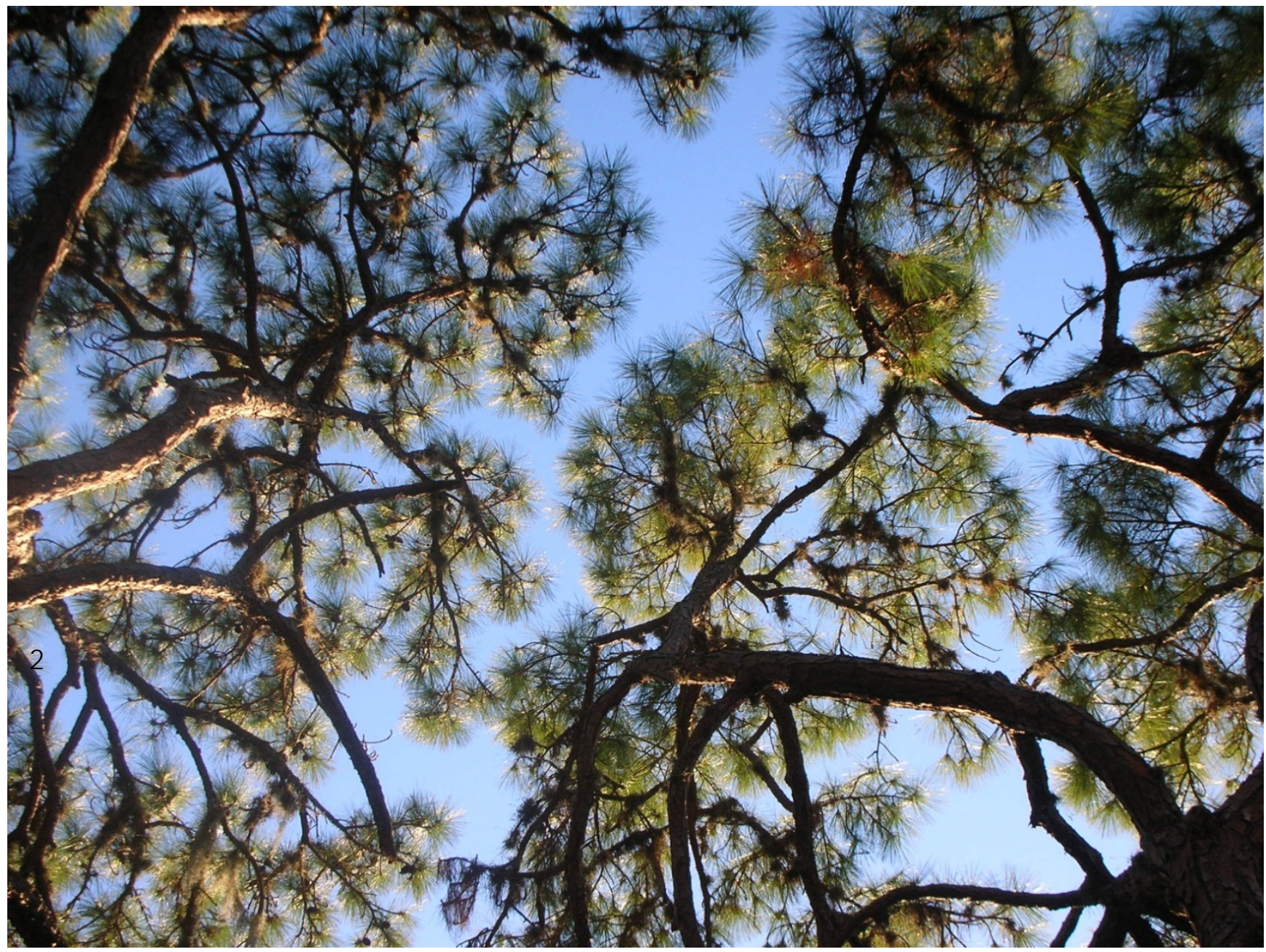

St Petersburg, Florida

The dreams we project have included the rituals and pageantry of kings and emperors, the ima gery of royalty and power. Dreams of earthly a spiration have combined with the primeval human longing for an afterlife. It is the passage and re-fomation of these dreams, and the ways in which memory re-interprets powerful visitations which have transformed Paradise. 


\section{Origins of an Idea}

The beginnings of notions of higher power, reward and retribution, and the promise of afterlife are as old as recorded time,(Moynihan, 1979) and quite possibly predate it. The struggle to make sense of the world, of natural elements (upon whose wanton mercy existence depended), of the mysteries of seasons and the star filled universe prompted the formation of systems of belief and ritual as a way to control the uncontrolla ble. Remarkably, the ideal of Paradise was a shared concept - common to disparate, unrelated societies (Moynihan, 1979).

This ancient idea persisted and flourished throughout the millennia. The earliest recorded instance of the Paradise myth appears in the first known writings of mankind (Moynihan, 1979. p.3) in Mesopotamia, and later in the Epic of Gilgamesh which desc ribes the titular ruler's life and adventures 2700 years before Christ (Moynihan, 1979). The Avesta - the holy book of the Zoroastrians - talks of a paradise promised by the Prophet Za rathustra (a round 600 to $400 \mathrm{BC}$ ), describing it as a place "with paths of bumished gold, pleasure pavilions of diamonds, and filled with fruit and flowers." (Moynihan, 1979. p.4) The Old Testament makes mention of "pardes" - from "Pa indaeza" in Old Persian - to denote a garden, followed by the identific ation of Paradise with the Garden of Eden in the Greek translation of the Old Testament, and the Bible's equation of Paradise with Heaven (Moynihan, 1979).

\section{Origins of a Place}

“The idea of Paradise as a garden is one of man's oldest ideals.... Belief in the myth has lessened the pain of life and fear of death." (Moynihan, 1979. p.2)

Manifestations of the idea of Paradise as an earthly garden first appeared in Sumer and Babylonia as the "Garden of the Gods" (Moynihan, 1979. p.3) in which Gilgamesh wanders, and in the writings of Homer as the "Elysian Fields" (Moynihan, 1979. p.4). Such "Dreams of Happiness" (Delumeau, 1995. p.1) were the hopes and aspirations which religion tapped into to create constructs such as "Gardens of Delights" (Delumeau, 1995. p.1) as the proverbial carrot with which behavior could be govemed. 
The logical extension to the idea of Paradise as a physical garden inhabitable by humans, is conceptua lizing the means of habitation. Speculation on how the functions of eating, drinking, and sleeping could be accommodated leads to the conclusion that some form of shelter would have to exist (Rykwert, 1972). Rykwert's inference from this line of thinking is that the beginnings of a rc hitecture were engendered by Paradise as a physical place(Rykwert, 1972). Medieval scholars speculated about the comoreal location of Paradise, and explorers sailed the ends of the earth in search of its whereabouts. Some of the greatest minds of the Renaissance endeavoured to recreate the Garden of Eden, and even the dawning of the Enlightenment only served to transfer the longing for the discovery of its physic al location to projecting and embodying the ideals in gardens (Delumeau, 1995).

This progression illustrates the manner in which the ancient idea of Paradise as a promise for the afterlife transformed into and overlaid the reality of Paradise Gardens, and earthly location serving as a "celebration of life" (Moynihan, 1979. p.12).

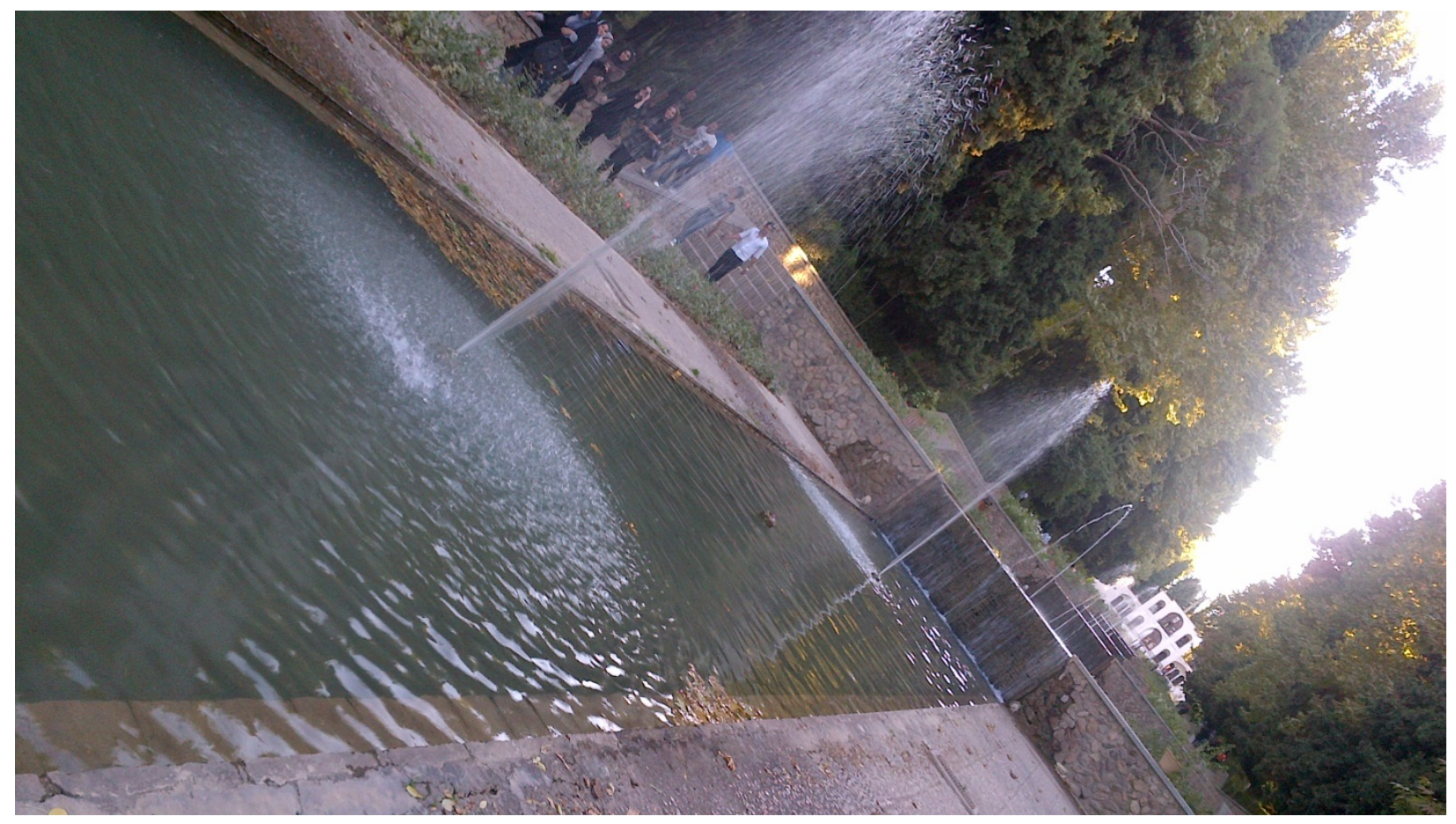




\section{Significance of Key Elements}

"The reverence for water, the mystic al feeling for trees, the symbolic division of the earth into quarters by the four rivers of life and the signific ance of a mounta in are among the most ancient and enduring traditions of the Near East, but to us the most important is yet a nother - the Paradise myth, the vision of Paradise as a garden."

(Moynihan, 1979. p.2)

The significance of the three key elements of a Para dise garden - water, trees, the quadripartite geometry - can be traced back earliest days of civilization in Mesopotamia (Moynihan, 1979). The power and primacy of these recuring themes acc retes from their universal existence - instances of which can be found throughout time and across our world.

The primacy of water - its power to give life as well as to destroy - led to its veneration. Trees represented re-birth as well as immorta lity - and a spiration to heaven - with the "Tree of Life" a signific ant symbol in early Mesopotamia (Moynihan, 1979. p.6). Belief systems such as a ncient Indian Brahmanism and Upa nishads a s well as Central Asian Shamanism refer to sacred trees, considering them in some instances "the symbolic axis of the world."(Moynihan, 1979. p.6) Major religions such as Islam and Christia nity a Iso make mention of sacred trees, as do Kabalistic writings of medieval times.

Finally, the idea of the "four rivers" which divide the earth is again ancient - the first known instance documenting it was pottery found in the prehistoric artifacts of the city of Samarra (Moynihan, 1979) in present-day Iraq dating back to 5500-4800 BC (Wikipedia, 2011). The four rivers also appear in ancient Indian beliefs, a re made mention of by Akkadian kings of Mesopotamia in 2500 B.C., and in Christia nity in the book of Genesis (Moynihan, 1979). This is how myth and symbolism generated the geometry which govems layout: "In the Paradise Garden, the crossing of the watercourses represents the four rivers of life ."(Moynihan, 1979. p.9) 


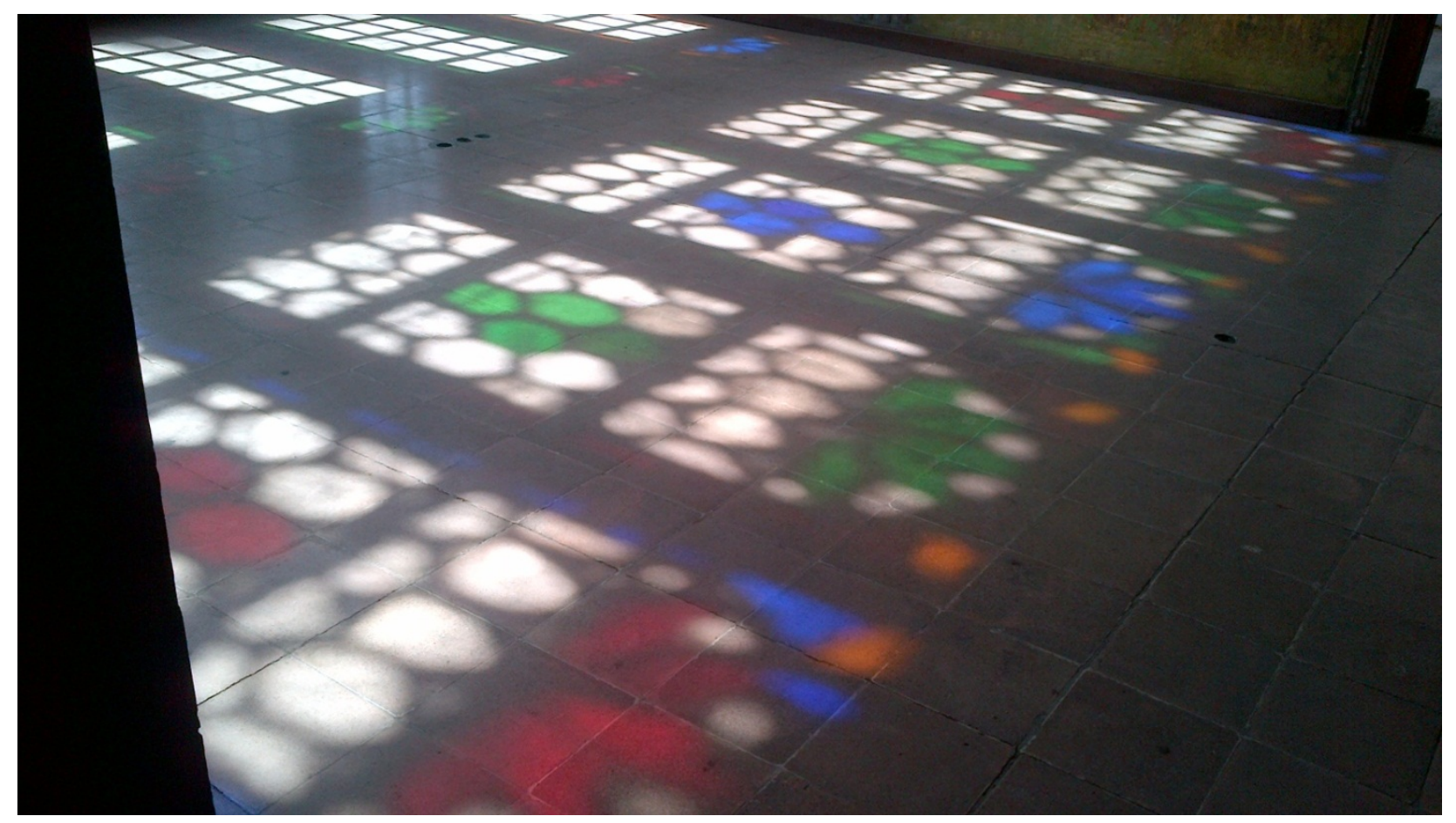

Na renjestan Garden - Shiraz

\section{Realm of Influence}

The Paradise Garden originated during the reign of the Achaemenid Dynasty, which was "considered to be the world's first powerful empire (under the reign of Cyrus the Great...), it was also the largest empire of the ancient world, stretching from the Balkans and Turkey in the west to Pakistan in the east" (Curatola \& Scarcia, 2007. inside cover).

Through travel and war, commerce and conquest, ritual and pomp, the Paradise Garden spread in retelling from the arid center of Iran to India, throughout the Isla mic world, to China, to Greece and Rome and points beyond - at times surprising the visitor with its unlikely presence. During a trip to India, Moynihan was a mazed by her first experience of a Paradise garden: "These geometric ally laid out, enclosed water gardens a re so foreign to the Indian environment that they are a lmost startling" (Moynihan, 1979. p.vi). 
While Iran's location a long the silk road provided exposure to travelers and created a web of influence through commerce, its critic al position between Europe and Asia ensured a steady stream of attacks and conquests - from Greeks to Mongols, Romans to Arabs. For a period of 400 years (642 - 224 B.C.) - before Iran was over-run by Islam and the Roman Empire fell, the powerful Sassanian Dynasty of Iran and Imperial Rome were rivals as well as exemplars of sup remacy, projecting their empires' splendor through displays of courtly ritual, the architec tural grandeur of palaces and gardens, and the visual arts. Such was the intensity of this exchange that the collapse of the two Empires in the $7^{\text {th }}$ century sent aftershock waves of influence rippling east and west (Canepa, 2009).

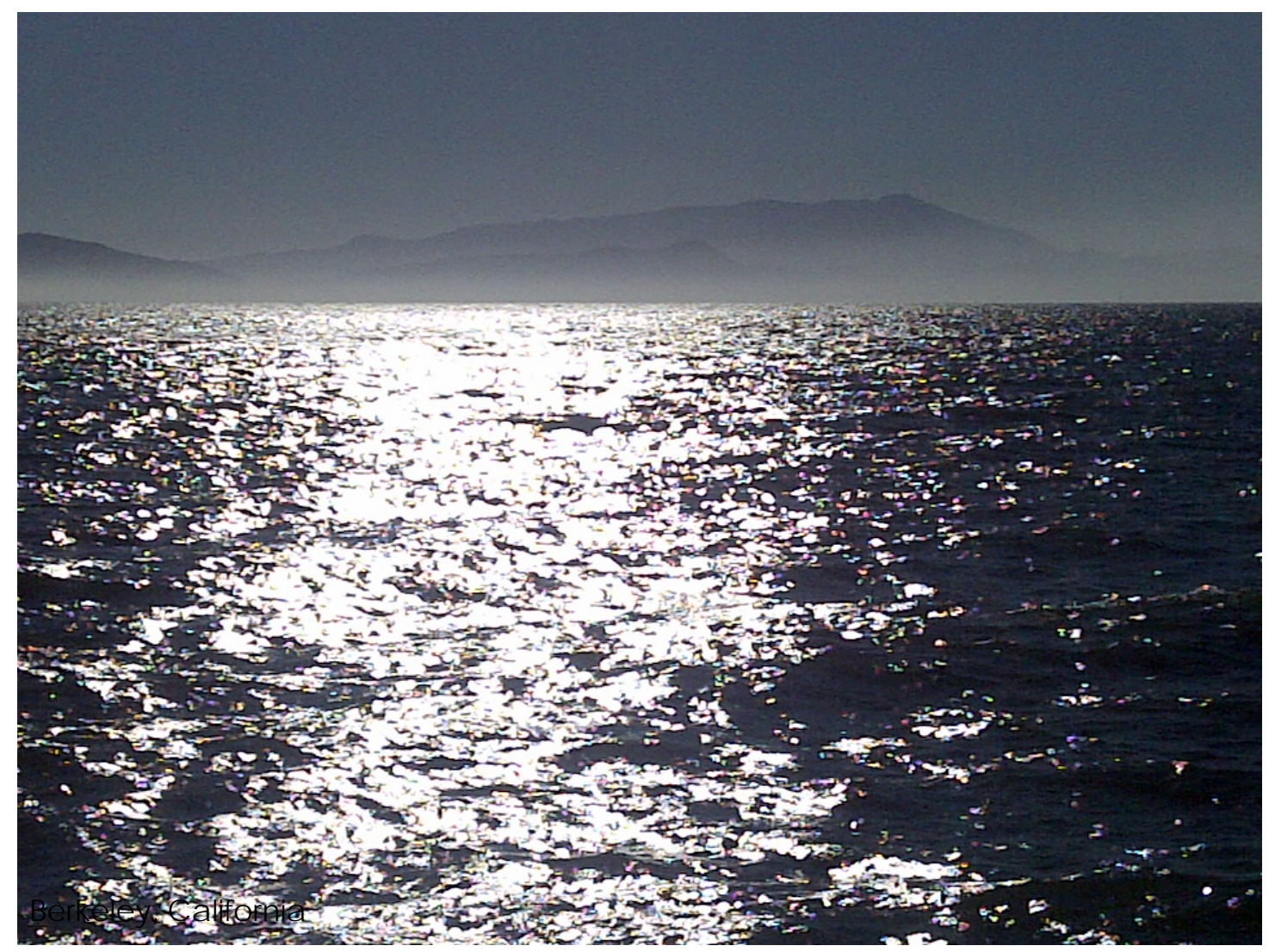




\section{Passage and Re-formation}

"Persia collects artistic examples and reworks them in its own a utonomous and shaded language, its extremely original, precise, and unmistakable manner, and then disseminates the whole with its generous cultural imperia lism."

(Curatola \& Scarcia, 2007. p.7)

Because Iran has been subject to conquest, occupation, and imperialism for much of its history, it is astonishing to think of it as an agent of cultural imperia lism. This paradigm can be understood through the importance of "passage" to the development of Iranian art and architecture - being located along the Silk Route Iran was possessed of the "...capacity to attract and influence adjacent worlds..."(Curatola \& Scarcia, 2007. p.6)

Astonishing also, is the survival and persistence of Paradise gardens through centuries of conflict and the rule of foreign powers(Moynihan, 1979). While some marveled at this resilience across time and vast distances - "A truly remarkable aspect of these gardens is their uniformity of design throughout the centuries and across so large an area of the world with so unsettled a history" (Moynihan, 1979) - others such as Vita Sackville-West found this consistency repetitive, noting that visiting a single example was equiva lent to seeing many (Hobhouse, 2004).

The exploration of and discovery of new lands across the oceans was a moment of transformation for the long-consistent Paradise Garden. Originating as vehic les for the projection of imperial power, thriving ascultivated oases painstakingly wrested from the desert, they now faced a cultural migration across the oceans. Alongside the cultivation of gardens, post-enlightenment explorers sought new lands anticipated to be a physical Paradise where some of the promises of Edenic Paradise could be fulfilled (Delumeau, 1995).

The drive for adventure and discovery which propelled the search for new temitory with the qua lities and potential fulfillment of Pa radise is signific ant. This compulsion for disc overy is key to understanding the divergent architectural a pproaches to 
ma nifestations of paradise in the west versus the east. As Vita Sa ckville-West observed during her joumey through Iran: "A garden in England seems an unnecessary luxury..."(Sackville-West, 2008. p.86) Where the enclosed paradise garden was an "unnecessary luxury" in Europe, its very essence of perimeter would become inverted into the notion of the wildemess and the expanding frontiers of North America.

Therefore, the idea of Paradise's earthly garden passed from one series of continents to a nother and across oceans, it underwent transfomation. The original and fundamental act of enclosure intended to separate two different realities was no longer vital to the meaning of Paradise in North America. The vastness of the green continent, and the spint of searching and adventure in which it was accessed set a very different stage. An unbounded wildemess defined only by the expanding frontiers of habitation would bring with it a different definition of paradise. Paradise in the west is less about the physical perimeter providing sanctuary and more about the intangible perimeter of the self. This intangible perimeter bounds the psyche, the imagination - the site where the dream visions play out.

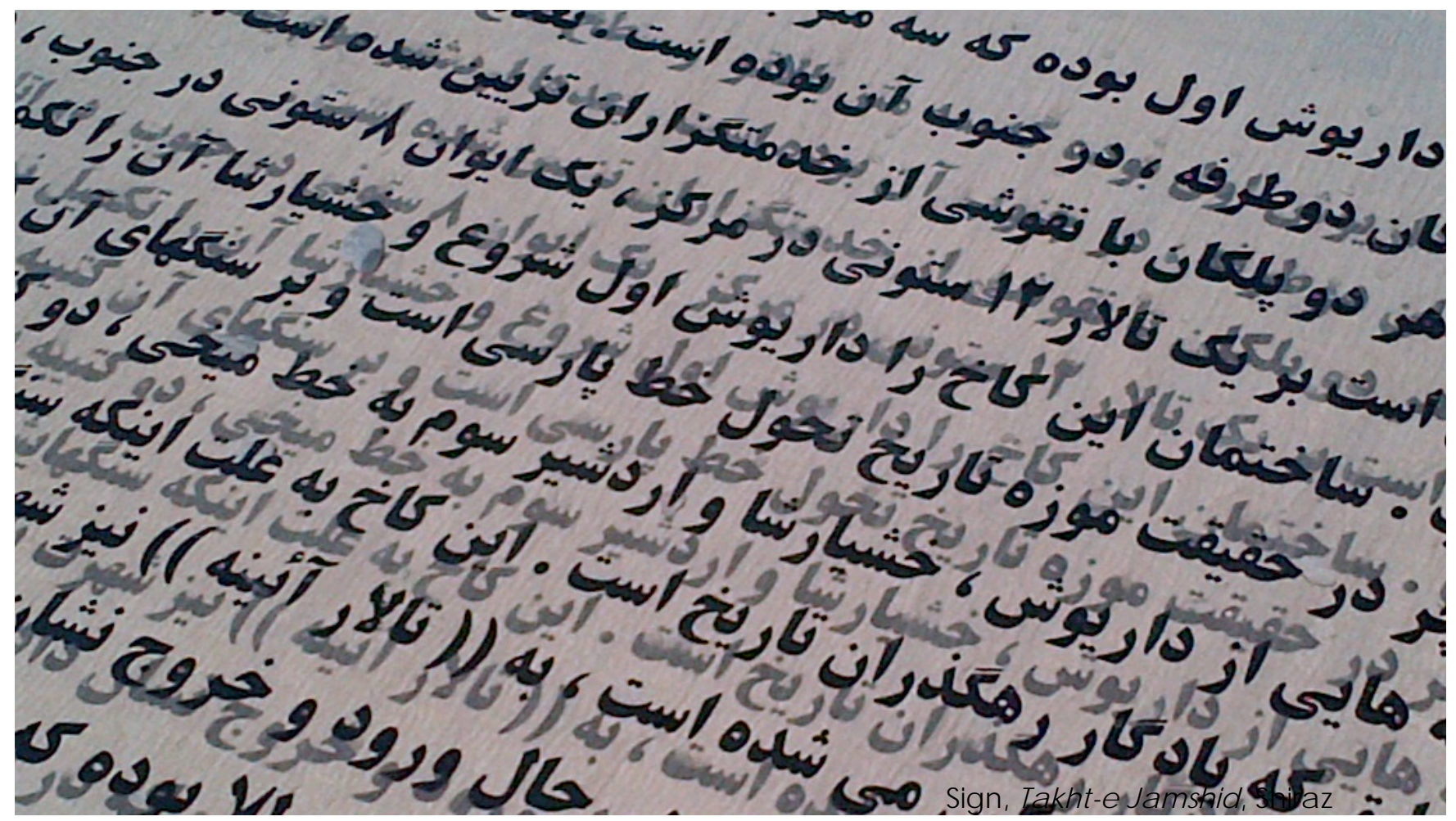




\section{Memory and Interpretation}

"Are the cities we believe we know and understand simply a reinterpretation of our own Venice, encountered again and again und er different guises?" (Bastéa, 2004. p.4)

“he'd never known before that migration wasn't one unbroken forward movement; it was sideways, backwards, forwards, a passa ge enlivened by indecision in the face of real and imagined danger."

(Hay, 2007. p.306)

While attitudes towards and experiences of the act of migration can differ, the powerful nostalgia for what one imagines to be homeland is consistent. Also consistent is the manner in which experiences of the place one has re-located to are tinged with memories of the past (Aciman, 1999). It is in fact, as if the memories of the old home become the prism through which one is able to vision the new.

In my own case, (and that of many contempora ries who left Iran under similar circumstances and with similar - or no - notions of what this leaving signified) I can relate that nearly 35 years on, my memories of Iran a re the most vivid and powerful of the cache I have accumulated. Any sight, smell, or sound that evokes Iran finds a direct path to my heart, and it in fact feels at times that the further I travel, the more unyielding the bonds grow. This, perhaps is what Sassen antic ipates when she writes of the intensific ation of an immigrant's bonds with the home country through repeated voyagesback and retums to the new land (Sassen, 1998).

The accretion of physical memories enables deepening experiences of place attesting to the powerful role of emotion in the corporeal act of presence (Bloomer \& Moore, 1977). Ina smuch as we may only occasionally acknowledge our physical selves, the body never lies. The successive la yers of memory empower our experiences and creativity : "Why do we visit signific ant buildings whenever we can, wherever we are, if not to imprint them in our memory, to lea $m$ their spaces by passing our body through 
them, to make them part of us in some ways, and maybe to draw from them in our own designs?"(Bastéa, 2004. p.3)

This line of thinking leads to a question : what happens if that site, once experienced and now enriching experience, is no longer - or is no longer acc essible (Homstein, 2011)? Does this impinge on the immigrant's a bility to re-construct experience? I believe this paradigm explains the urge to document - in words, images, memory - signific ant moments of physical experience as a means of transporting "architecture back and forth (in a sense) from its physical site to locations in the imagination...losing site, and finding it again in the many different places where arc hitecture exists."(Homstein, 2011. p.1)

So it was that each visitor, court emissary, or chance traveler came a way with memories and emotional responses to the Paradise Gardens. Each poem extolling Paradise, letter describing it, carpet representing it, or painting depicting it was a nother layer of interpretation, of the magical replay of memory and emotion transforming experience. As accretion of memories enabled intemal architectures of the psyche, expressions of such memories overlaid with desire transformed the original physical place into a potent concept. The powerful core of the place as sanctuary, and its genesis as the perimeter of stark contrasts made it a natural vehic le for spintual aspirations. So it is that "Paradise" today has the dictionary definitions of "Garden of Eden" and "Heaven" (Hoad, 1986. p.335). 


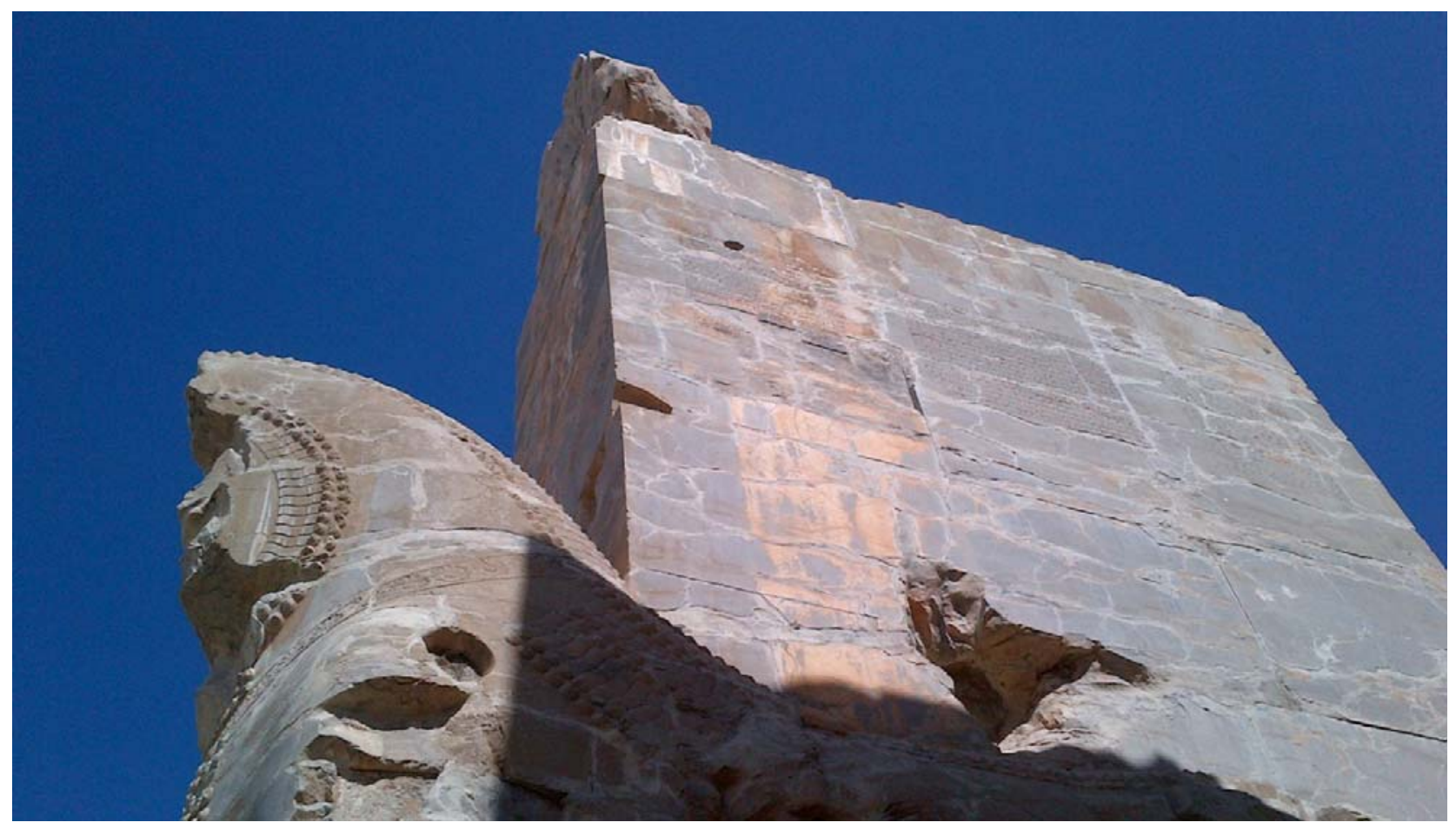

Takht-e J a mshid, Shiraz

There is an intemal landsc ape within each of us where all the places we've ever visited, seen, or dreamt of reside as virtual pa rallels to the physic al constructs - with the physical serving as a point of departure for the layering of real and manufactured memories (Homstein, 2011). This paradigm illumina tes my impulse to capture the images of paradise as I encountered them in my travels this year. Formally documenting the memories as digital images a llowed an easily reviewable archive through which to "explore the relationship between memory and place, and ways in which architecture triggers memory" (Homstein, 2011. p.1). Architec ture not only triggers memory, it shapes and influences its development - and the identity of self. Therefore, architecture is not limited to the realm of the physical, it simultaneously inhabits the imagination and the heart (Homstein, 2011).

For these reasons, this project situates itself within the realm of memory in order to explore "the question of what it means to live in a world of material objects and physical place, yet be conjoined to the metaphysic al" (Homstein, 2011. p.7). 
We are defined by memory. Memory is the imprint of our joumey through life, of the emotions attached to physical experiences. Memory desc ribes the architecture of our psyche, from which flow our projections and creations. Consequently, the passage and re-formation of dreams and the ways in which memory interprets powerful visitations a re the forces which have shaped this project. 


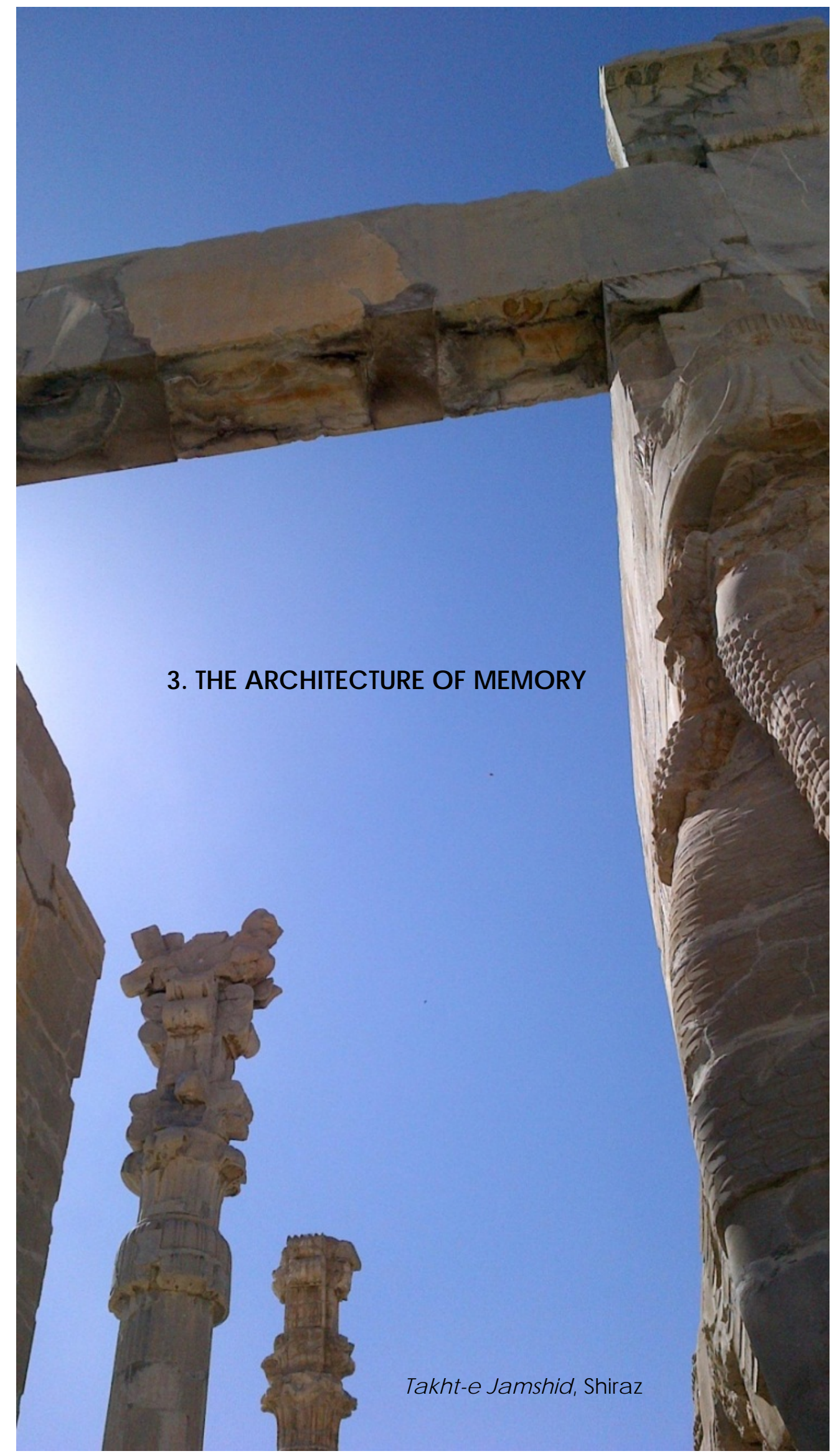


"Uprooted and dispersed, these (former neighbours) constantly refer

back to the architecture of the home itself, which...structures their memories" (Google Book Review, 2012)

I have spent sizeable portions of the past year traveling - and pondering paradise. Most signific antly, in Oc tober and early November of 2011, I tra velled throughout Iran in search of Paradise in gardens and elsewhere. Looking back at the trip and how I have represented it here, I am struck by the compulsion to see and faithfully relate as much as possible. To validate my home of origin - and thereby myself - by bringing back and sharing memories.

Guided by Bakhtian's Road Atlas of Iran (Bakhtiari, 2010), within whose orthographic rendition of my country I scratched out the roads used to traverse its geography, the physical joumey began. We set off from the north eastem city of Mashhad, Iran's most popular pilgrimage destination with the shrine of Imam Reza at its heart - and the city where I was bom. In this sense, the joumey was a reverse pilgrimage, its intention as much exploration of the past as resolution of the future.

I travelled south-west through the Binaloud mountains, through Gonabad with its budding field s of saffron, and down to the desert city of Tabas - whose outskirts fea ture a husk of a US military helic opter displayed in commemoration of the US's failed 1979 attempt to free its hostages - and site of a 7.8 earthquake in 1978 (Wikipedia, 2012) which destroyed much of the city.

From Tabas I continued along the salt desert to the ancient city of Yazd at the very center of Iran - na rrow kutcheh (alleys) intric ately woven a long mud walls, tall bad-gir (wind catcher) reaching up to a ir currents, and blue tiled domes set against the dun of the dust. J oumeying south-east found Kerman - with the Shazdeh Gardens in nearby Mahan a green oasis in the midst of desert. And always, stately layers of purple and grey mounta ins stood sentinel a longside the black ribbon of road. Receding into the horizon in majestic tiers, the mounta ins sanctified the joumey. 


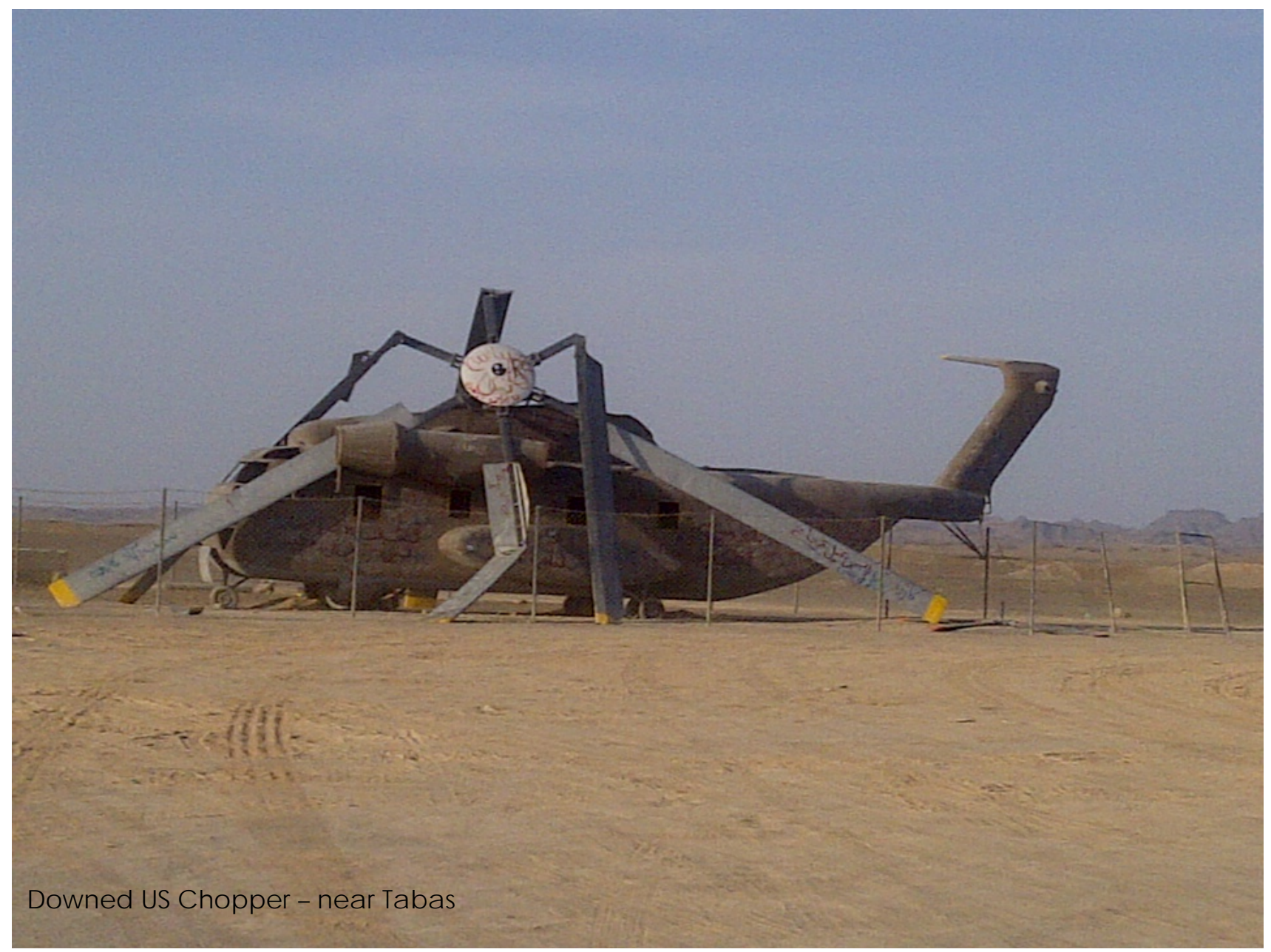

Southwest to Shiraz - city of wine (pre-Islamic Revolution) and poetry - and in the plains nearby the historic ruins of Persepolis (used as a backdrop by the Shah for a multi-million dollar pageant staged with the intent to legitimize his sovereignty to the world and to his subjects). Thence the joumey swung north to Esfahan with its fabled bridges dancing across the ironic ally dry Zayandeh Rood (river of life) - courtesy of the Islamic Republic's irrigation plans - and a detour to the city of Kashan to visit the Fin Gardens where a threatened Qajarera king exiled and later put to death his progressive and na tionalist prime minister (Burke \& Elliot, 2008).

As the mountainsclosed in and multiplied, we climbed north-west a long their flanks to Hamadan - site of the ancient city of Hegmata neh (Burke \& Elliot, 2008) - and to the Turk city of Tabriz whence the Qajar dynasty (late $19^{\text {th }}$ and early $20^{\text {th }}$ century) - infamous for relinquishing large parts of Iran's teritory in various treaties in order to subsidize their lavish lifestyles - originated. 
Tehran (Iran's capital since 1795 (Wikipedia, 2012), and its largest city) was the terminus of this joumey - and the city of my child hood. It was from Tehran's Mehrabad Airport hat I flew west all those years ago. It was at this same airport that I touched down a life-time later, furtively bending down to smell and kiss the asphalt of the tarmac while attempting to maintain the unfamiliar hijab (the protective garb all women must wear in public).

In Tehran I visited the park-like grounds of the Saad Abad complex, site of several Pahlavi-era mansions and palacesand now a complex of museums, and peered down at the city through the smog surrounding the recently ina ugurated Milad (birth) Tower. As the clouds of smog shifted, it was easy to imagine the layening of other cities, other experiences of rea lity onto that particular instance of presence.

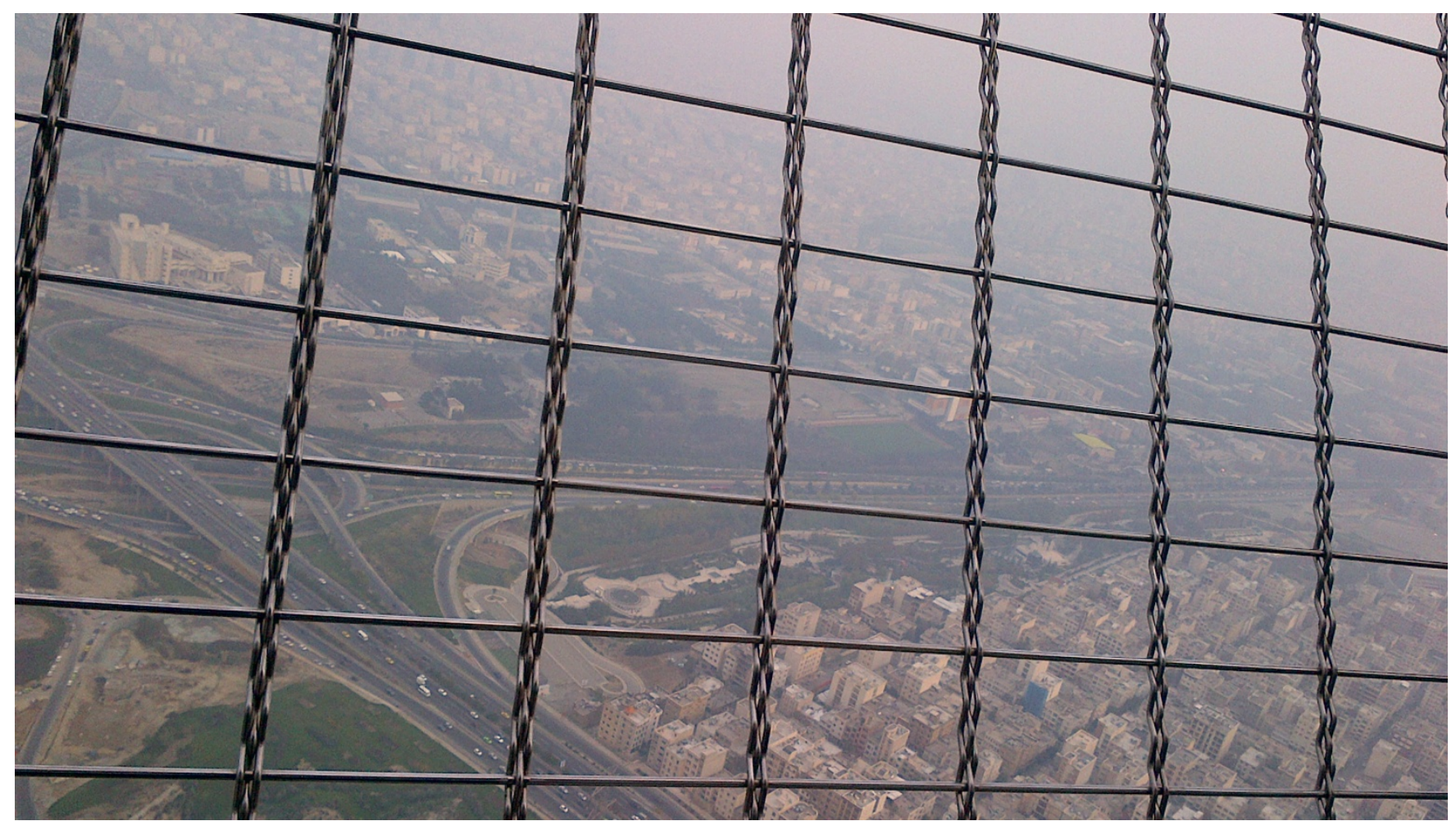

Top and Bottom - Milad Tower, Tehran 


\section{Gardens (and Parks)}
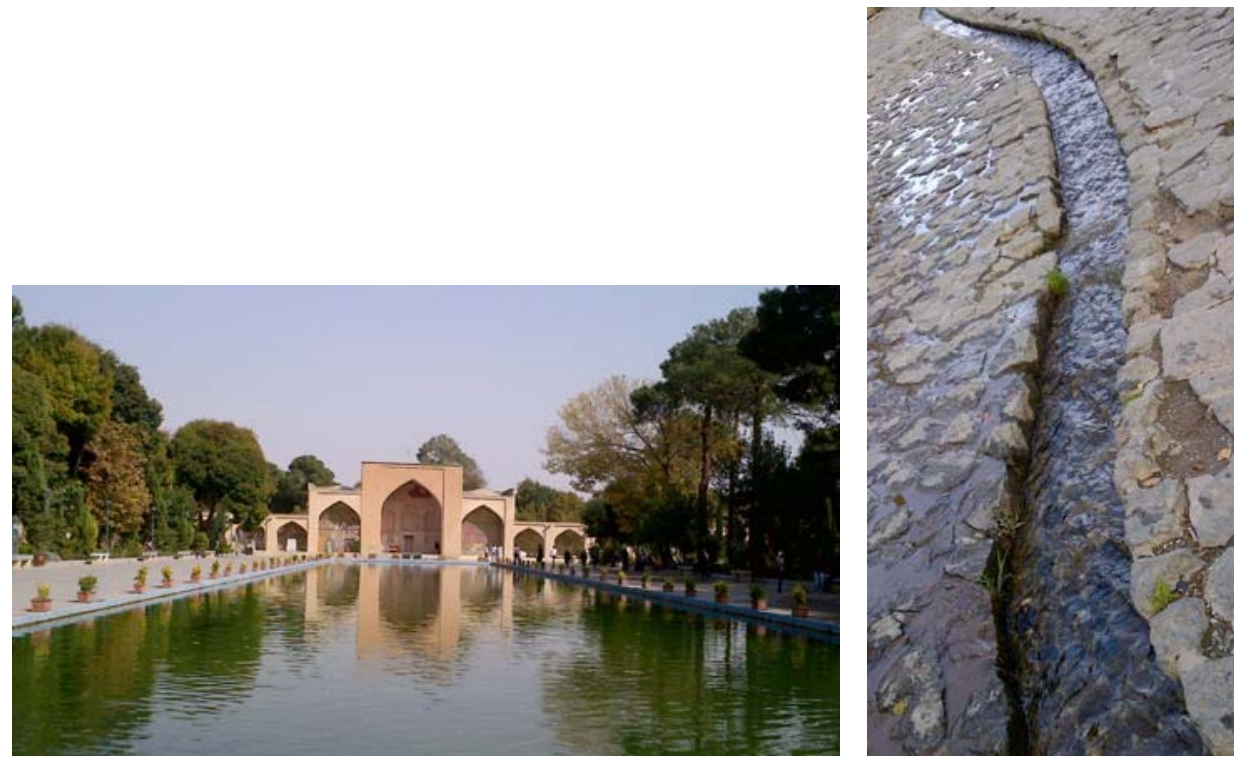

Chehel Sotoon Palace - Esfahan

Ganj-nameh -Hamadan

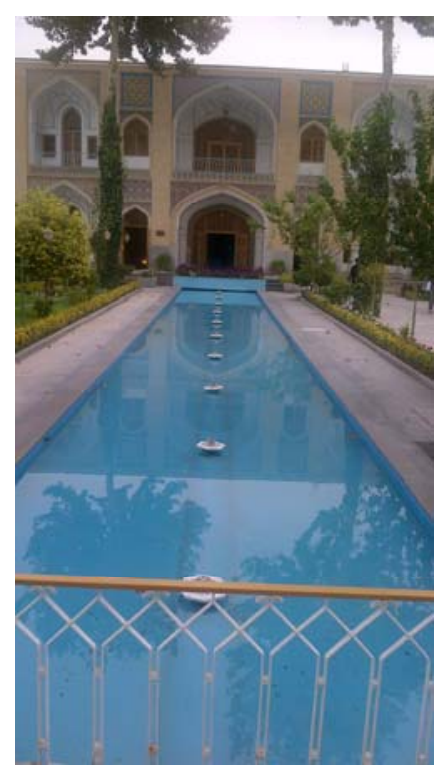

Abasi Hotel Esfahan

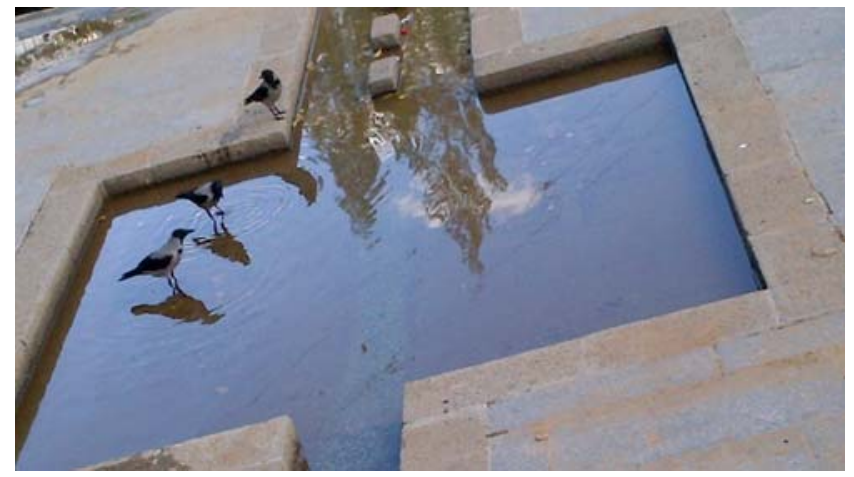

Ganj-nameh - Hamadan 
Para dise Gardens are very formula ic - as noted by travelers such as writers Vita Sackville West and Penelope Hobhouse (Hobhouse, 2004). Often rectangular in configuration, they are organized in some multiple of the quadripartite char bagh (fourgarden) plan. The geometry is rectilinear due also to the paramount dictates of water distribution.

The resultant layout is strongly axial, usually with a primary central axis spanning the length of the garden. The ma in approach, water features, and important buildings and pavilions are organized a longside this axis. Secondary axes lead off the main axis, and flanking planting beds featuring rows of tall trees-poplar, plane, cypress, or date palm - march a longside for emphasis.

There is a profusion of flowers and greens and sights and textures, and of course, water everywhere -the extravagance of its presence within flouting its $p$ absence without. Channels, streams, reflecting pools, waterfalls, and founta ins all attest to the miracle that makes such verdant abundance possible in defiance of the desert. Its movement, stasis, leaps and falls create a symphonic backdrop layered over the hush of desert and mountains.

The mythm of repeated elements is striking - exhibited in the tall trees which accentuate a venues and prospects as well as the architecture of the buildings included in the construct. Views framed by and seen through elements - openings, archways,

a brick screen with a pattem punched out of it - are given emphasis.

A transitionary entrance building is mandatory as the portal delineating the sacred within from the profane without. The visitor passes from blinding sunlight into shadows to emerge into the cool mystery of the garden. The architecture can include additional feature buildings, pavilions, and occasionally entire wings spanning one or more sides of the garden. 


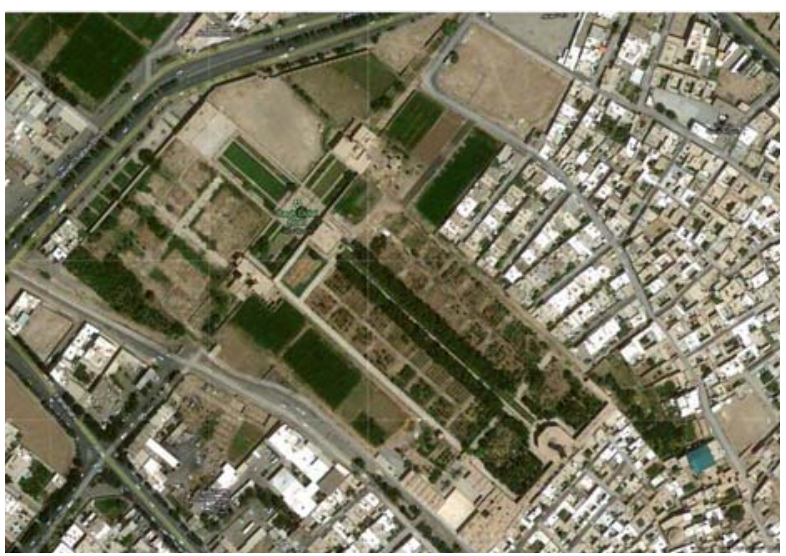

Golshan Garden - Tabas

(Google Maps, 2011)

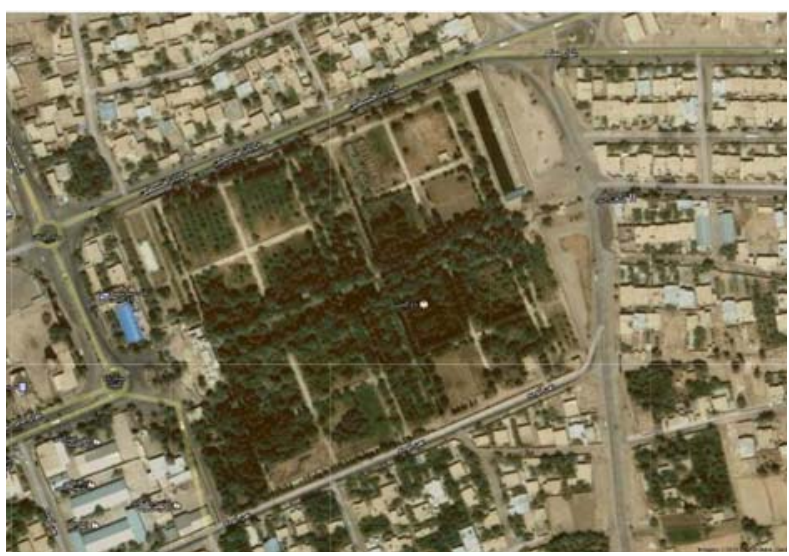

Dowlatabad Garden - Yazd

There are numerous distinct exemp lific a tions of this fo mula throughout Iran. I visited Golshan Garden located within the city of Tabas, Dowlatabad Garden around which the city of Yazd has grown, Mahan's Shazdeh Garden located an hour south-east of Keman and set in the foothills of the Saheb Al-Zaman mounta ins in the midst of a salt desert, Kashan's Fin Garden just outside of the city, the sma ll Narenjestan Garden within the city of Shiraz, and (a less consistent example) Shiraz's Eram Garden. Located within, on the edges, or outside of major cities, they are all deep green oases where the temperature perceptibly drops and the concems and conflicts of the world outside recede.

First on our route was Golshan Garden - re-built after the massive quake in 78 - resonant with the sounds of rushing water and featuring white pelic ans solemnly wandering the paths a longside visitors. Situated a long an east-west axis, the ma in entrance is at the west end of the garden. At the opposite end, ripples of heat emanate beyond the perimeter wall at whose foot a wide stream emerges from under the stone paving. Rushing into the garden in a wide channel, it quic kly bifurc ates to run the length of the garden on either side of the main prospect. 


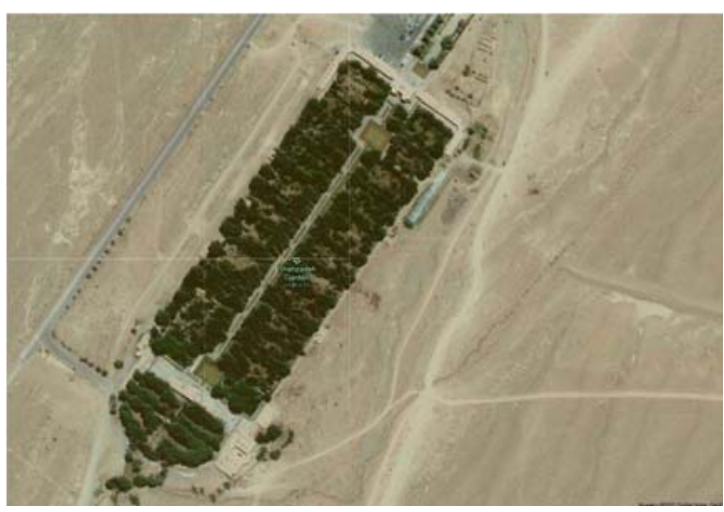

Shazdeh Garden - Mahan

(Google Maps, 2011)

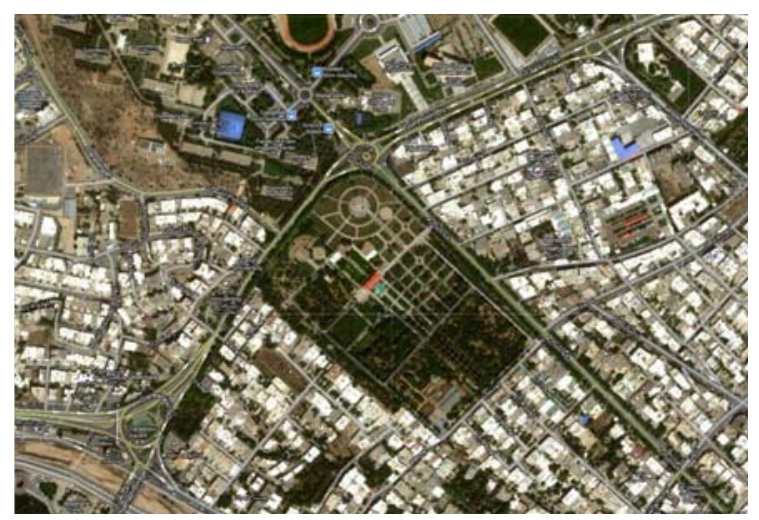

Eram Garden - Shiraz

While Golshan Garden features only an entrance building (it was always a public garden), the much larger Dowlatabad Garden in Yazd features a complex of buildings. The entrance building is situated along a secondary axis, itself part of a smaller walled garden through which visitors pass in order to access the main garden. The terminus of the primary axis oriented north west-south east is a series of build ings. These feature a centralized and omate series of rooms, balconies, and pavilions cooled with the tallest (Beazley \& Harverson, 1982) bad-g ir in Iran. The rooms a re decorated with fantastic stained glass sc reens representing nature in geometric pattems.

Shazdeh Garden was built as the summer residence of a Qajar-era prince (hence the name - Shazdeh meaning prince), and is ea sily the most spectacular of the gardens I visited. Set aga inst the panorama of mountains beyond its high walls, the main garden is accessed through a smaller secondary garden along the same axis. The ma in garden steps upwards a long the north-east - south-west axis, with large pools, founta ins, and waterfalls heightening the dramatic sense of ascent. Tall poplars line the walks, and excited clutches of starlings chatter in and out of their green abodes.

Eram Garden is the anomaly in this batch of Paradise Gardens. It adheres to the formula in one section of the central layout where an omate ma in building is reflected in a large pool facing it and both are part of an axial organization of a portion of the rambling park. Affiliated with the adjacent University of Shiraz, it is a teaching and hortic ultural garden as well as a pleasure ground. Unlike the others, this sp ra wling 
garden does is not organized along pools and channels of water. As befits the city of Shiraz (in whose outer ed ges the garden is located), I met a poet gardener who recited his poems for me as I avoided the spray sprinklers.

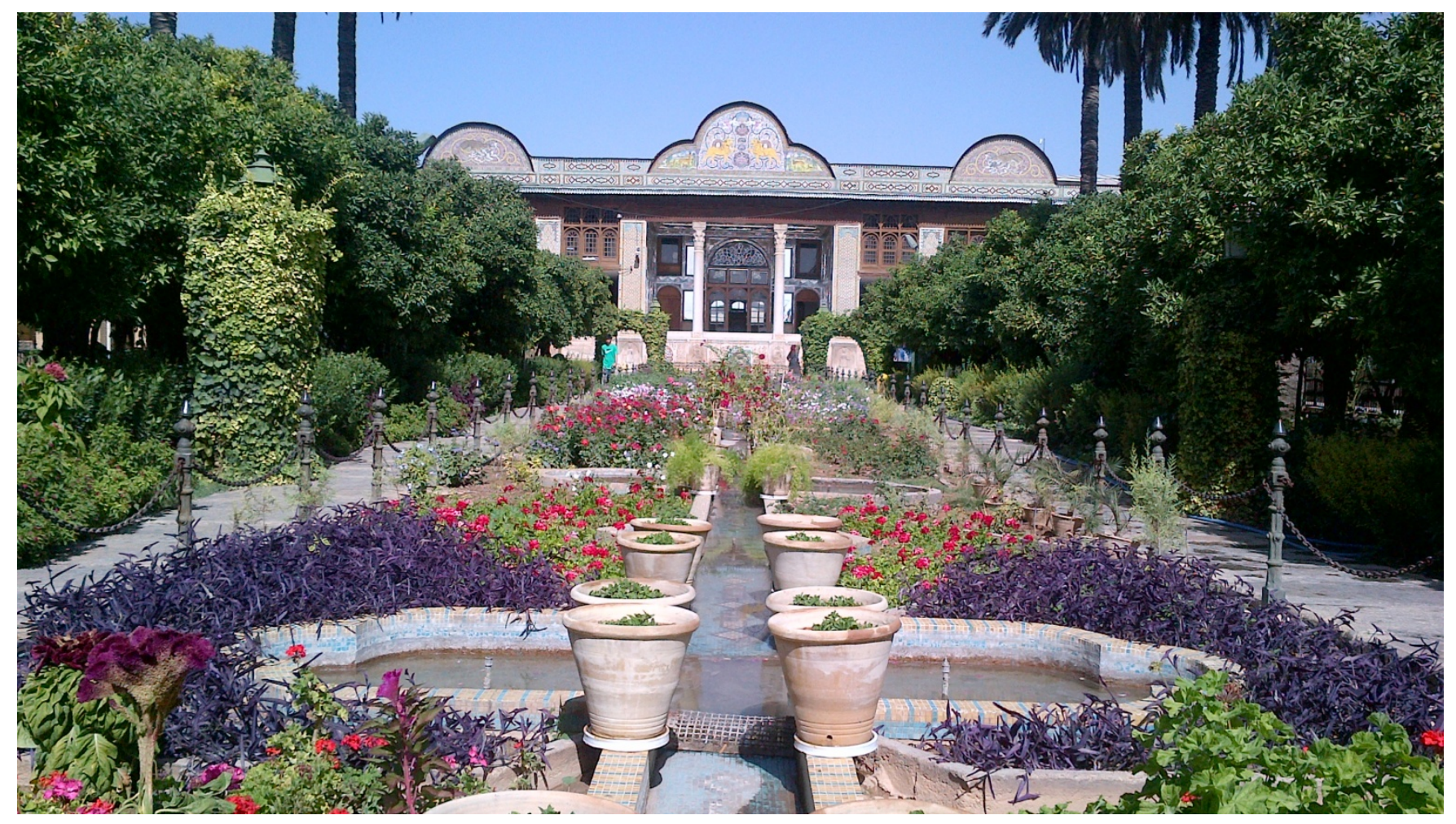

Na renjestan Garden - Shiraz

The other garden I visited in Shiraz was Narenjestan - the priva te garden of a residence that was used foryears by the archeologist and Persian historian Arthur Upham Pope as office and research facility. The basement of the main building features a museum dedic ated to Pope and his work. The smallest of all the gardens due to its function and mid-city location, it featured rows of narenj (bitter orange) trees - whose sc ent must bewitch in springtime. The entry buildings feature intric ate and colourful tile work including -uncharacteristic ally - human figures (photo) as well as plant and floral motifs. The pools and channels of water a long which profusions of potted plants are a rranged were nearly dry. But the wom hollows of the flagstones along the central axis retained puddles of imigation water, capturing reflections of the sky underfoot. 


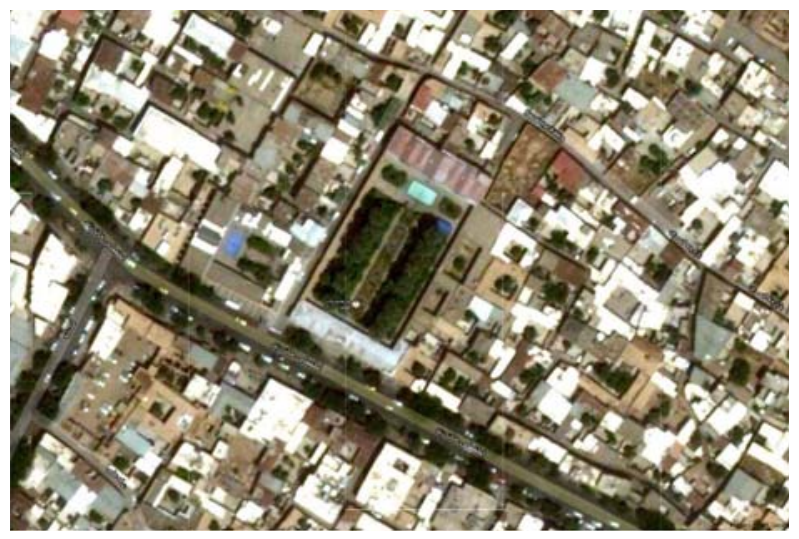

Na renjestan Garden - Shiraz

(Google Maps, 2011)

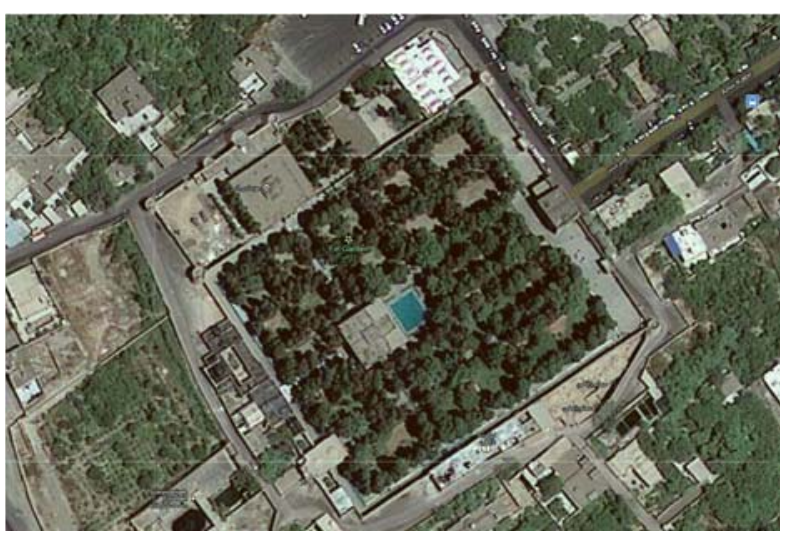

Fin Garden - Kashan

Famed for its hand-woven carpets, the city of Ka shan is just north-east of Esfahan and Natanz - in Iran's nuclearheartland. Fin Garden lies on the westem outskirts of the city and just off of the Q om-Ka shan Freeway (Q om is Iran's second holiest city and erstwhile home of Ayatollah Khomeini). The garden is filled with tall ancient trees, with cha nnels and streams and pools woven throughout. It is a large complex containing multiple buildings - library, museum, and the infamous “Fin Baths" where Qajar-era prime minister (Pimia \& Ashtiani, 2007) Amir Kabir's death sentence was ca mied out by opening his veins to the warm waters.
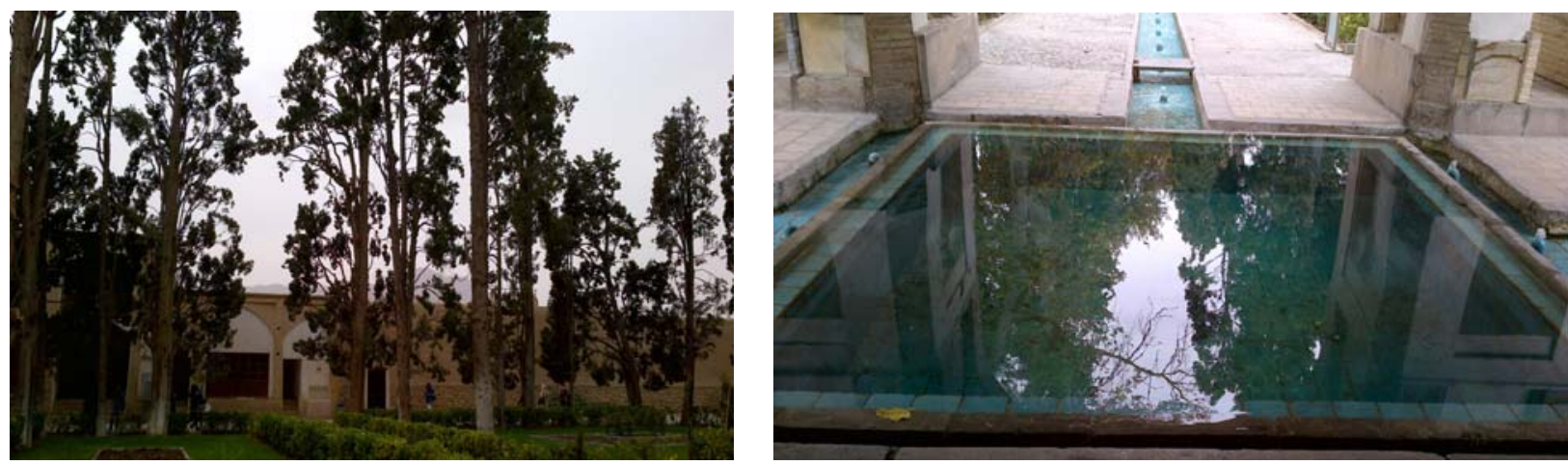

Left and Right - Fin Garden, Kashan

I include II Goli Park and the Saad Abad Complex in this category as points of comparison. Bounded by roads on all sides, II Goli aspires more to wildemess than Paradise, and if anything exhibits a reverse-paradise parti : a building set in the middle of an artificial lake. Sa ad Abad Complex is a small forest of trees and rivers enclosed by 
a wall. Nestled at the foot of the Alborz mountains, it is dotted with the palaces and mansions of the Shah and his family.

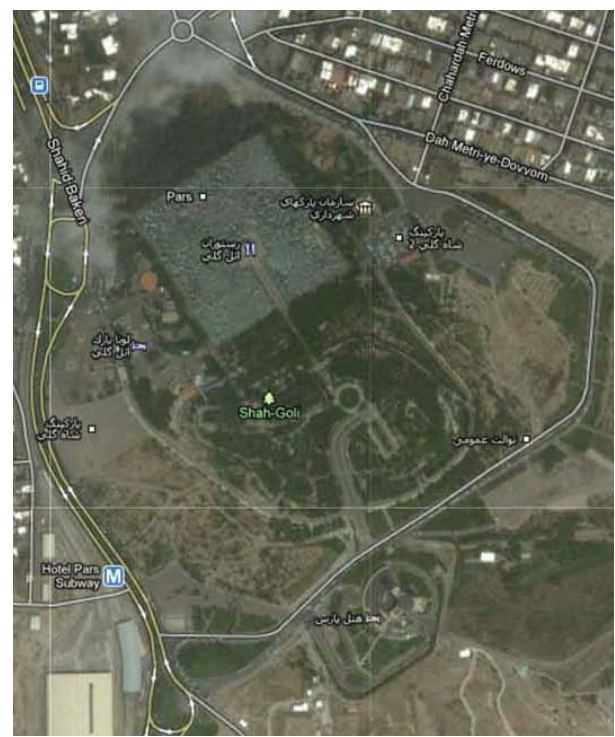

II Goli Park - Tabriz

(Google Maps,2011)

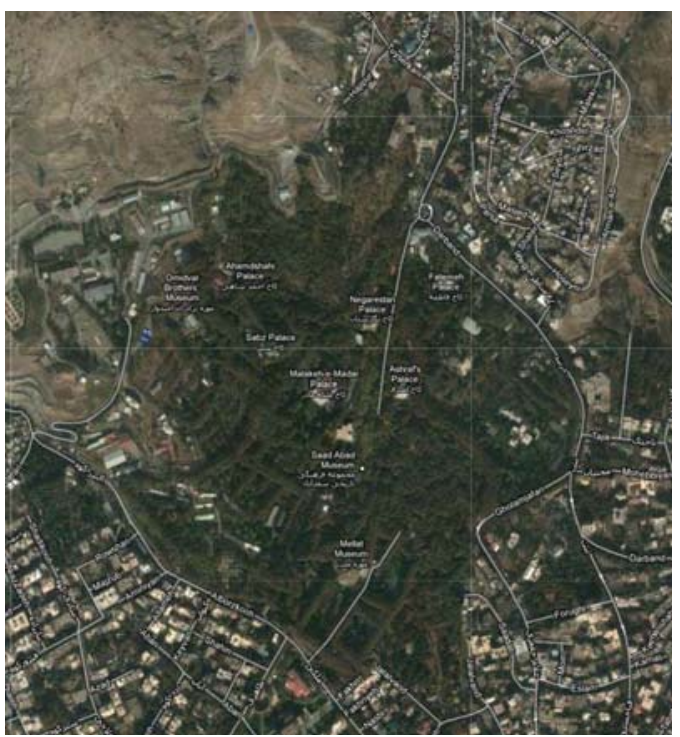

Saad Abad Complex - Tehran

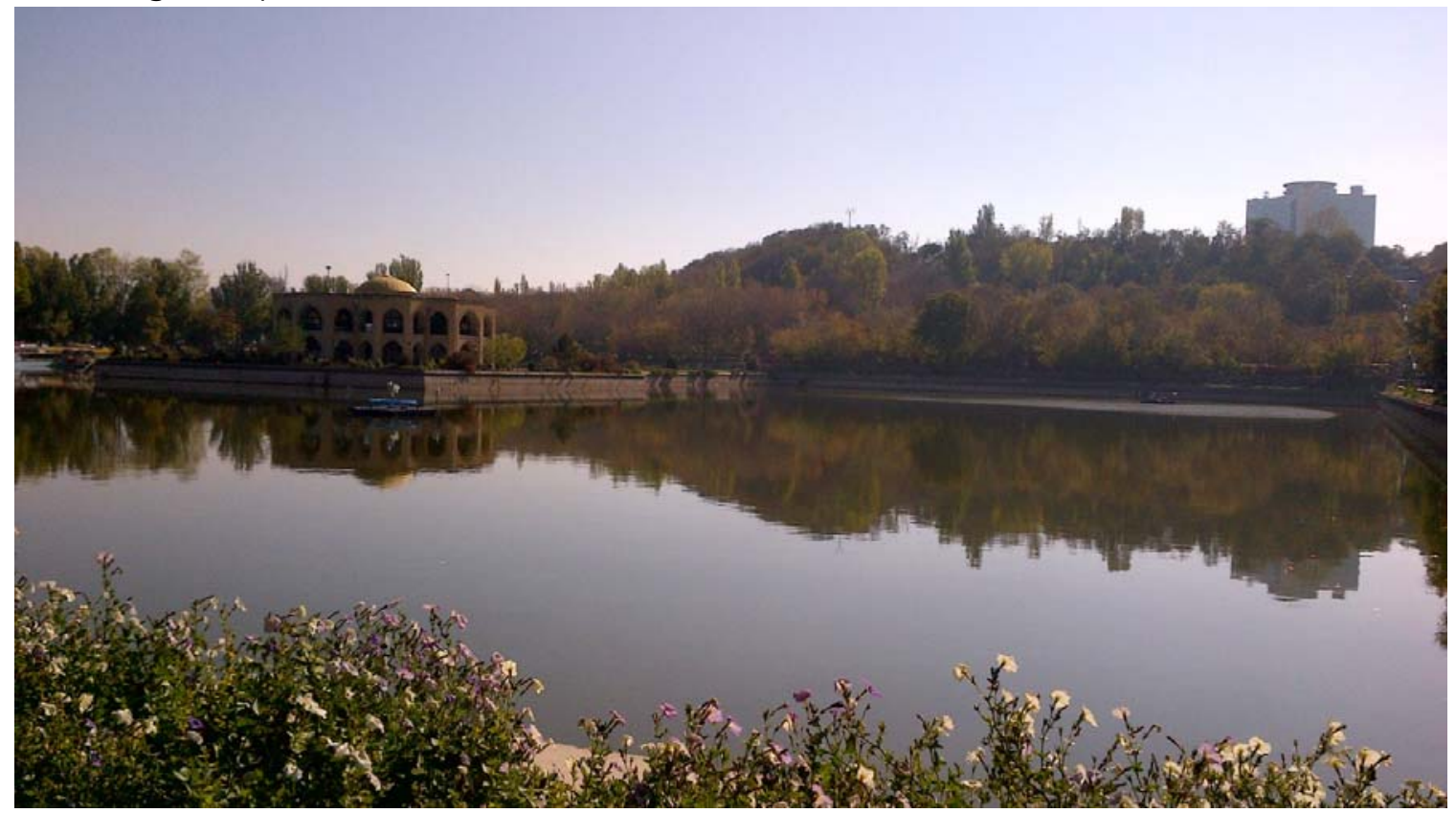

II Goli Park - Tabriz

\section{Buildings}

\section{(Manifesting the Paradise Parti)}

The building typologies influenced by the paradise parti include houses, mosques, shrines, hotels, public squares,... The architectural expression ranges from the simple vema cular style of a mud-hut in the desert, to decorative residential examples of Qajar- 
era affluence, to the rich, a lmost ba roque explosion of natura listic decoration in build ings such as Esfahan's Abasi Hotel, and the ostentatious architec ture of major Isla mic shrines such as Mashhad's Shrine of Imam Reza.

What these buildings have in common a layout which diagra mma tic ally transla tes into a central courtyard or plaza, a round which the functions of the building - rooms of a house, lobby and restaurant and guest rooms of a hotel, spaces for prayer and congregation in a mosque - are arranged : "In many Iranian build ings, it appears that the designer's first consideration was the central courtyard and its proportions, followed by the organization of various spaces a round it."(Kasraian \& Nadeni, 2003. p.17)

There is also the modem re-interpretation of this parti in high rise buildings in Iran and elsewhere : an atrium occupying the center of the building and stretc hing upwards to the sky, housing an arrangement of plants and flowers below a glass roof.

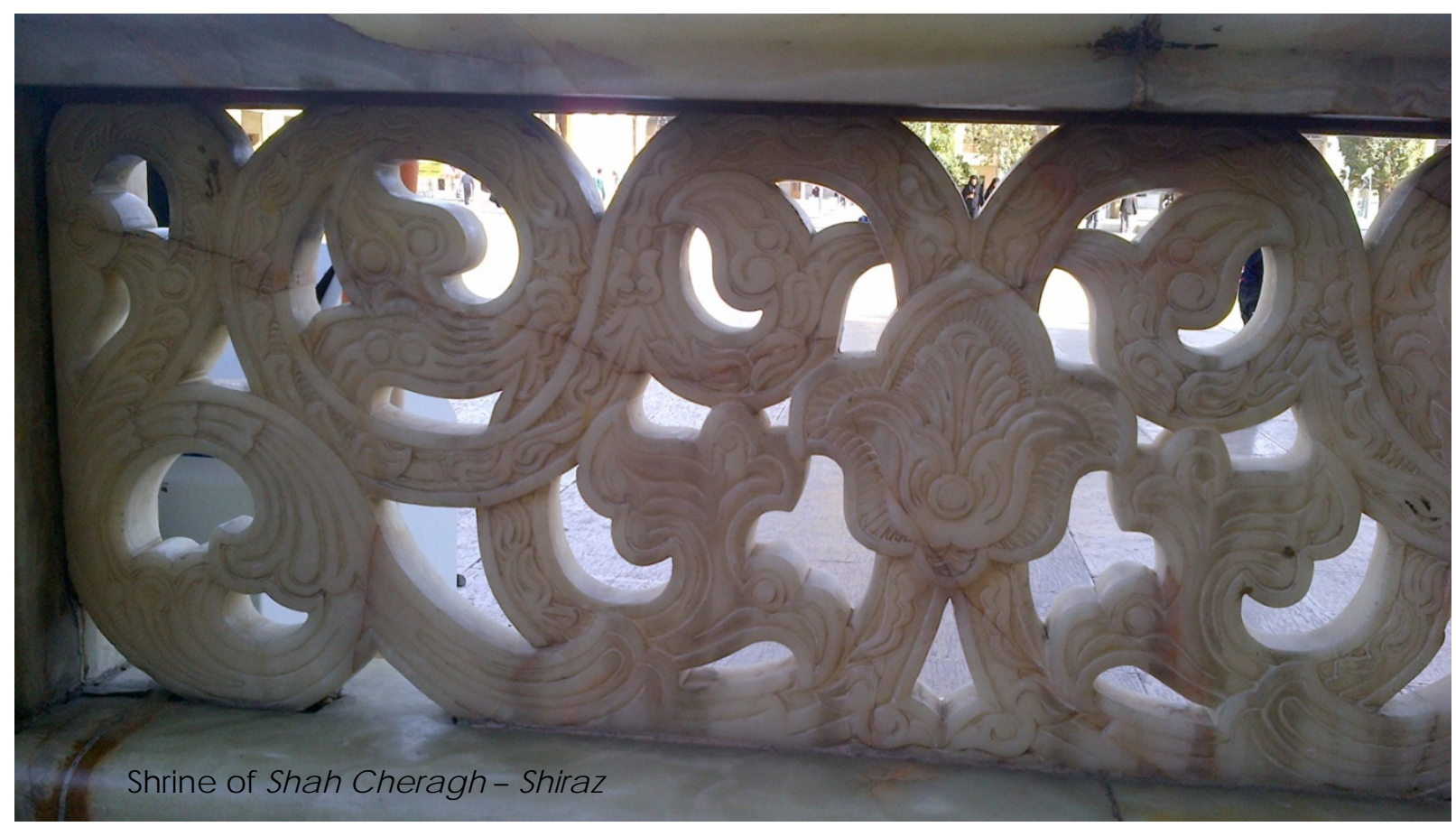

\section{Houses}




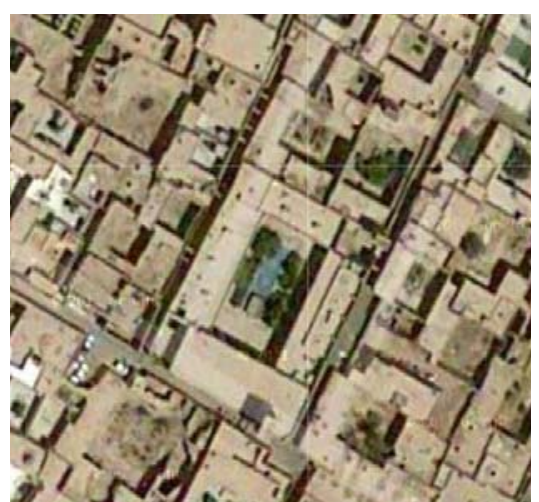

Boroujerdi House - Yazd (Google Maps, 2011)

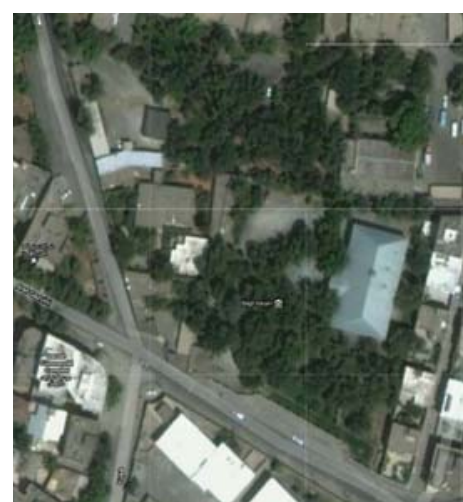

Nazari Garden - Hameadan

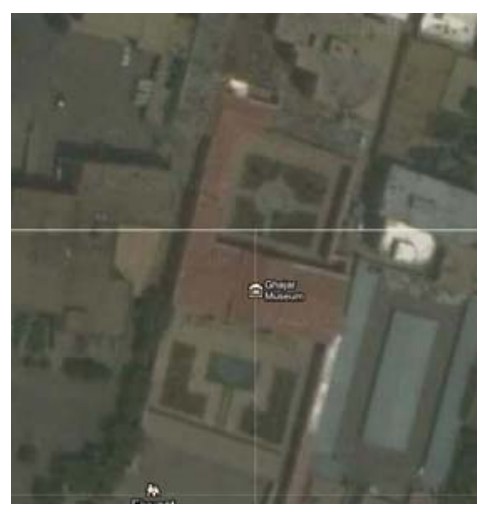

Qajar House - Tabriz

I visited the Boroujerdi House in Yazd, Nazari House and Garden in Hamadan, and Qajar House in Tabriz. The Boroujerdi and QajarHouses (museums now) both follow the paradise parti of a perimeter building and/or wall surrounding a central garden with a water feature sited along the central axis of the garden.

The more formally organized Qajar House features an outermain garden (birooni) accessed through an entry building off the alley as well as a smaller inner garden (andarooni) reached through the house. Such residences often featured two gardens a birooni and an andarooni - inner and outer orprivate and public yards to observe the religious dictates of modesty for women. Even houses not la rge or wealthy enough to afford the two gardens were equipped with two knockers of different designs and weights - which would issue different wamings according to the gender of the person requesting entry.

Qajar House's a nadarooni (outer) garden is organized in a quadripartite geometry, with a small pool at the crossing of the two axes. While both houses feature decorative stained glass, tile and plaster work, it is interesting to note their differences in the expressions of climate in the architecture. Located in the dry heat of the desert, Boroujerdi house features several bad-gir, a partially enclosed terrace with a high barrel-vault ceiling, and a raised platform erected above the large pool - features to mitigate the heat, capture breezes, and use the large water surface for cooling. In contrast, Qajar House's Tabriz is located in the cooler foothills of Sa hand mounta ins in north-eastem Iran, where mitigating heat was clea rly not a concem. 


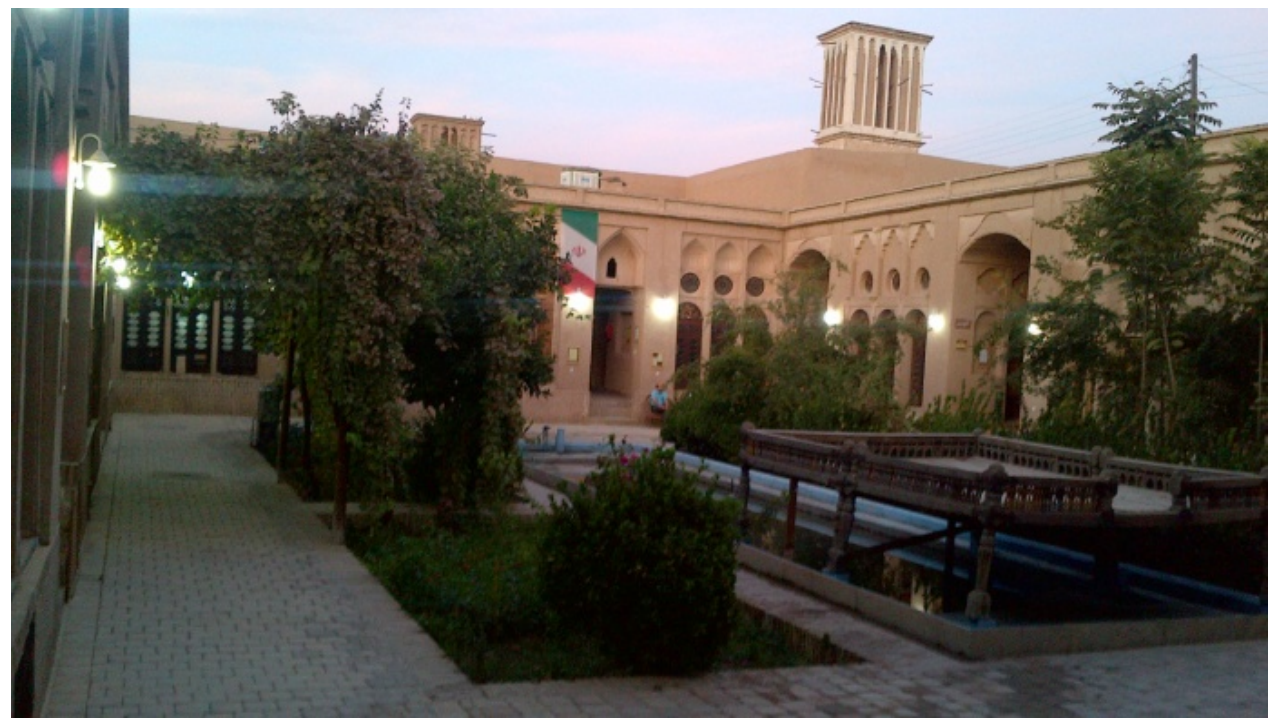

Borujerdi House - Yazd

Stric tly speaking, Nazari House and Garden in Hamadan (now govemment offices with the house off-limits to visitors - although I wheedled access by walking along the wrapa round portico to enter from the back) more closely fits the garden typology than the house. It is an enclosed garden with an entry building leading off the street, and you pass through the garden to reach the house - which is not built as part of the perimeter wall as is norma lly the case.
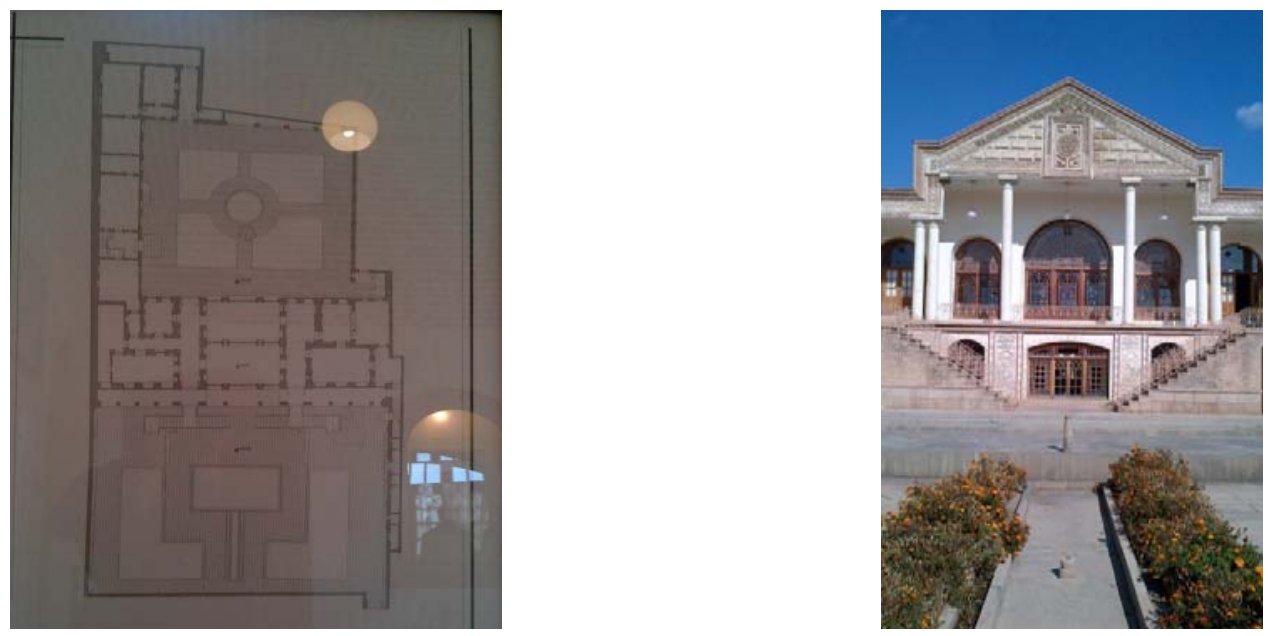

Qajar House - Tabriz. plan and birooni view

Nazari and Qajar houses' tectonics as well as their use of neo-classic al elements such as pediments, columns, and portic os, exhibit the European influence of their early $20^{\text {th }}$ 
Century era. In contrast, Borujerdi house reta ins the classic Isla mic arc hitectural language of pointed arches expressed in the traditional mud-wall construction of Yazd's desert ancestry.
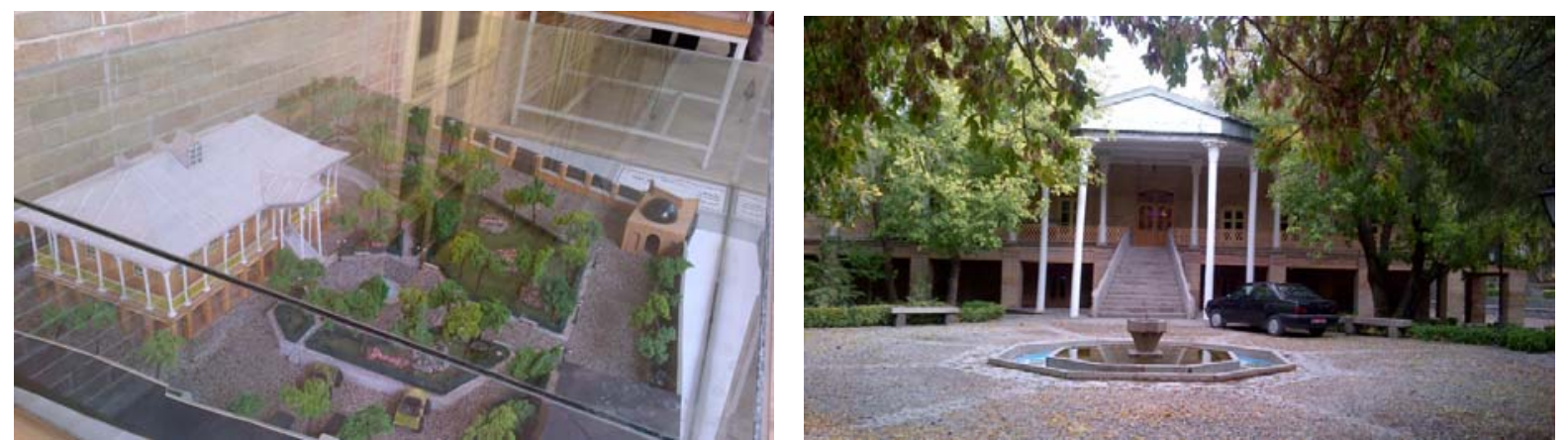

Left and Right - Nazari House and Garden - Hamadan

And a closing note of wonder and awe : the small kalleh ghandi (sugar cone) houses carved into the stone peaks of the mountains west of Tabriz. Although they do not embody the paradise parti, they a re regardless set in paradise - unintentionally exemplifying a more westem manifestation of para dise as shelter set amidst wild emess.

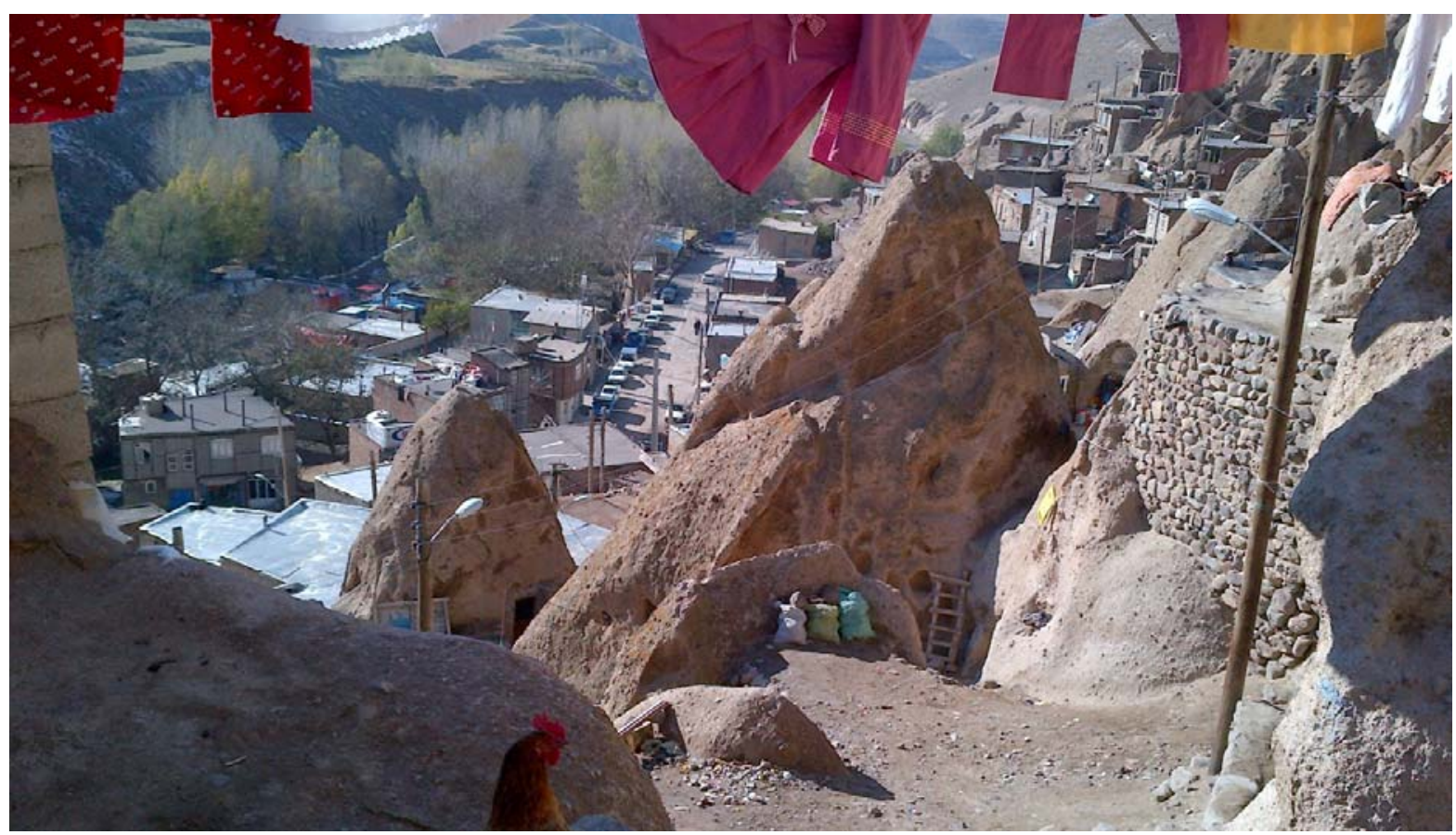

Above and following page, Village of Kandovan - nearTabriz 


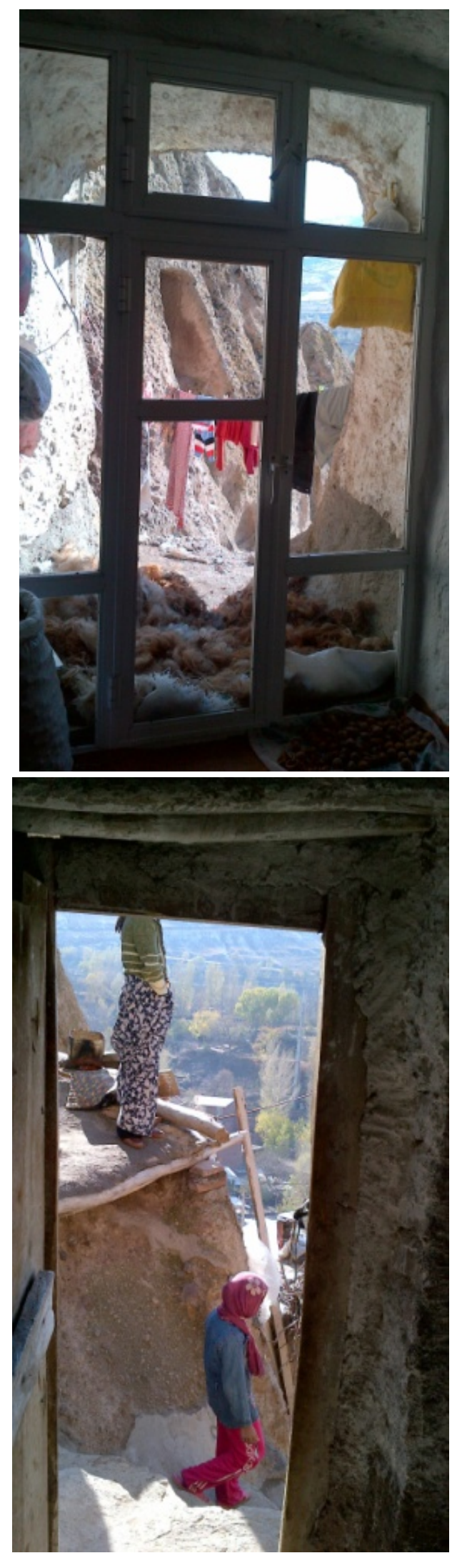




\section{Hotels}

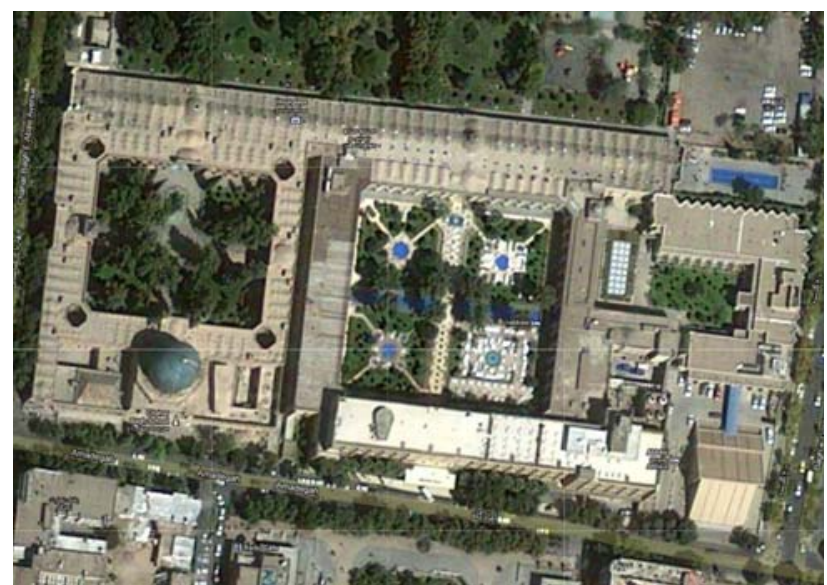

Abasi Hotel - Esfahan

(Google Maps, 2011)

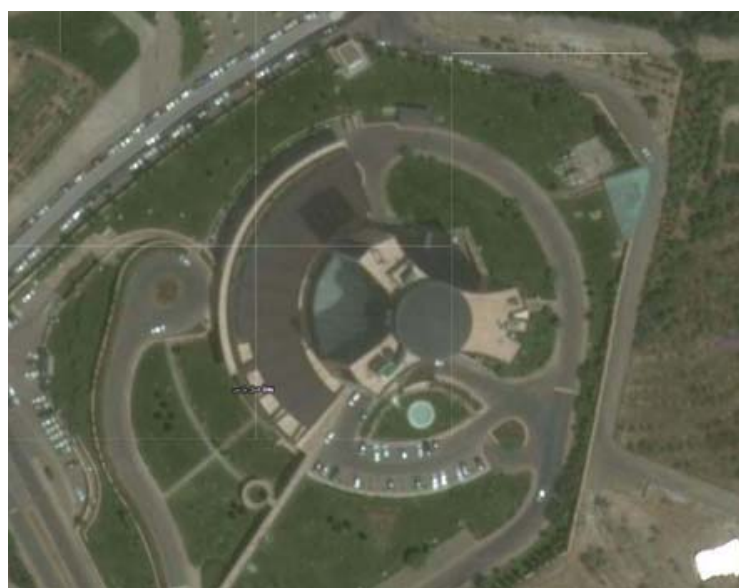

II Goli Hotel - Tabriz

(Google Maps, 2011)

While the majority of hotels in Iran are built in some (usually non-descript) variation of modemism, two of the hotels visited on this trip are noteworthy. In the case of Abasi Hotel in Esfahan, it is for the authenticity of its adherence to the paradise parti and the uniqueness and extent of its architectural decoration. In the case of Hotel II Goli in Tabriz it is for the unexpected (and belated) realization that it embodies a very different expression of the same parti.

Although manifesting the same parti, the two buildings hark from very different eras, a re located in contrasting contexts, and could not be more different in their architectural expression. The Abasi is located in the dense urban center of Esfahan, near the intersection of Char Bagh Avenue (yes, the same charbagh referencing the four rivers of life which generated the geometry of the axial layout for the gardens), and is the renovated and expanded reinca mation of a three century old Safavid era caravanserai (Burke $\&$ Elliot, 2008). It is built in the tra ditional Isla mic style of the period, and is situated to the ancient Char Bagh seminary whose blue tiled dome and minarets can be seen from the lush garden of the hotel's central courtyard. 


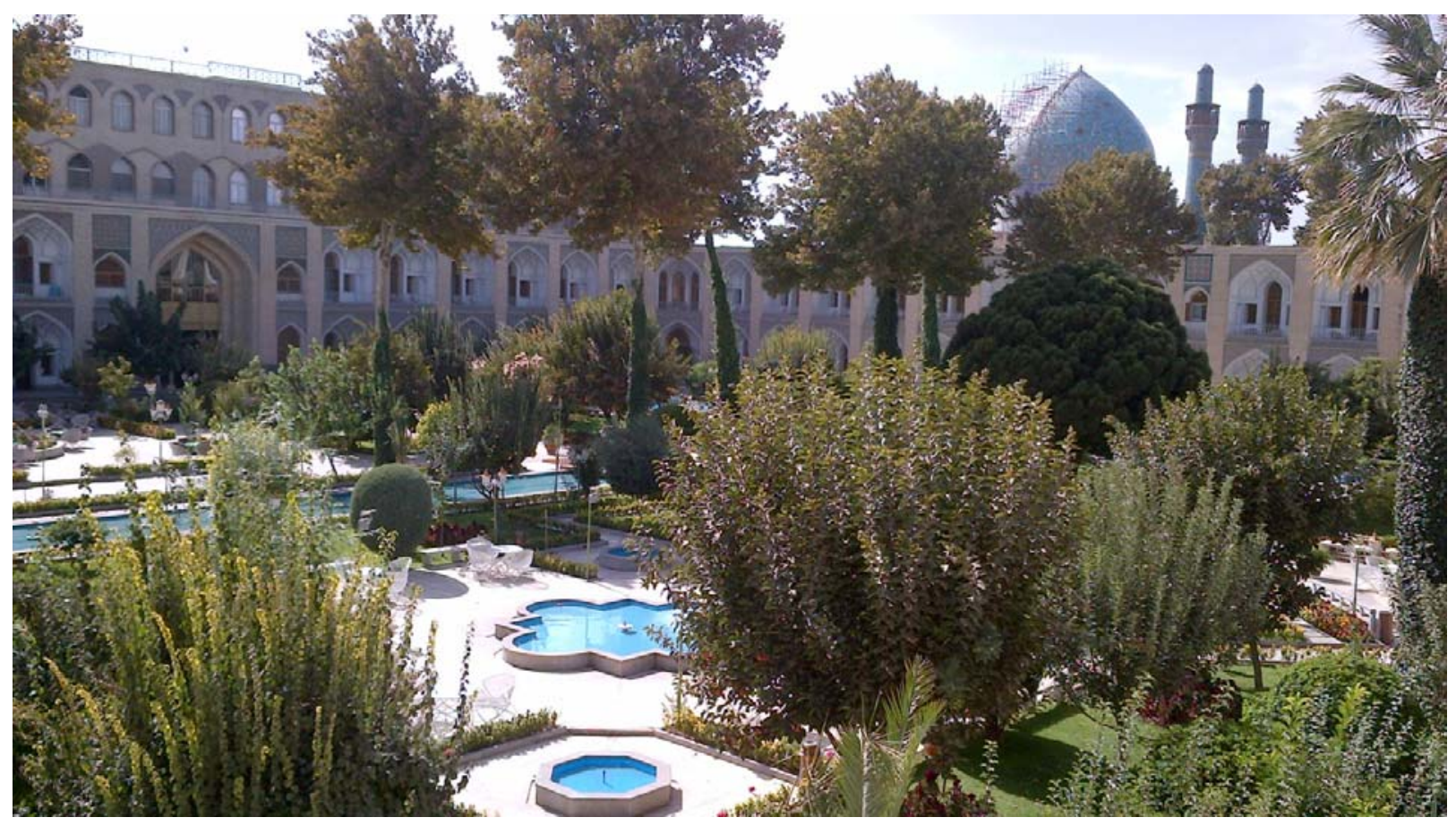

Abasi Hotel, Esfahan

The II Goli, located on the outskirts of Tabriz is a recently built glass and steel high-rise much as you might find in any modem city, a nywhere. Looking back at the photographs, the only clue as to location afforded someone merely seeing the image is the tall poplars planted a longside it.

Abasi Hotel's most salient feature is the main building's inner courtyard a round which guest rooms a re arranged, a long with the lobby and several restaurants. The traditional cross-axial organization neatly divides the courtyard into four equal qua drants. The lobby and a traditional tea-house anchor the north-south axis and are connected by the central promenade, with a secondary (though equidistant) axis featuring two long reflecting pools. Fruit trees (quince, persimmon), date palms, flower beds which are replanted each season, and borders and hedges abound . 

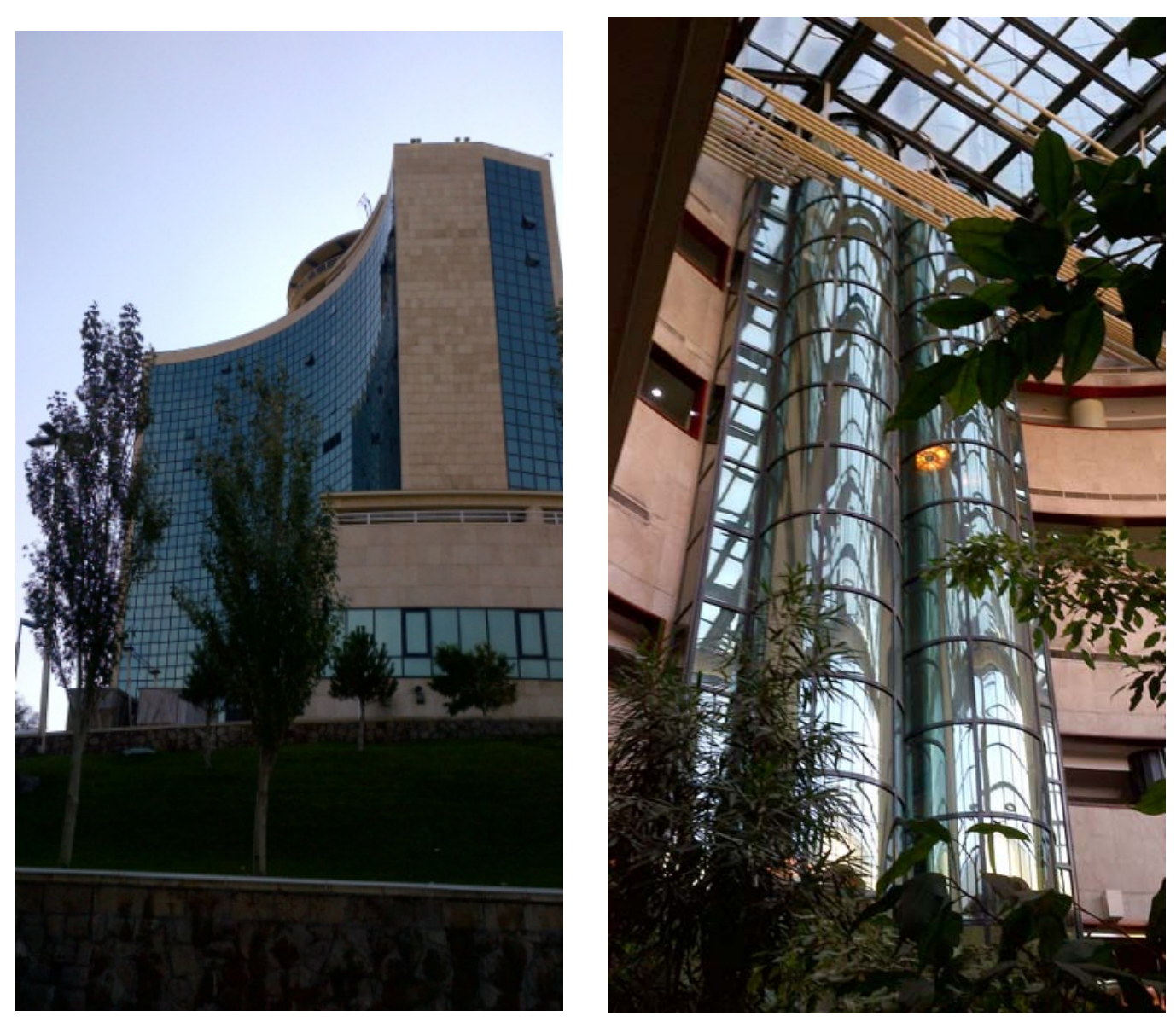

Left and Right, II Goli Hotel - Tabriz

This lovingly tended garden paradise is the epitome of the best of Iran. Colours, textures, sounds and scents of paradise surround the senses. The turquoise blue of the clear sky echoed in the colour of multiple pools and the tiles of the Char Bagh seminary adjacent, plays off the lush green of trees and shrubs, accompanied by the music of splashing fountains in the background. I have spent many sunny Iran aftemoons on a balc ony overlooking this garden, watching birds wheel a round the blue dome as twilight falls, the founta ins come to life, and the call for prayer sounds from the minarets. My children know of where my a shes shall go. 
The II Goli meanwhile plays extrovert to Aba si's introvert. Its loc ation affords magnific ent views of the adjacent II Goli Park, the city, the mounta ins and plains. It is a prototypical high rise with central a trium featuring plantings - which is the point of its inclusion under precedents as it strikes me that the atrium is a vertical paradise expression of the Paradise parti.

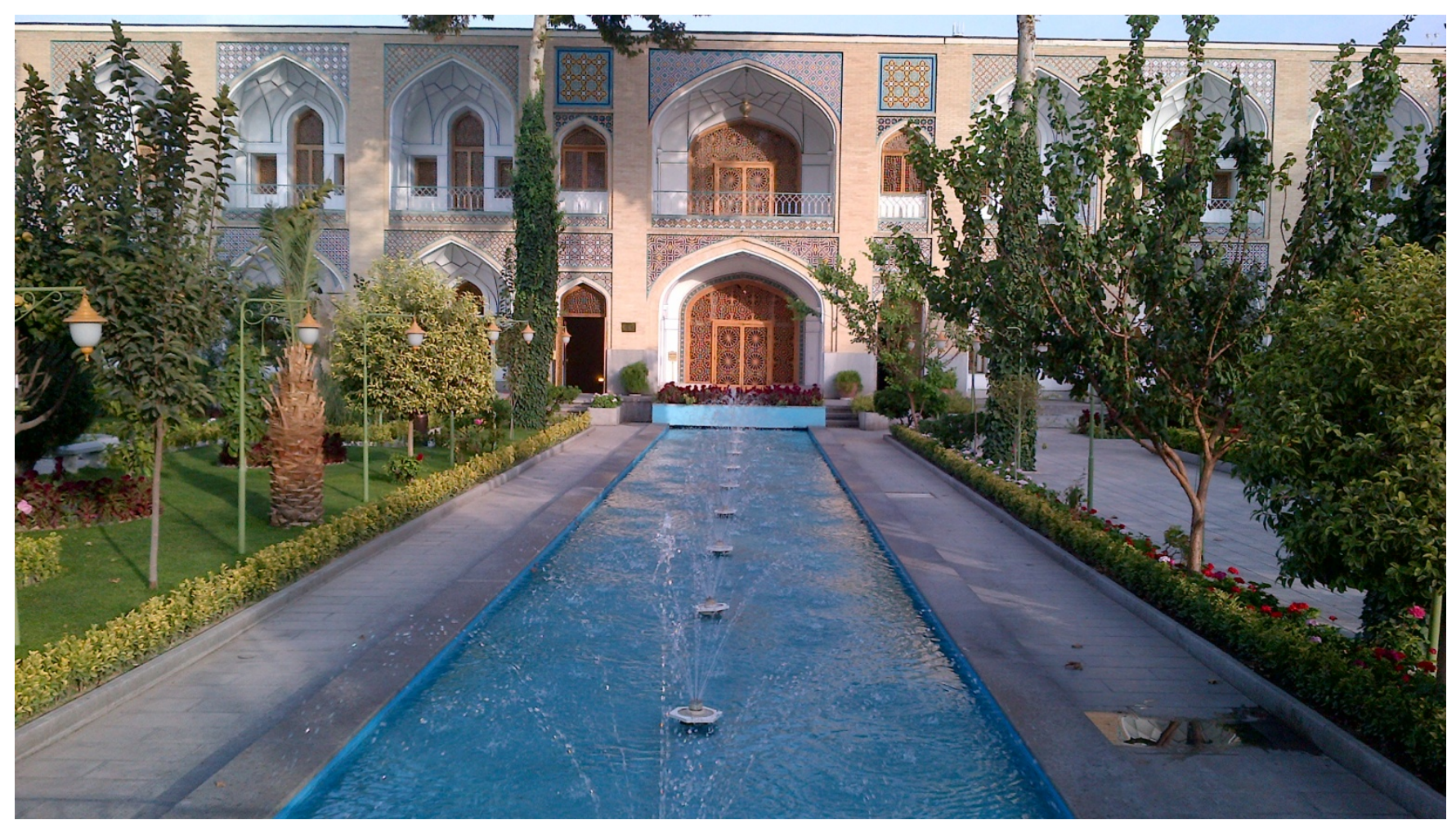

Abasi Hotel, Esfahan

I think of Abasi Hotel as a multi-la yered - perhaps even seven tiered - paradise.

Location, la yout, spatial orga nization, the garden sanctuary with its plantings and water features, and the dizzying detail and intricacy of its architectural decoration all conspire to intoxic ate and bewitch. Nearly every possible expression of Paradise has been employed in this building's execution. 
A dazzling profusion of plaster and glass pomegranate trees, cypresses, plants and flowers cover the lobby and comid or walls, the ceilings are tiled with coloured mirors worked with intric ate geometric pattems in plaster, the wooden banisters are a screen of tracery, and colourful tiles clad the stringer and floor opening faces.

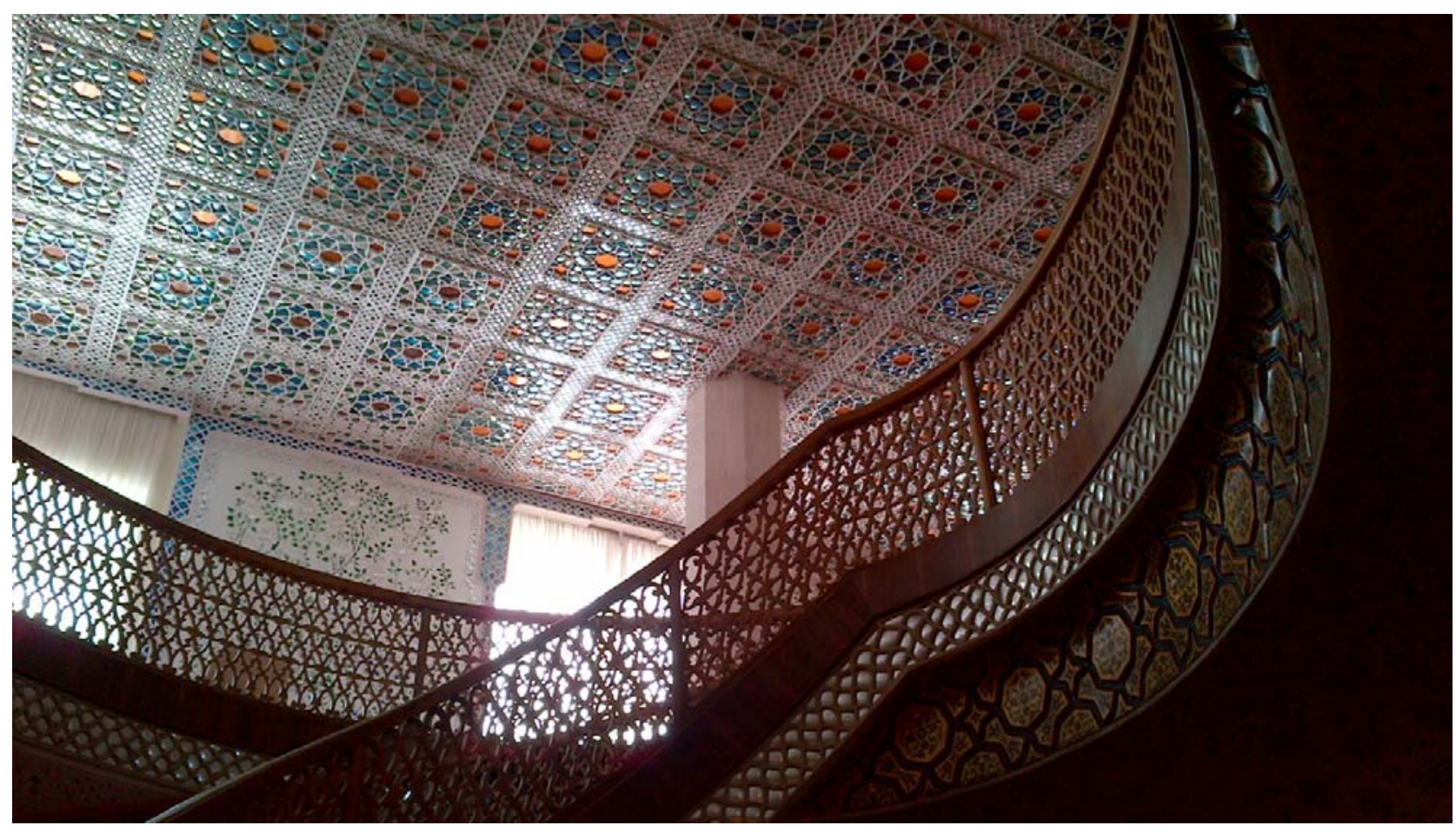

Abasi Hotel, Esfahan 


\section{Sacred Arc hitecture}

\section{(Mosque, Shrine, Tomb)}

As commemorative architecture and objects of pilgrimage, the examplesl've included in this section are all located within the closely knit fabric of the cities they are located in. Indeed, because they attract visitors, they a re often responsible for stimula ting the growth of their settings.

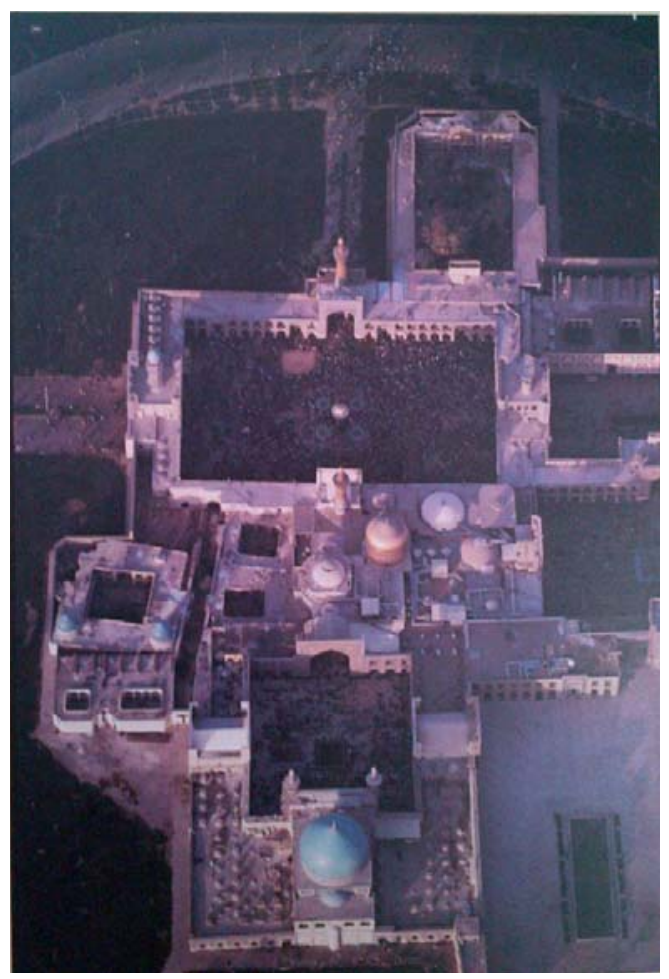

Shrine of Imam Reza - Mashhad, Iran in the 1950's

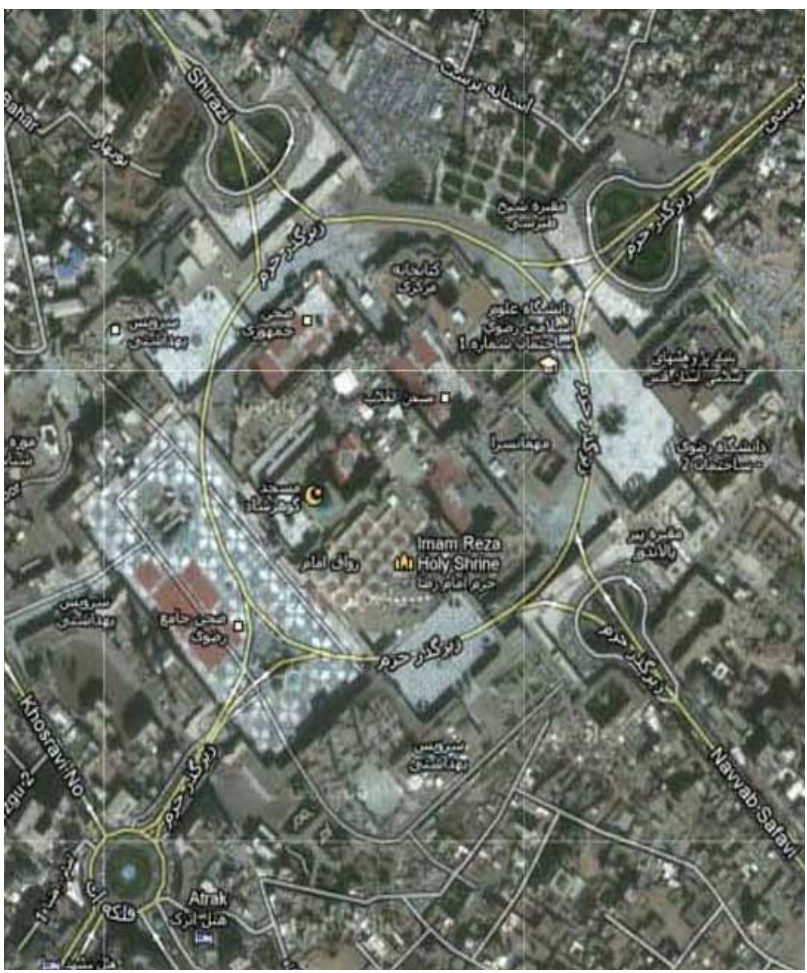

current view (Google Maps, 2011)

)

A prime example of this phenomenon is the northeastem city of Mashhad - where an entire city grew into being around a shrine. Mashhad meansplace of martyrdom, in this case that of the $8^{\text {th }}$ Shiite Imam Reza who was designated regent and sent into exile by the Caliph in order to neutralize the threat of his growing popula rity. He was forcibly sent on a hejira from Medina to the city of Marv in the north-eastem province of Khorassan. Although he was transported via a route intended to minimize his exposure followers, Imam Reza's exile caused enough uproar that in the end he was poisoned (with grapes) and buried in the village of Sanabad in 823. Sanabad is now one of the multitudes of neighbourhoods that comprise sprawling Mashhad. 
Today, the vast expanse of the Shrine of Imam Reza is located at the crossing of four of Mashhad's major streets (the char bagh parti at work again), and comprises multiple mosques and courtyards - extemal buildings a ranged a round a central space within which water and plantings occur.

While water is necessa ry for the performance of ritual ablutions required before prayer, plantings in mosquestend to be sparse. These are often limited to pots lining a reflecting pool - though when used in abundance anda ranged with zeal - as is the case in Shiraz's Nasirolmolk Mosque - they are a highly effective means of relieving the expanses of brick paving). (add photos of potted plants) What they invariably possess in abundance are stretches of paved ground necessary to accommodate large religious gatherings - as for Friday prayer or during the holy months of Ashura and Tasua which commemora te Imam Hossein's (the $3^{\text {rd }}$ Shite Imam) martyrdom. The intensity and pitch of religious fervour during these months is such that that a first-time witness of a festival would be justified in thinking the Imam had only just been killed (De Bellaigue, 2005). Even for a non-believer, the pageantry and intensity of the rivers of huma nity pouring out their desire and grief is moving.

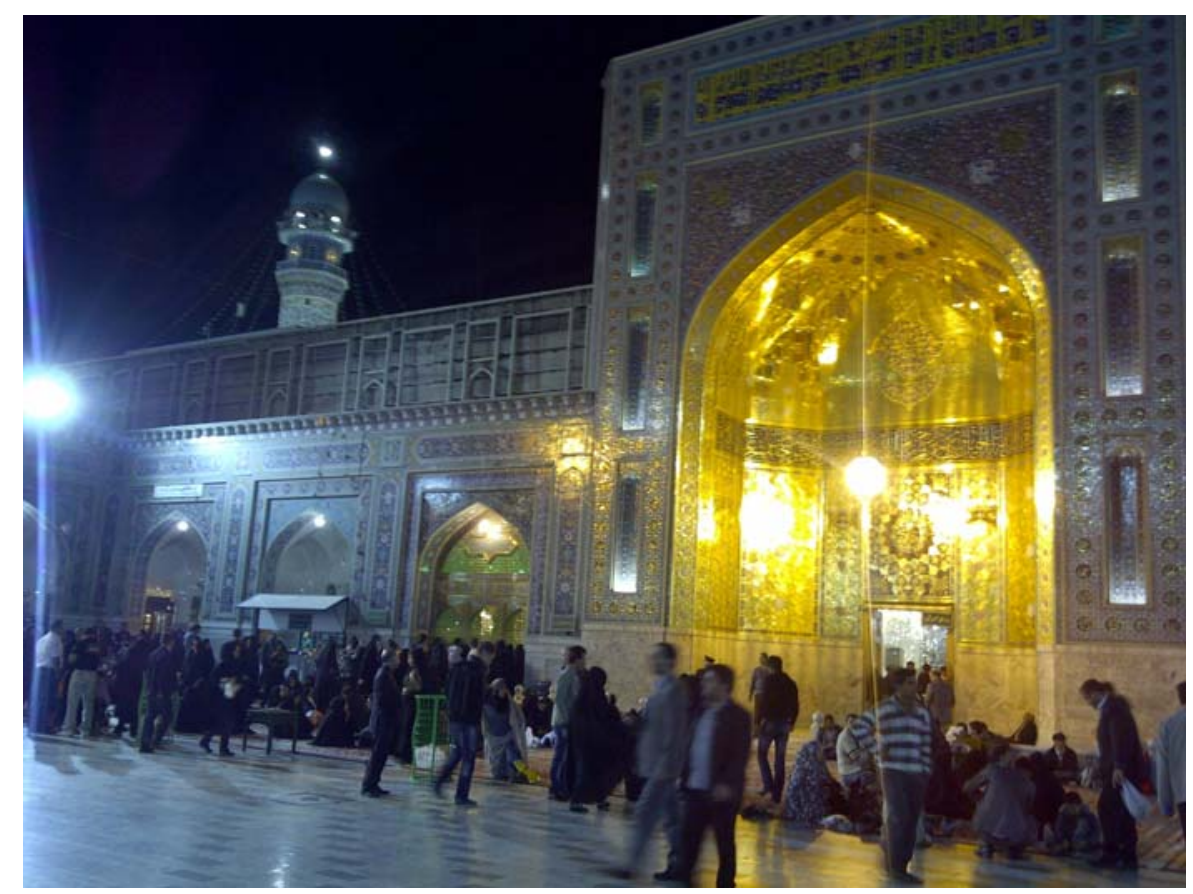

Shrine of Imam Reza - Mashhad 
In very large (and profitable) mosques such as the Shrine of Imam Reza, the paving is marble, and enomous (10x12m) Persian carpets line the entrances into the buildings suggesting planting beds lining the promenade of a garden. On these wool gardens, pilgrims rest, pray, camp out, or as is often the case when I visit - watch in awe (and trepidation) as the enomity of faith unfolds before their eyes.
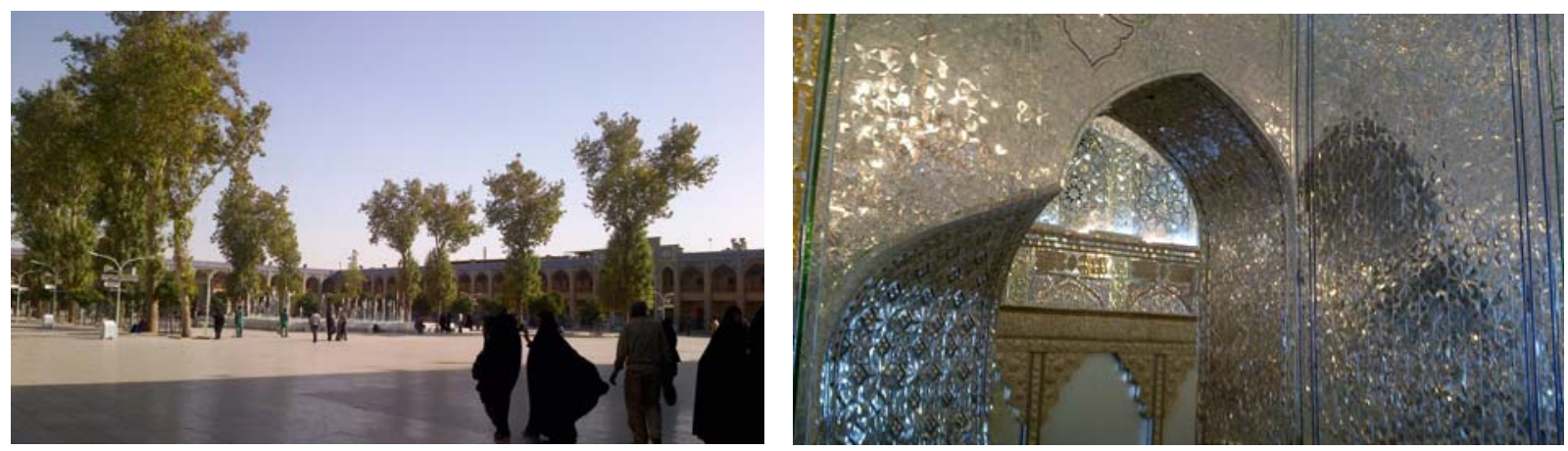

Left and Right, Shrine of Shah Cheragh - Shiraz

The paradise theme is a lso explicitly expressed in the elaborate mirror, tile, plaster work, and wood carvings which cover every a va ila ble surface centimeter attesting to the success of religion as a lucrative enterprise. These decorations employ flowing figurative lines or stylized geometries to depict trees, plants, sun, sky, water. The mirrorwork in the Shrine of Imam Reza and (coincidentally) his brother's Shrine at Sha h Cheragh in Shiraz is astoundingly intric ate, casting delic ate refractions of light and images in all directions. The scent of rosewater and the pilgrims' passions energize the detailed depictions of beauty, making devotion a very attractive possibility.

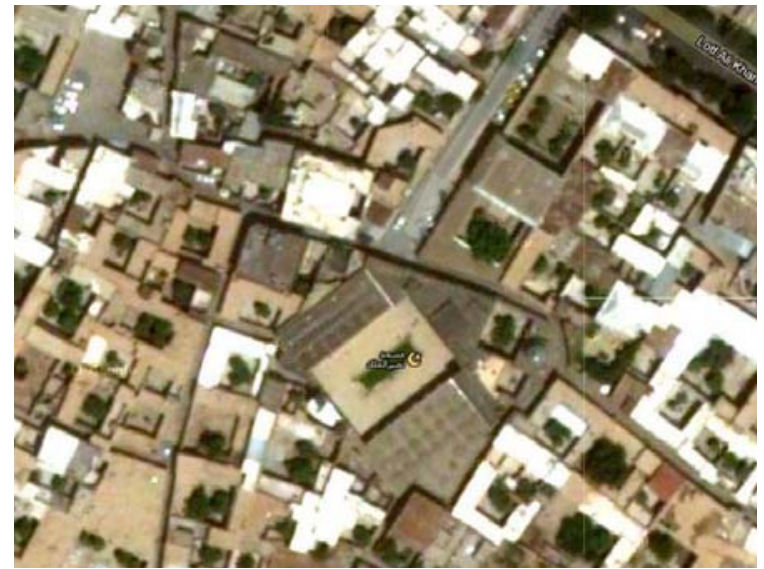

Nasirolmolk Mosque - Shiraz

(Google Maps, 2011)

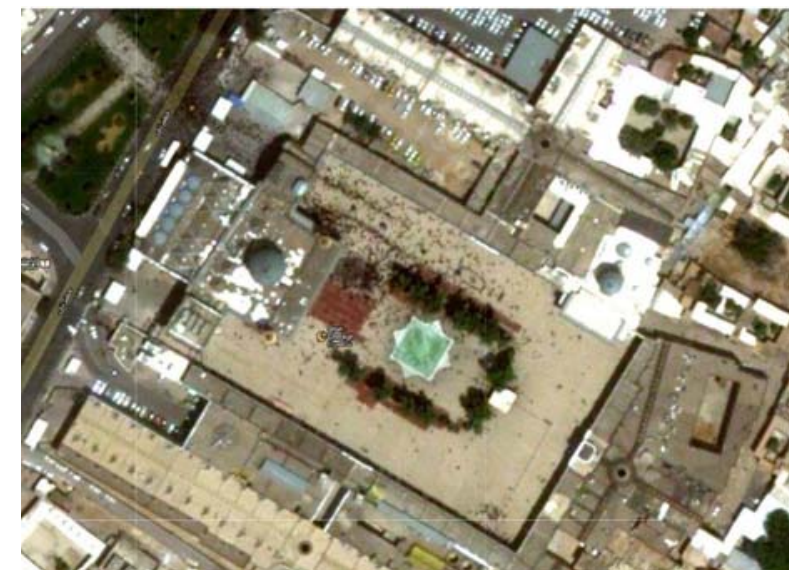

Shah Cheragh Shrine - Shiraz

(Google Maps, 2011) 

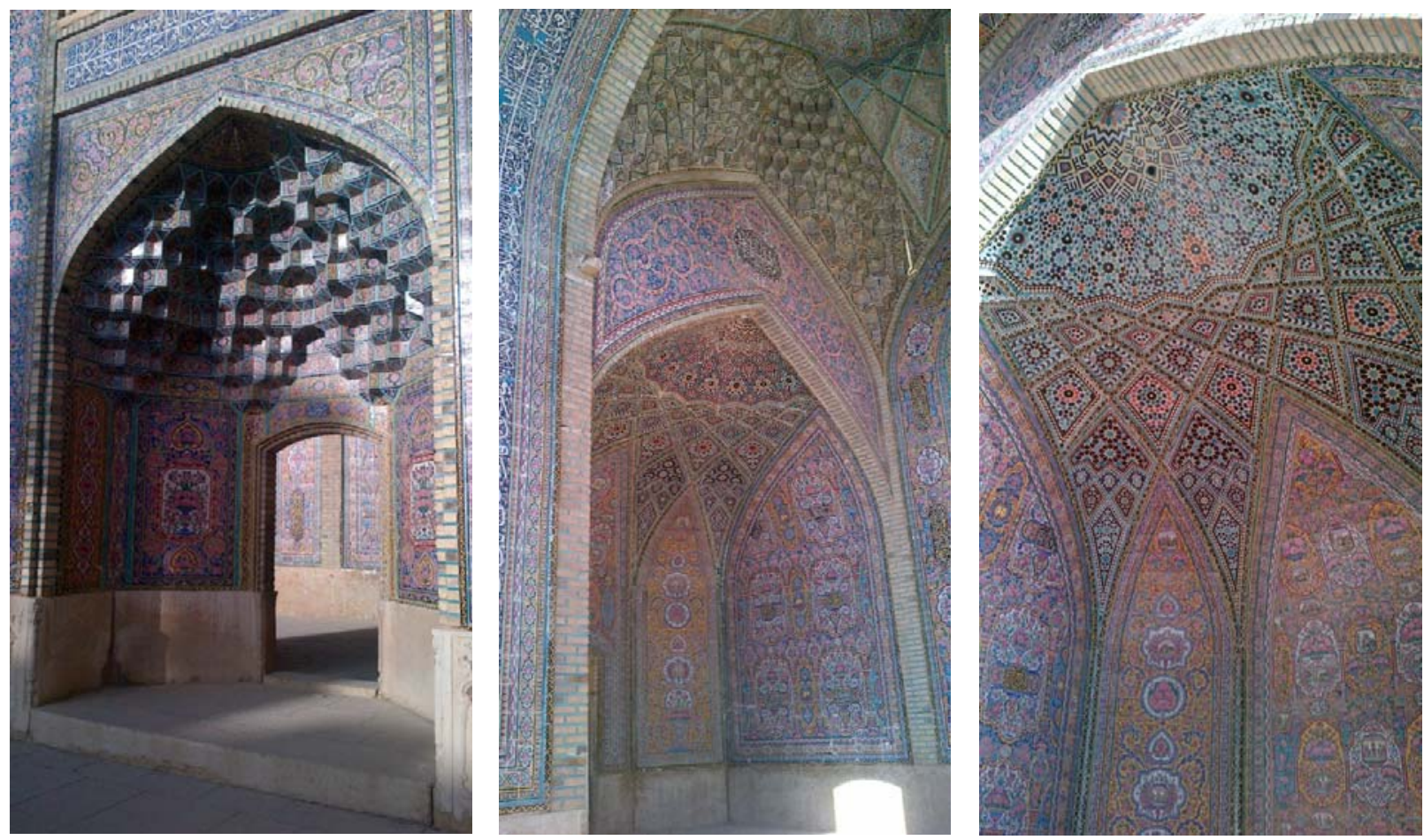

This Row, Nasirolmolk Mosque - Shiraz

Such buildings also feature fantasies of colourful ceramic tile worked into a symphony of arches and pendentives. Shiraz's Na sirolmolk Mosque features particularly dazzling tile work whose a rabesques a mplify the geometry of the pointed arches-causing the heart to contract with their unfathomable beauty.

Among this group, the tombs of the renowned poet Hafez in Shiraz and (to a lesser degree) the Islamic mystic Shah Nematollaheh Vali in Mahan are destinations more spinitual than religious. This absence of the need for formal congregation helps expla in why these two sites are more garden-like, feature inner courtyards and plantings developed in accordance with the traditional Paradise Garden layout. The multiple gardens in the tomb of Hafez are separated by brick walls with a punched out pattem - a common device seen in walls, parapets, and guards. Such deta ils a re as decora tive in their tracery and shadows as they are practical in allowing the transfer of scant breezes while providing privacy. The tension of the field/ground contrast creates a sc reen which in the case of the gardens surrounding Hafez's tomb intensifies the mystery of the adjacent garden as well as the desire to experience it. 


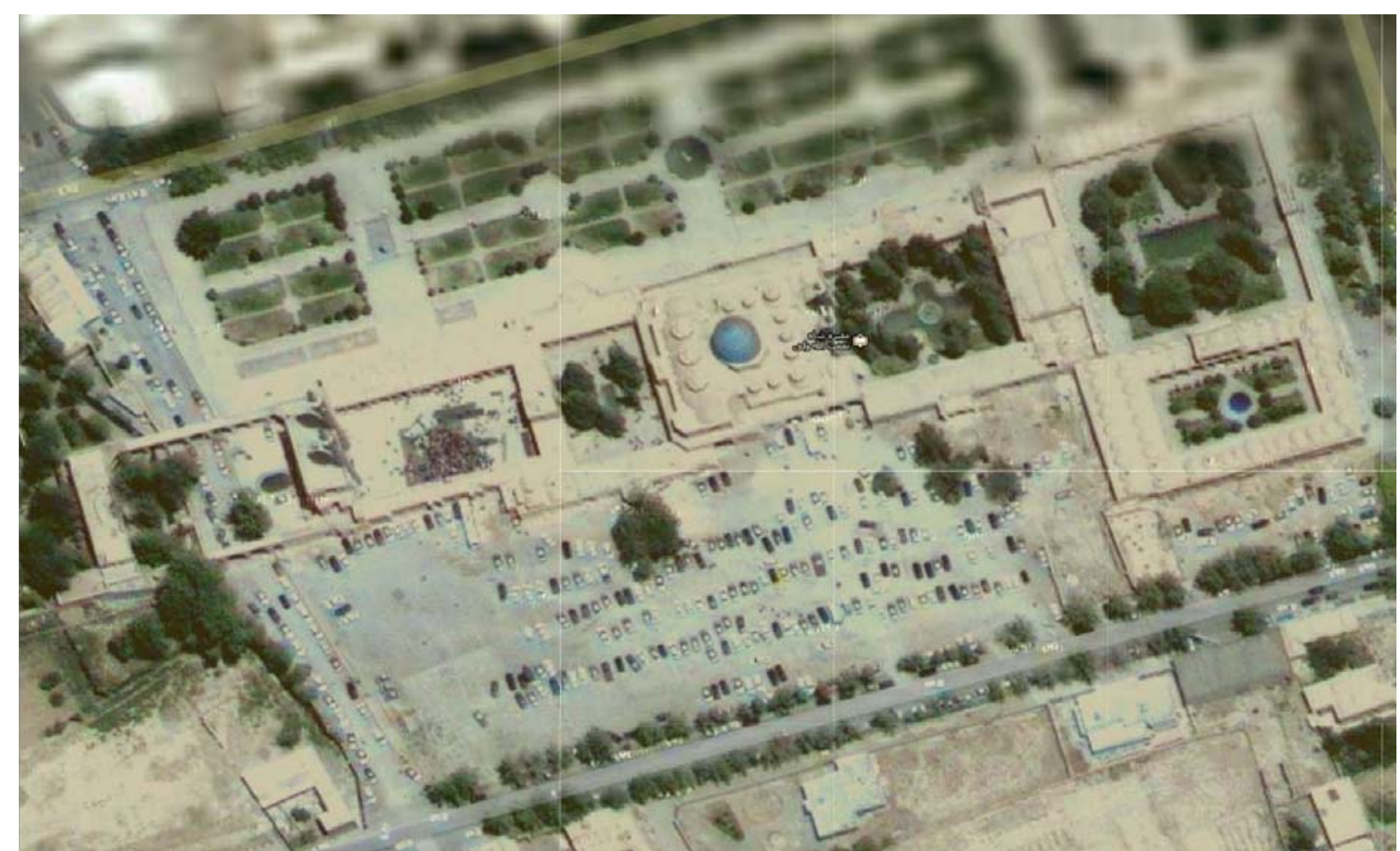

Shah Nematollaheh Vali Tomb - Mahan

(Google Maps, 2011)

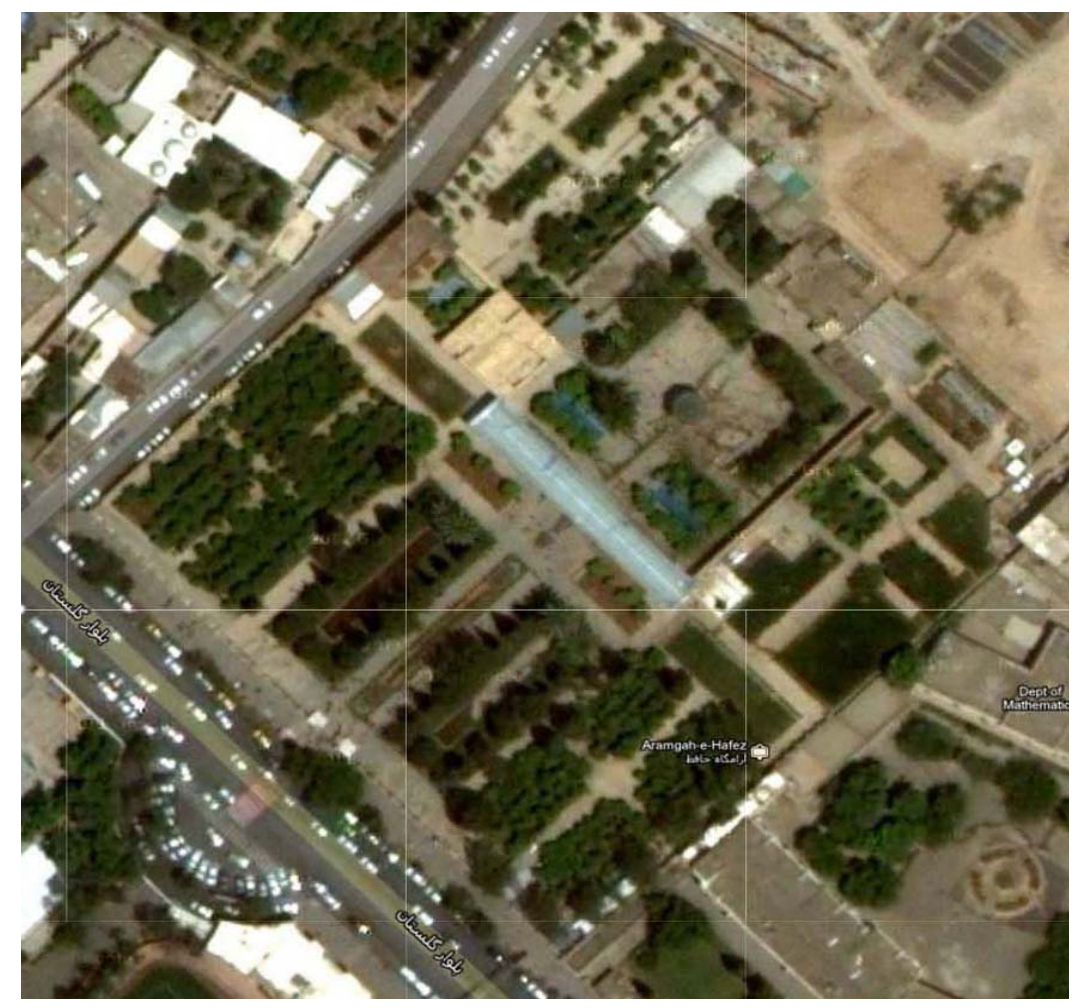

Hafez Tomb - Shiraz

(Google Maps, 2011) 


\section{Public Architecture}

(Square, Bazaar, Museum)

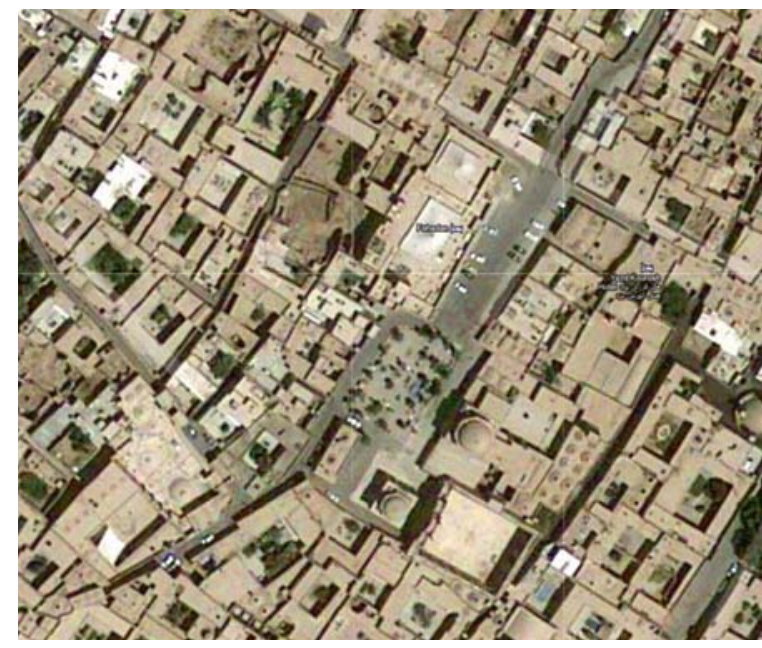

Square - Yazd

(Google Maps, 2011)

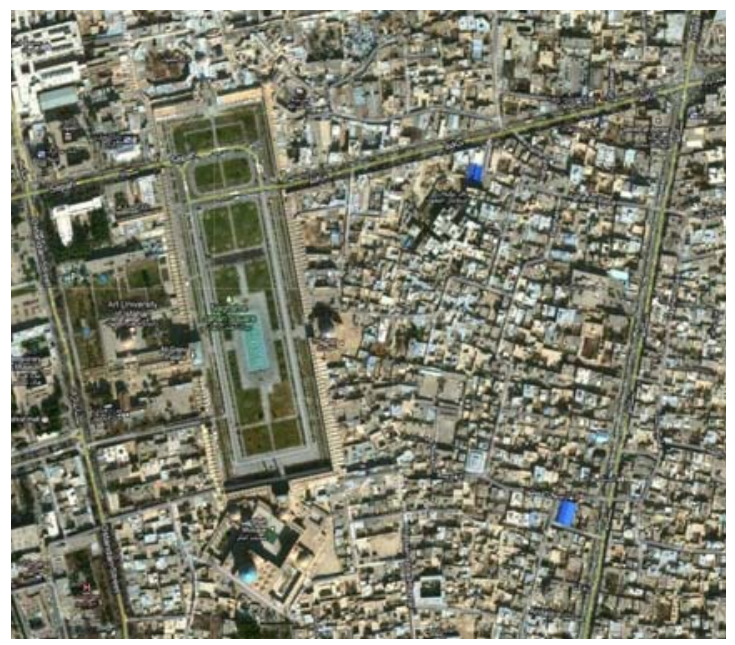

Naqsh-e Jahan Square - Esfahan

(Google Maps, 2011)

The grand public piazza and the incidental square, the mud tunnels of bazaars punctuated with the cadence of domes whose oculi glow with the rays of the sun, and the grounds of a palace tumed museum populate the inquiry of public architecture manifesting the paradise parti and themes.

The grandeur of Safavid era Naqsh-e J ahan (pattem of the world) Square prompted $16^{\text {th }}$ century French poet Renier to desc ribe Esfahan as "half of the world" (Burke $\&$ Elliot, 2008. p.232). This $512 \mathrm{~m}$ long by $163 \mathrm{~m}$ wide plaza (second largest in the world - first is China's Tiananmen) is surrounded by some of the finest examples of Safavid era Islamic a rchitecture (Burke \& Elliot, 2008). It features a grand basin which by day languidly reflects - the rhythmic arches of the bazaar at its perimeter, the blue and gold dome of the J ameh Mosque, and the passing of clouds, birds, and a implanes. By night, the founta ins come alive and Esfahanis jo in tourists in enjoying the dramatic setting. 

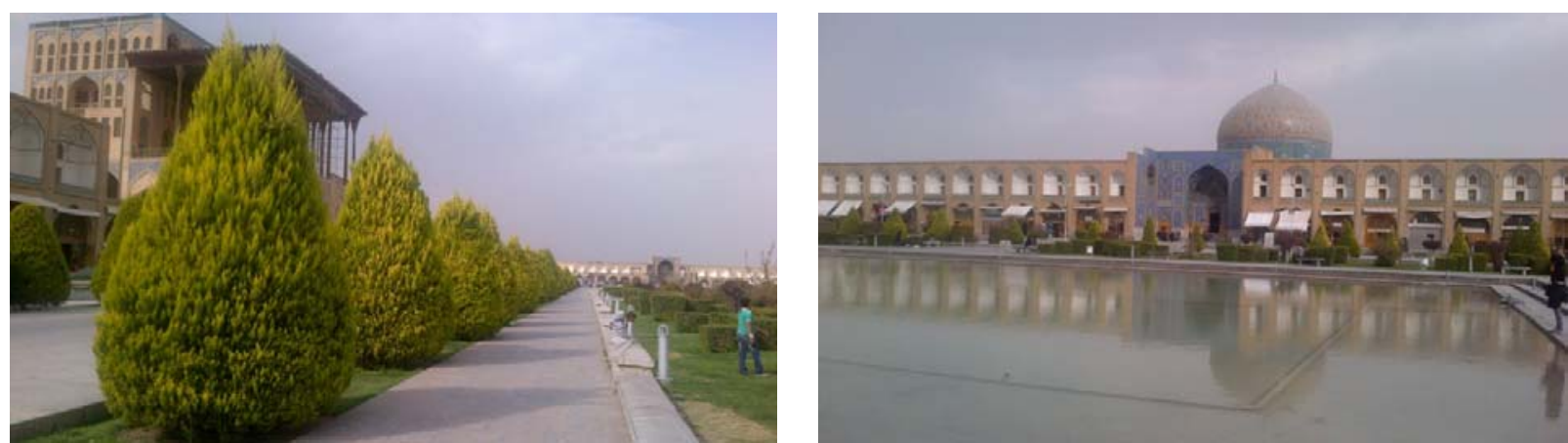

Left and Right, Naqsheh J a han Square - Esfahan

The grand reflecting pool is centered on a crossaxis anchored by the Ali Qapu Palace and Gohar Shad Mosque along the east-west and the Jameh Mosque and the Great Bazaar in the north-south direction. Plantings surround the pool, and the central "garden" area is encircled with altemating bands of walkways and trees. Groomed globe cedars line the paths, separating the pedestrian lane from that used by horsedrawn carriages which trot visitors a round the plaza. The Safavid king Shah Abas the Great held military processions and marches as well as polo games in this plaza, which he could survey from the vantage point of Ali Qapu 's grand terrace.

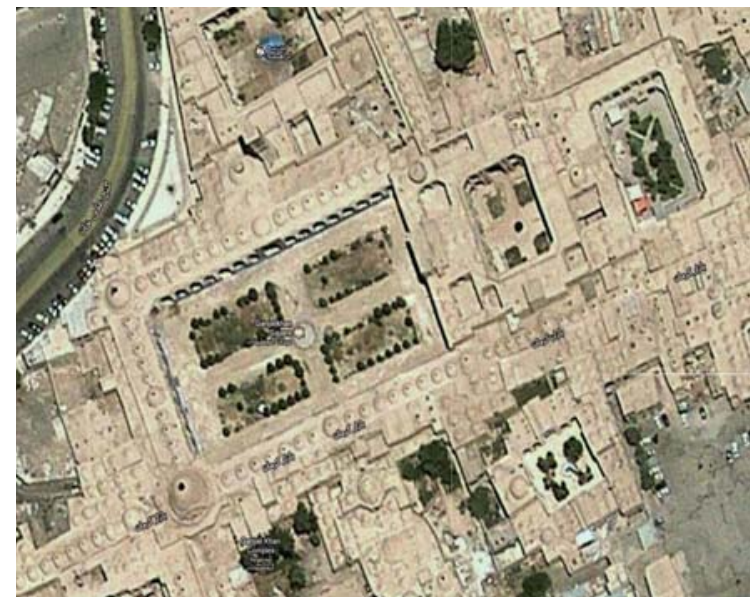

Bazaarand Ghanjali Khan Square - Keman (Google Maps, 2011)

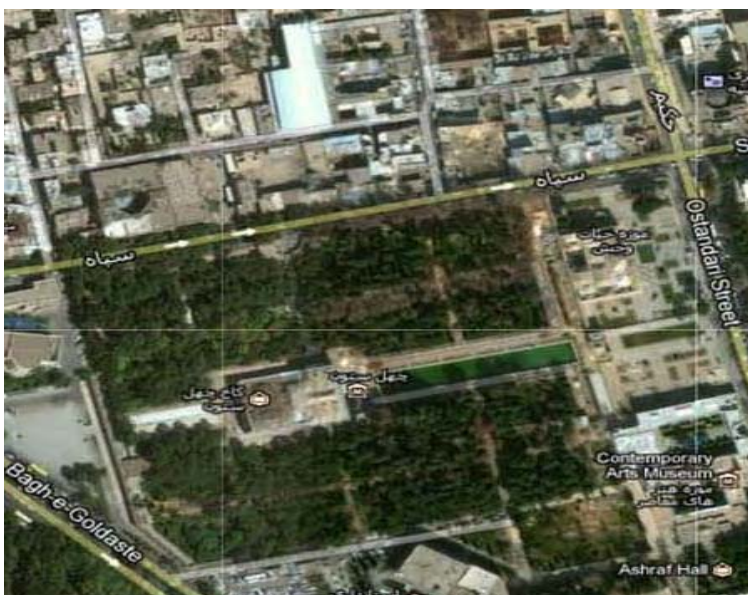

Chehel Sotoon Palace - Esfahan

(Google Maps, 2011)

Constructs such as the squa res which intermittently punctuate Keman's Bazaar and Esfahan's Chehel Sotoon Palace Museum (Chehel Sotoon means forty columns - so called because of the reflection of the twenty columns of its entrance portico in the 
elongated reflecting pool leading up to the palace) are clear replications of the Paradise Garden layout. So to a lesser degree is a seemingly incidental pocket of space left over from the mad labyrinth of Yazd's old city. The narrow mud-walled alleys open into space enough to allow one to rega in bearings by seeing the sky or a distant dome. The square defined within the respectful distance of the mud walls is not grand some uneven stone paving, a few benches, a small pool of waterpainted the traditional turquoise, a few scraggly trees struggling against the intensity of the sun. Still, it is a small moment of refuge - a chance for respite, and a second wind.

Yazd's Amir Chakhmagh Square is a convincing instance of the occasional failure of planned plazas- Paradise elements notwithstanding. Despite the it axial layout, water feature with fountains, and plantings, the absence of an immediate edge to separate its grass and walkways from the busy streets adjacent make it unwelcoming - indeed a place to seek refuge from. The evening I visited, the presence of forbidding militia throughout the square added to the sense of unease. 


\section{ARCHITECTURE OF THE HEART}

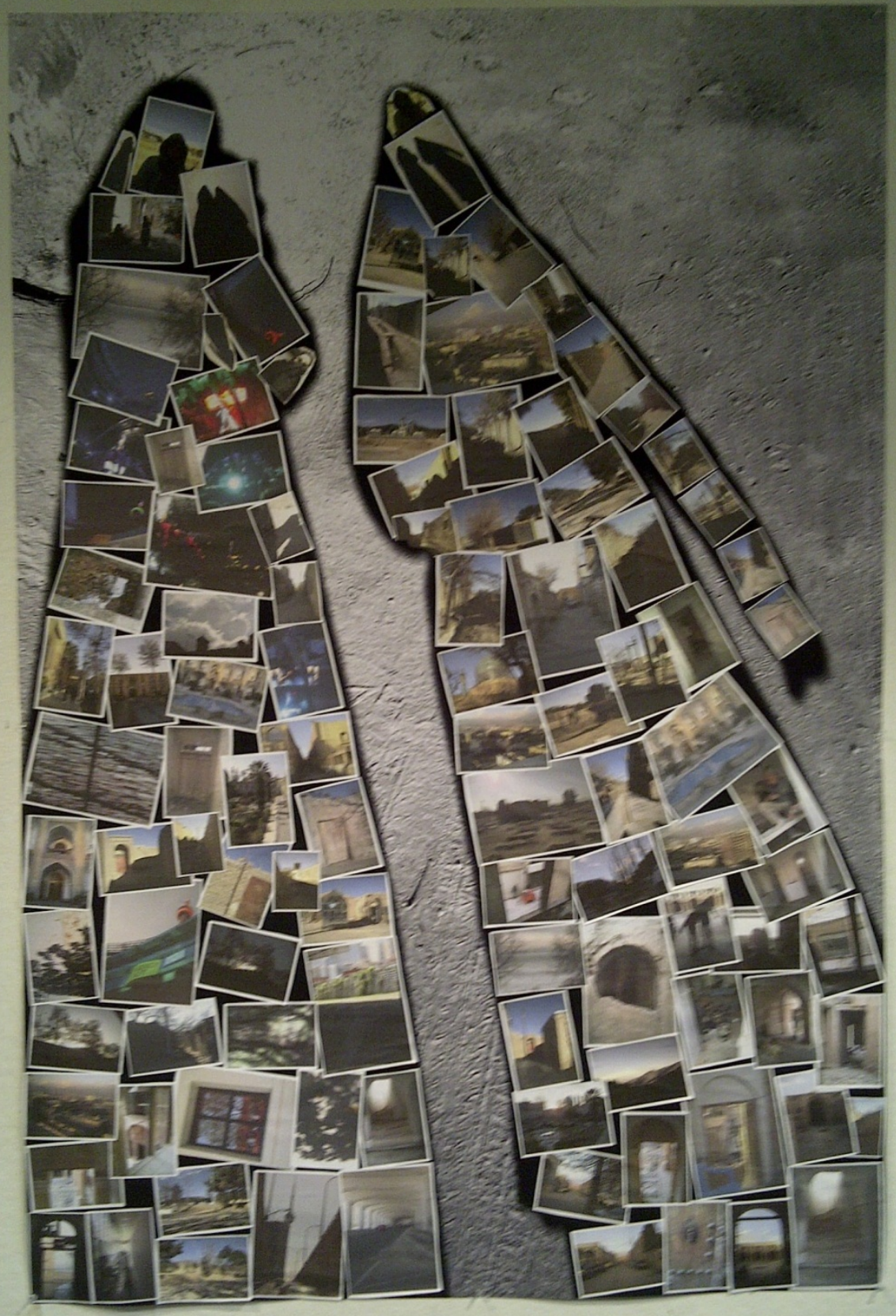


"At times all I need is a brief glimpse, an opening in the midst of an incongruous landscape, a glint of light in the fog,.... I will put together, piece by piece, the perfect city, made of fragments mixed with the rest, of instants separated by intervals, of signals one sends out, not knowing who receives them. If I tell you that the city toward which my joumey tends is disc ontinuous in space and time, now scattered, now more condensed, you must not believe the search for it can stop." (Calvino, 2002)

“...a na rative of the universal process of design and construction - which is to say, the age-old story of how dreams get tumed into drawings that then get tumed into wood and stone and glass, finally to take their place in the palpable world...Architec ts do their work on the frontier between the ideal and the practical, translating wisps of idea sinto buildable facts..."(Pollan, 2008)

So it is that the investigation I have conducted - including extensive field research - has been as much about understanding Paradise and its joumey as about understand ing the implic ations in my own life. My personal joumey has paralleled that of Paradise in its east to west trajectory, and in the tension of the attending contrasts.

While notions of joumey and transfomation are central to the project, issues of contrasts (such as desert vs. paradise, inside vs. outside, memory vs. dream, the arid plateau of Iran with its underground dreams of watervs. the lush lakeside of Toronto with its dreams of sanctuary), and parallels (of various types of joumeys and rea lities) set a gainst the pervasive presence of memory all shape the landscape of the project. 


\section{A J oumey}

“...memory becomes the construction of a social and cultural identity whose symbolic teminology tends to challenge the experience of the current reality. The past becomesa strategy for legitimating the present. The house, as it is remembered and described in great material detail, represents a symbolic entrenchment into a human and geographic al environment that has vanished. Memory unfolds as a symbolic denial of migration, separation, and cultural strangeness...".

(Bahloul, 1996. p.2)

"Our very existence as individuals depends on the faculty of memory, to recall or ma inta in all that we are and offer an ever-changing prelude to all that we will become."

(Kuberski, 1992. inside front cover) 
This project has used Paradise as the topic, and memories as the language through which dreams are explored. If memory is what defines us - forming the sanctuary of the psyche - then dreams are what give flight to our aspirations, what impel our joumey. Thus, while paradise the garden is about the stasis of sanctuary provided by perimeter, paradise the dream is about joumey. A joumey propelled by thousands of memories, new layering on the old.

My joumey in search of paradise was camied out over the course of many travel adventures as well as the humdrum of the daily trip along familiar roads. In the beginning, I thought about paradise and looked a round - finding it everywhere. Water splashing in a fountain, blue sky through new leaves, a plate of olive oil, light playing on the heft of concrete piers marching below the Gardiner. It seemed imperative to capture and keep these images because the photographs which document this joumey are memories: virtual representations of the physical experience and its accompanying emotions. Re-viewing the photographs later brought additional layers of emotions and memory: "...we bias our memories of the past by attributing to them emotions or knowledge we acquired after the event......emotions a re closely linked with perception and registration of incoming information, which in tum influence the formation of new memories."(Schacter, 2001. p.9\& 10) 


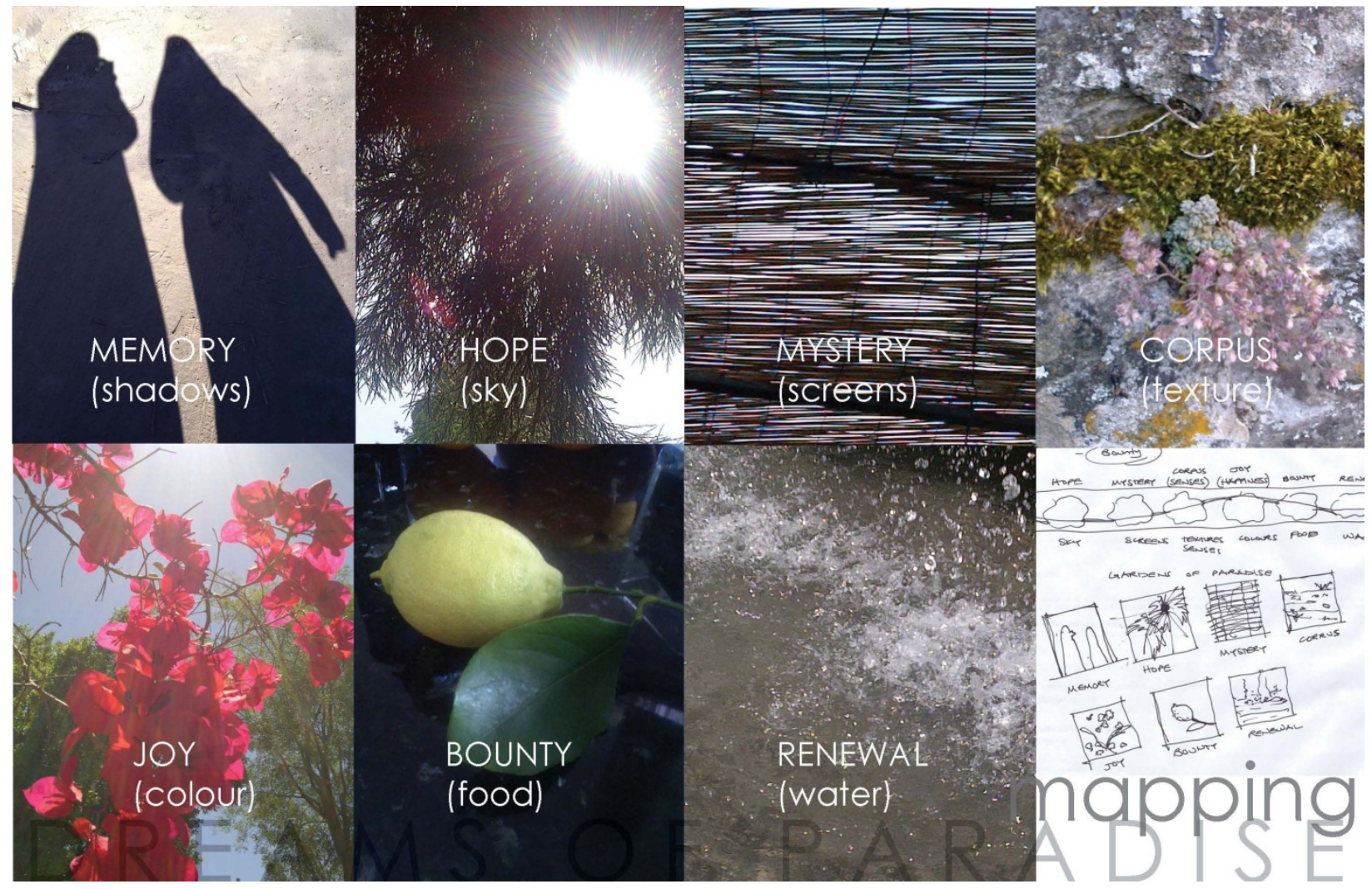

The design process began with analysis of memories of the joumey in search of paradise as reflection on the growing array of images, and questions of what was poignant and why led to a taxonomy of seven themes: water, sky, colour, food, texture, screens, and shadows. Further analysis and mapping developed physical attributes, and probed the attending emotions to get at the symbolism associated with each theme. 

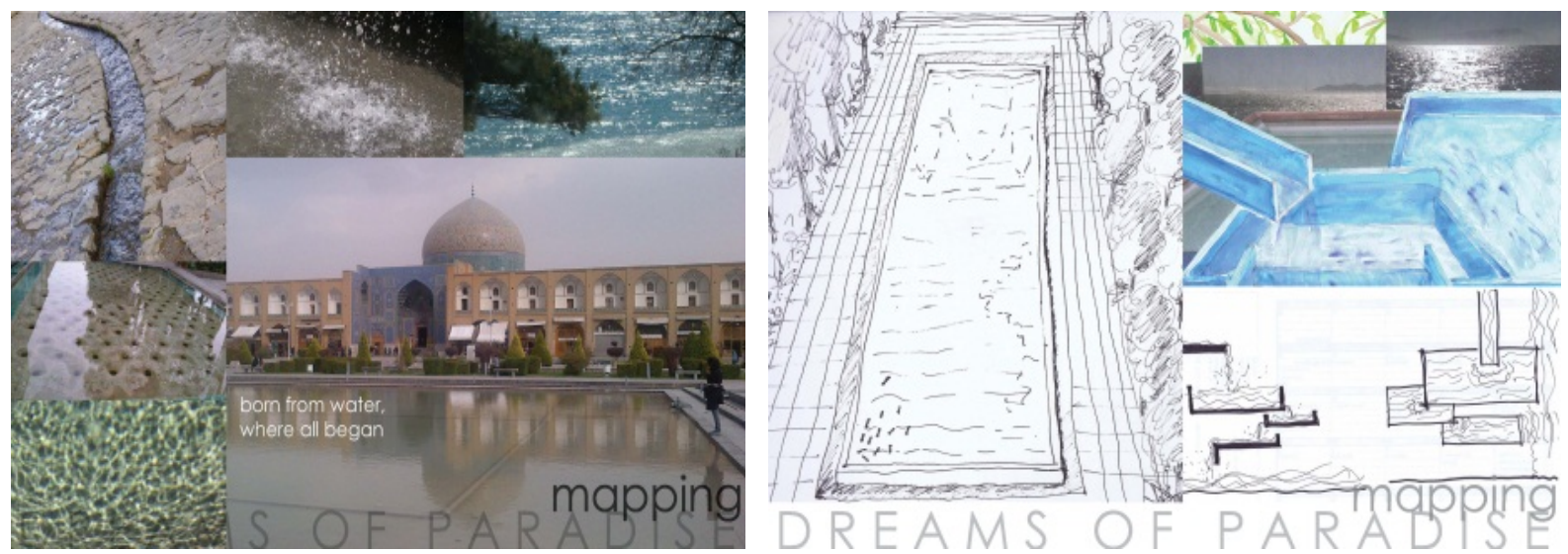

Water is physic ally a mbiguous and malleable. Water is omnipresent as it flows, rushes, dances aga inst the sky, pudd les obsc urely underfo ot -a lways serving a s reflection. Water evokes calm as well as sorrow, as it symbolizes not only birth and beginnings, but etemity. Therefore, it is also a reminder of the finite interval of life.
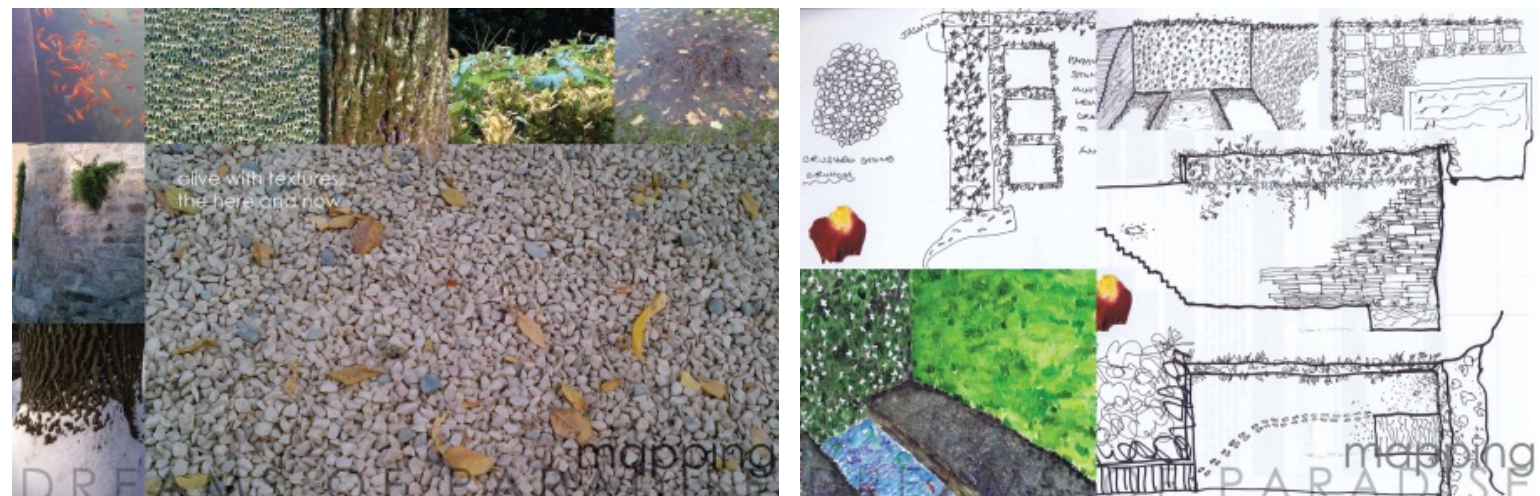

Texture speaks to the here and now, to the tactile a wareness of being alive. It represents the physicality of body as the fragile enclosure for the spinit. 

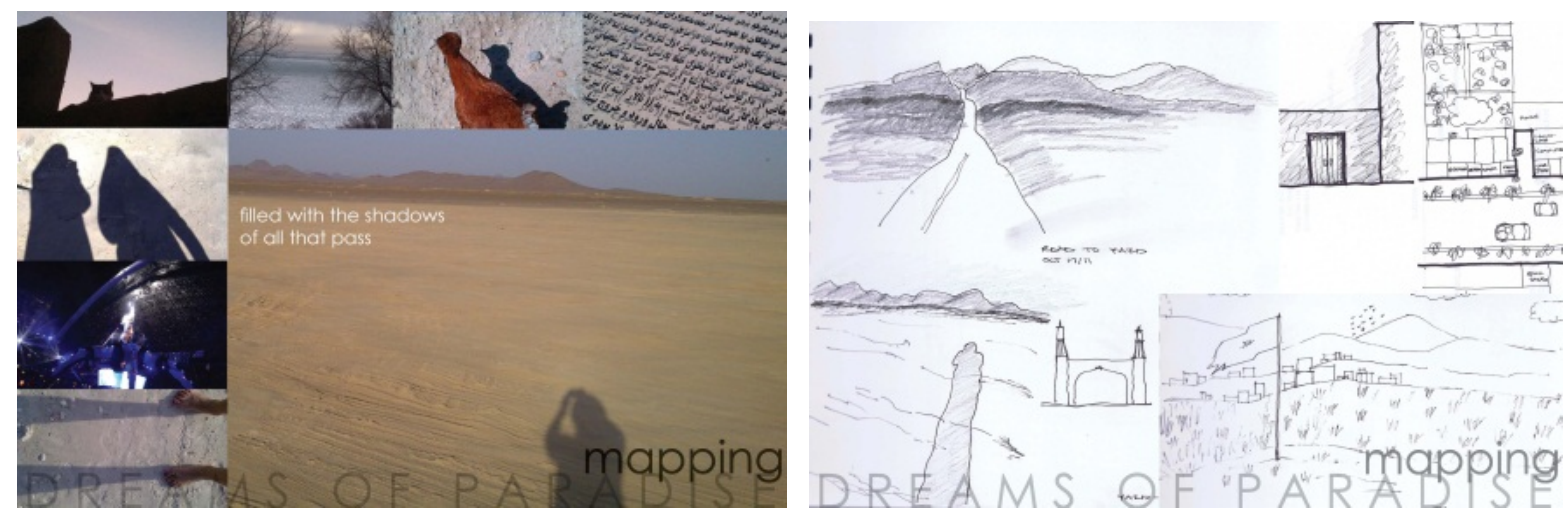

Shadows are intangible, defined only by what has passed. Because they are the imprints left behind, shadows are about looking inward, about contemplation of the past. Shadows are memory.
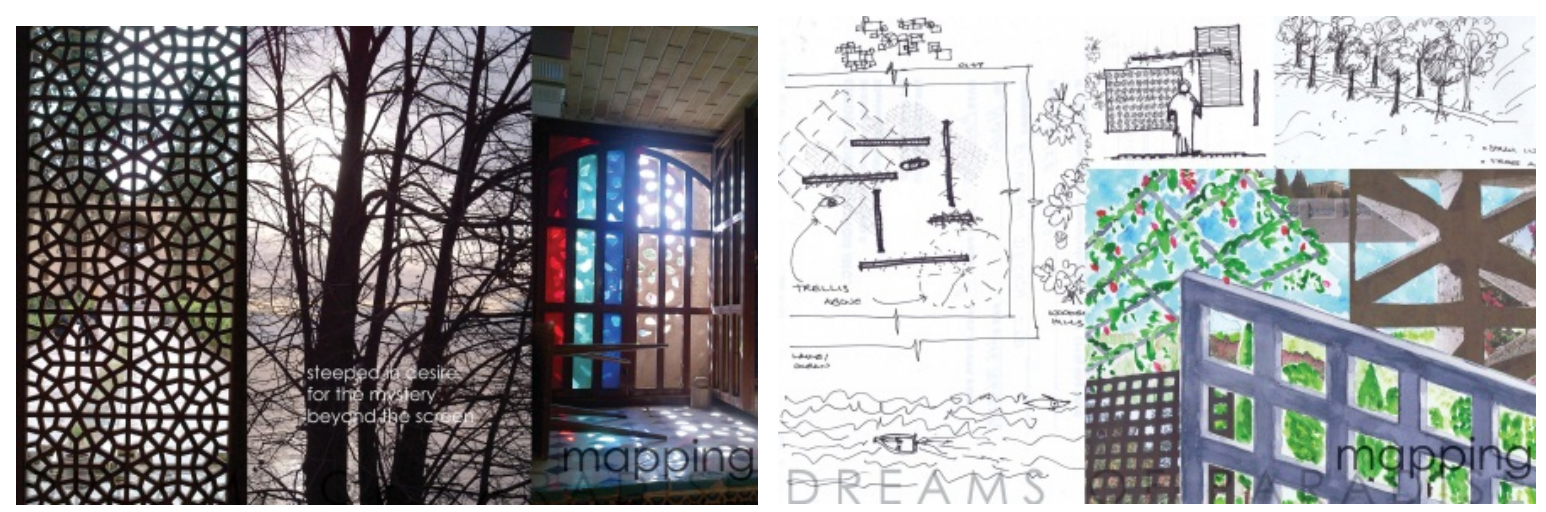

Screens are planar, layered, and semi-opaque. They are the veil of desire through which the mystery just beyond is contemplated : a garden, a dream, a nother world. 

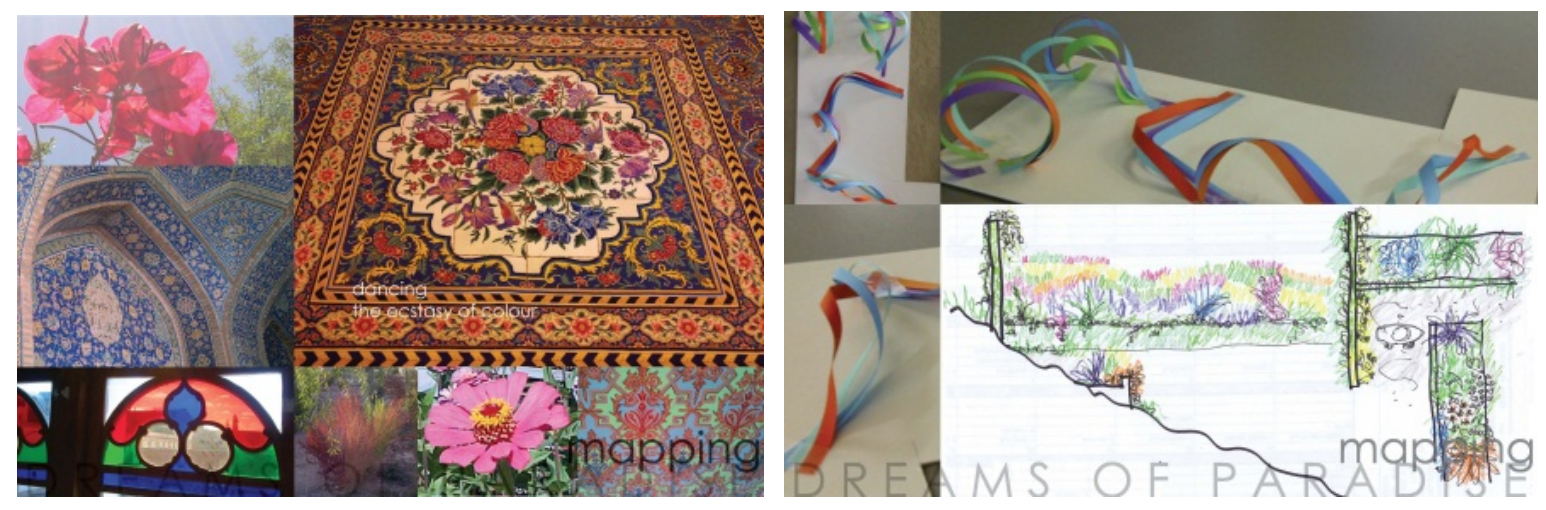

Colour is open and innocent, it is movement. Colour is the madness of joy, the energy of motion, the emotion of exhilarated abandon.
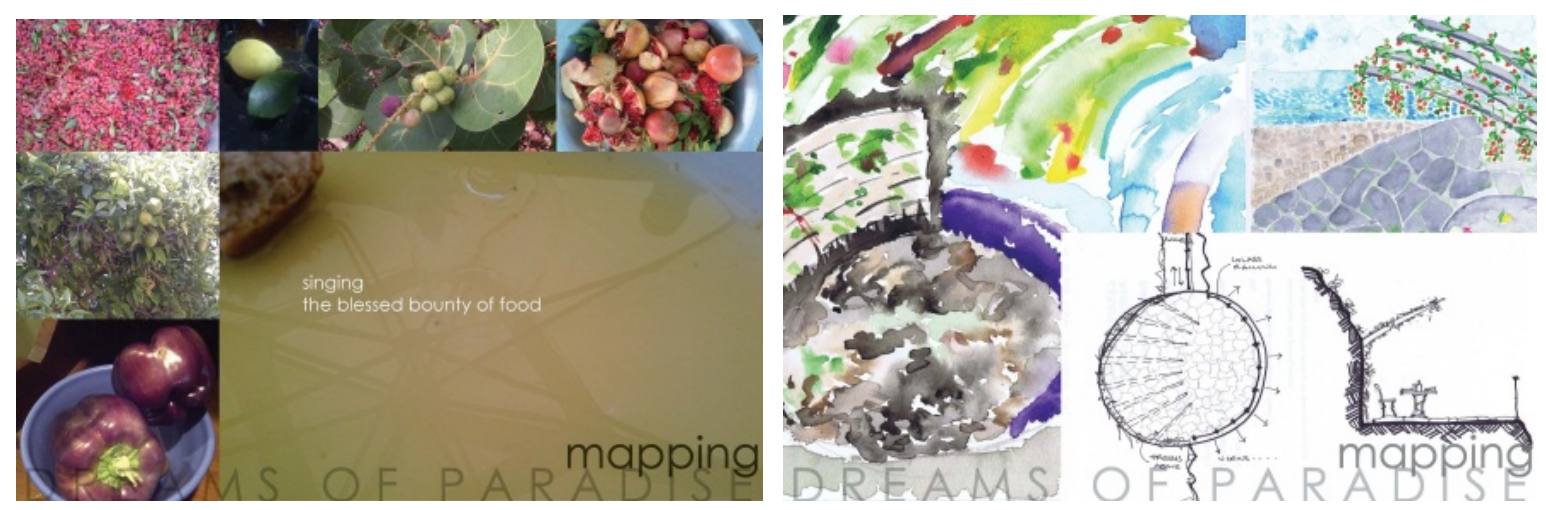

Food is looking inward in contentment, and out in celebration. The comfort of feeding the body gives flight to the soul in gratitude.

Food is holy, the vital ritual of maintaining life. 

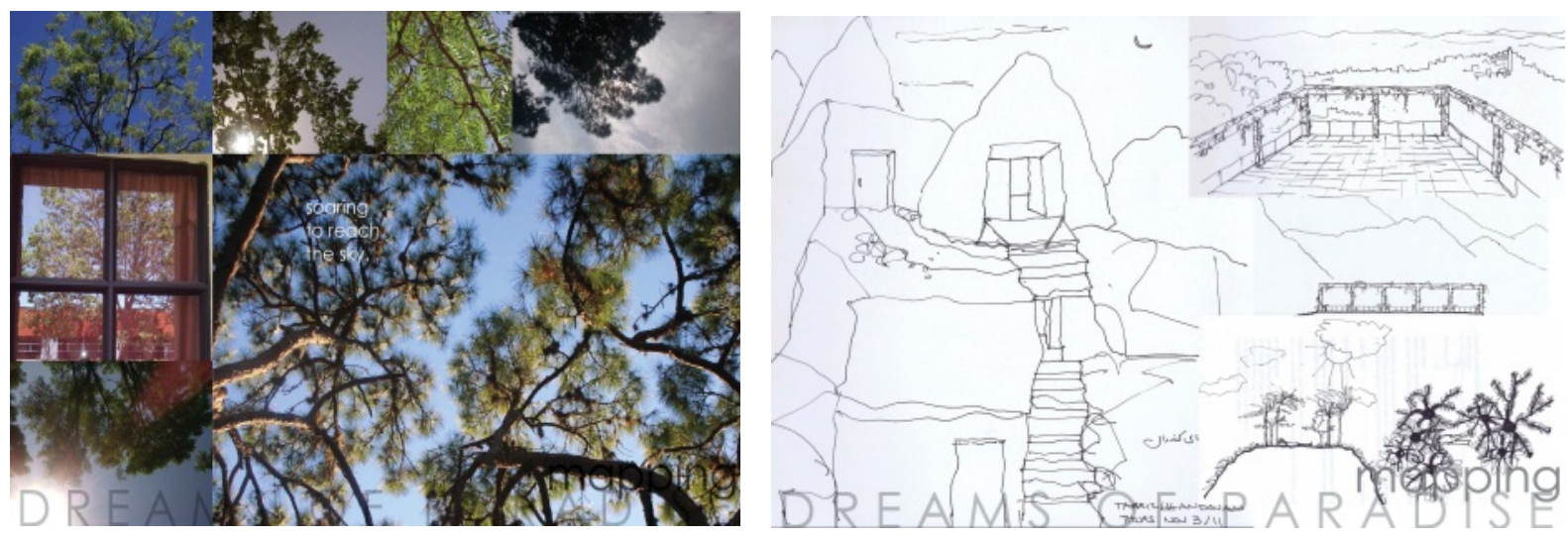

The openness of sky naturally speaks to a physical direction. Sky is also a hierarchy, refeming to ceiling and roof, spires and airplanes, mountain top and crescent moon. sky is about ambition and aspiration. It is the search to find and leam, the yeaming to be more.

Grappling with the meaning and place of these myriad images, I wasconvinced that they formed the core of what I was seeking - yet uncertain as how the accumulated archive of images would play into this attempt to translate a thousand and one memories of paradises into new dreams of paradise. The idea of photographsasa way of seeing wasa clue - as photographs speak to the interactions between current physical reality being shaped by, and in tum shaping memories as well as our inner emotional landscape.

J uxtaposing the need to honour memory with the idea of Paradise as a Garden, collage represented a means of bringing the two together. Thus began a series of investigations into the meanings of the images representing the seven themes of Paradise. Working in 4'x6' format, I made initial explorations into the themes of shadows (memory), water, and sky. The collages served as a starting point, a vehic le to connect the visual images to the deeper mea nings of joumeys, a mbiguities, parallel rea lities, and dreams as visions. 


\section{Intentions}

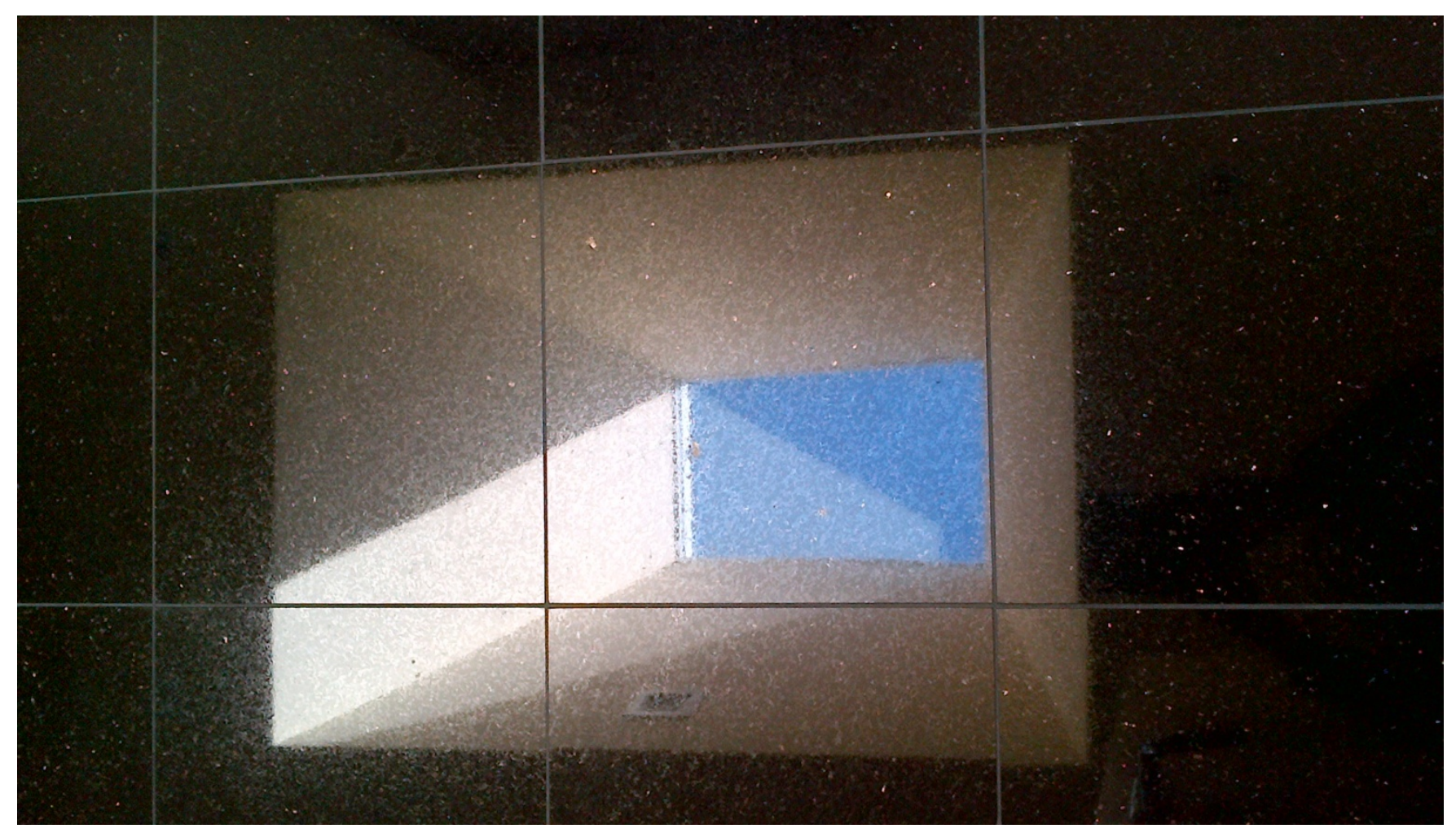

Toronto

To re-phrase intention, I have taken a central idea, and used it as a prism as it makes a shift from Iran to Canada. I have investigated the translatability of concepts between countries, climates, and cultures. Ultimately, I have undertaken the translation of one joumey into another. And in translating paradise through joumey, I have retained fidelity of the imprints of memory.

Thus, the taxonomy of 7 themes generated by memories of paradise served as the structure for the design of seven dream visions - each dream a joumey of exploration, discovery, and transformation. A translation of one reality into a nother. 


\section{Site \& Program}

As previously discussed, Paradise in the west is less a bout the physic al perimeter providing sanctuary and more about the intangible perimeter of the self. This intangible perimeter bounds the psyche, the imagination - the site where the dream visions play out.

Simulta neously, the physical site paralleling the intangible rea lm of the imagination is the evocatively named Gardiner connecting east and west. The Gardiner is a physical joumey which serves as meta phor for the spiritual joumey of seeking. I a m not interested in urba nism or infra structure issues of whether the Gardiner is good or bad, whether it should stay orgo, or how it should be intervened with - only in how its traversing can enable dreams of paradise.

This site within a site mirrors the construct of a story within a nother story which structures this paper, and serves as a joumey which facilitates the fragmentation of experience into memory and the coalescence of memory into visions of desire.

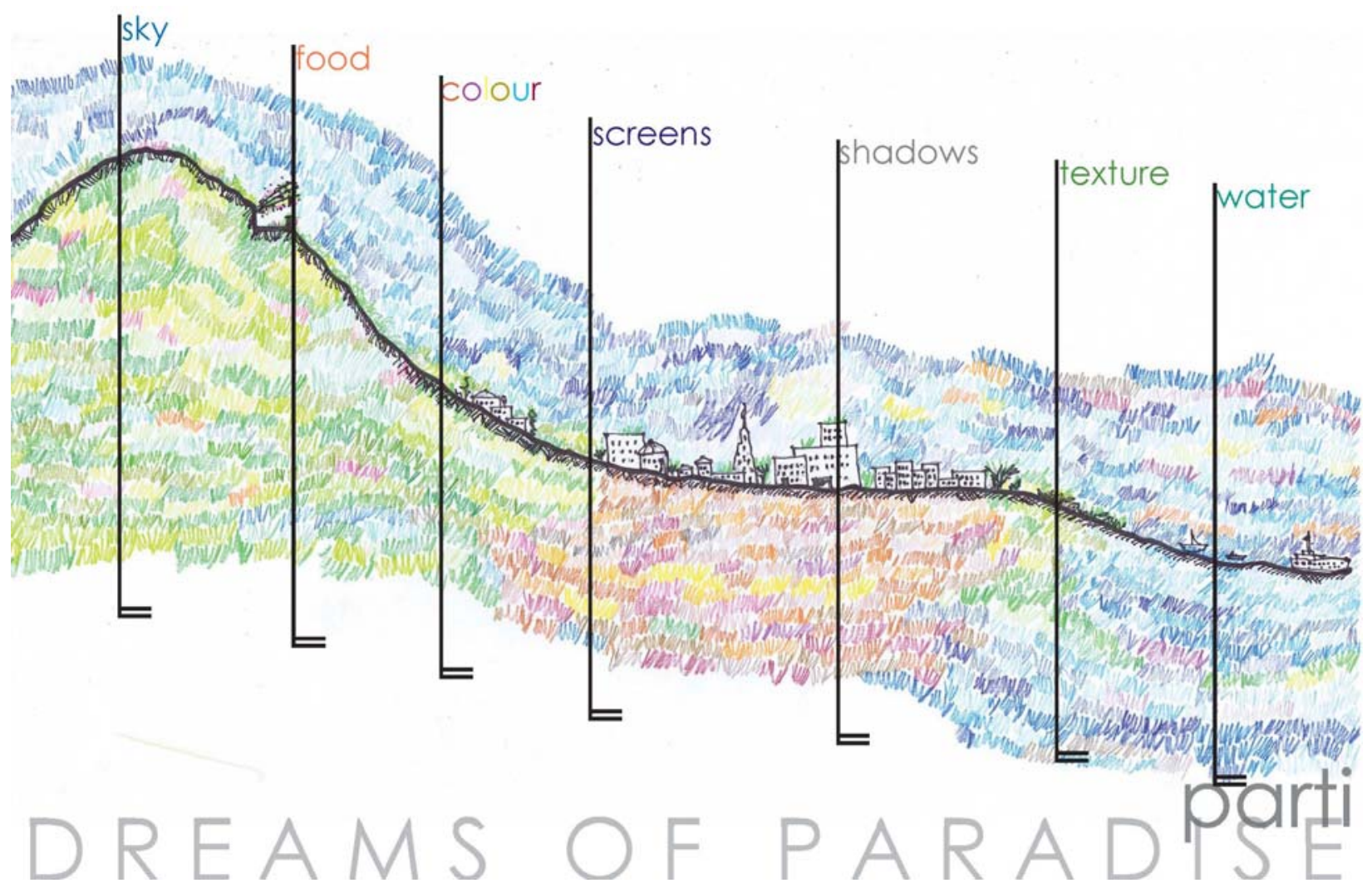




\section{Parti}

The dreams are situated as episodes along the joumey, with each constructed dream series comprised of a series of snapshots taking the dream from abstract intention to architectural expression. The first set of dreams are initial explorations of vision for the themes: water, texture, shadows, sc reens, colour, food, sky, while the next tier designs are flattened, abstracted representations which initiate a search for architectural expression.

The third tier is about the beginnings of coalescence, as the overlay of desire intensifies the images, and the final series presents seven tangible spaces charged with emotion, each an architectural expression of the theme, its emotions and symbolism using memory overla id with desire.

While the dreams are fragmented by nature, each series ma inta ins a consistency of intention in approach, exploration, colour palette, formal language and architectural expression. Each series a lso expresses dua lities, the tension of a ltemate rea lities.
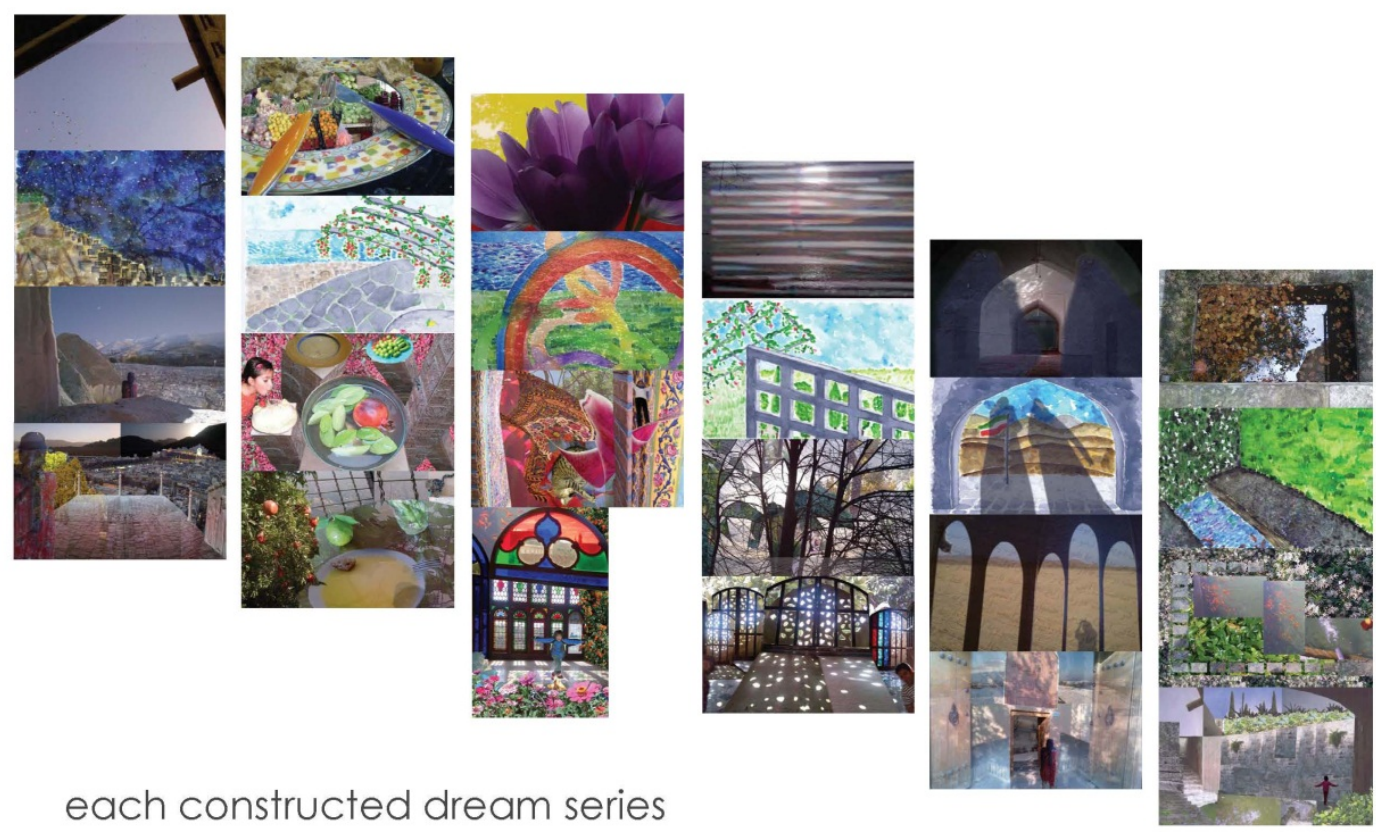

each constructed dream series takes the dream from abstract intention to architectural expression
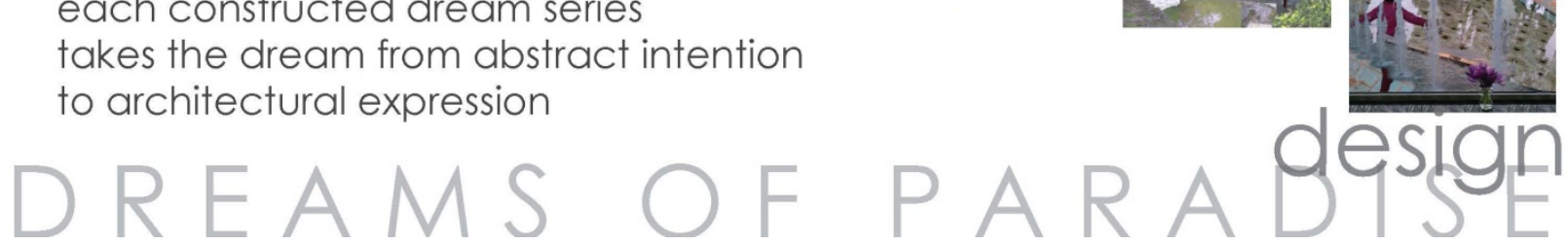


\section{Materiality}

The metaphoric building material for the construction of these dreams is memories (the photographs). Overlaid with desire, the constructed dreams exemplify the themes while moving from past to future as memories transform into aspirations and projected visions. Taken from travels back to my old home, a round the world of possibilities, and the sta sis of Toronto which is my current home, memories of the past embrace the present and a re given flight to envision a world of future possibilities.

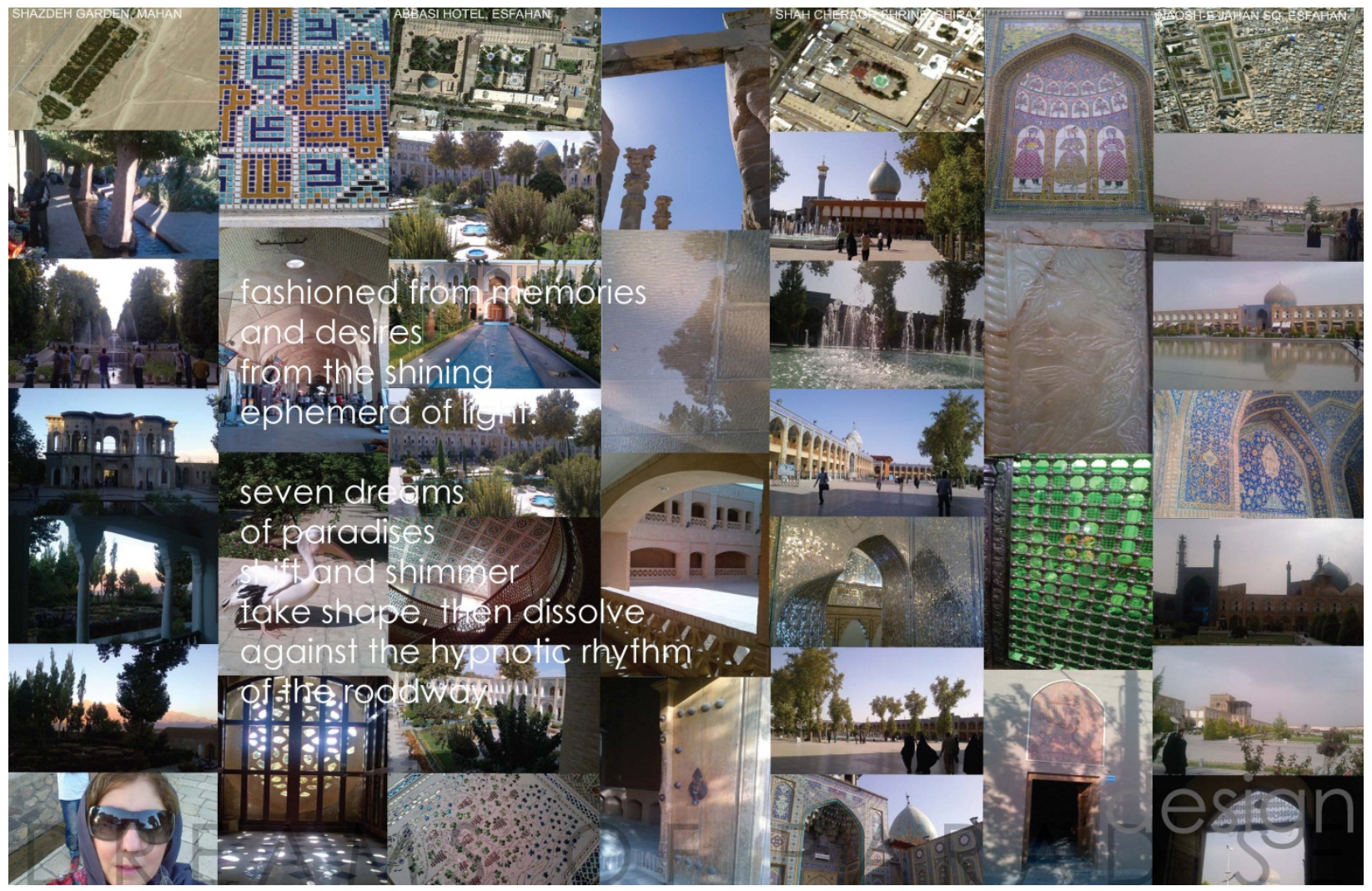




\section{THE PERSISTENCE OF MEMORY}

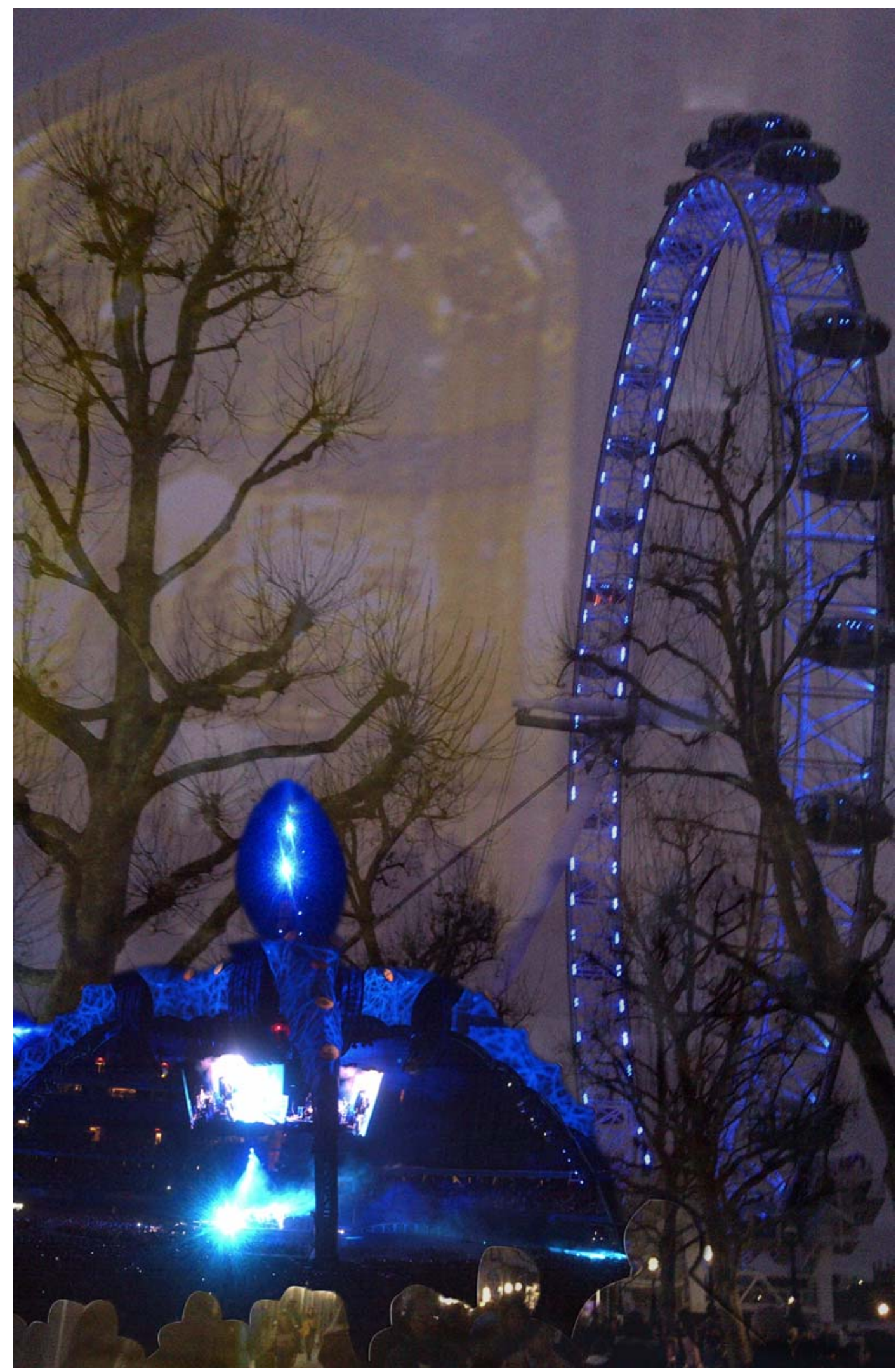


WATER

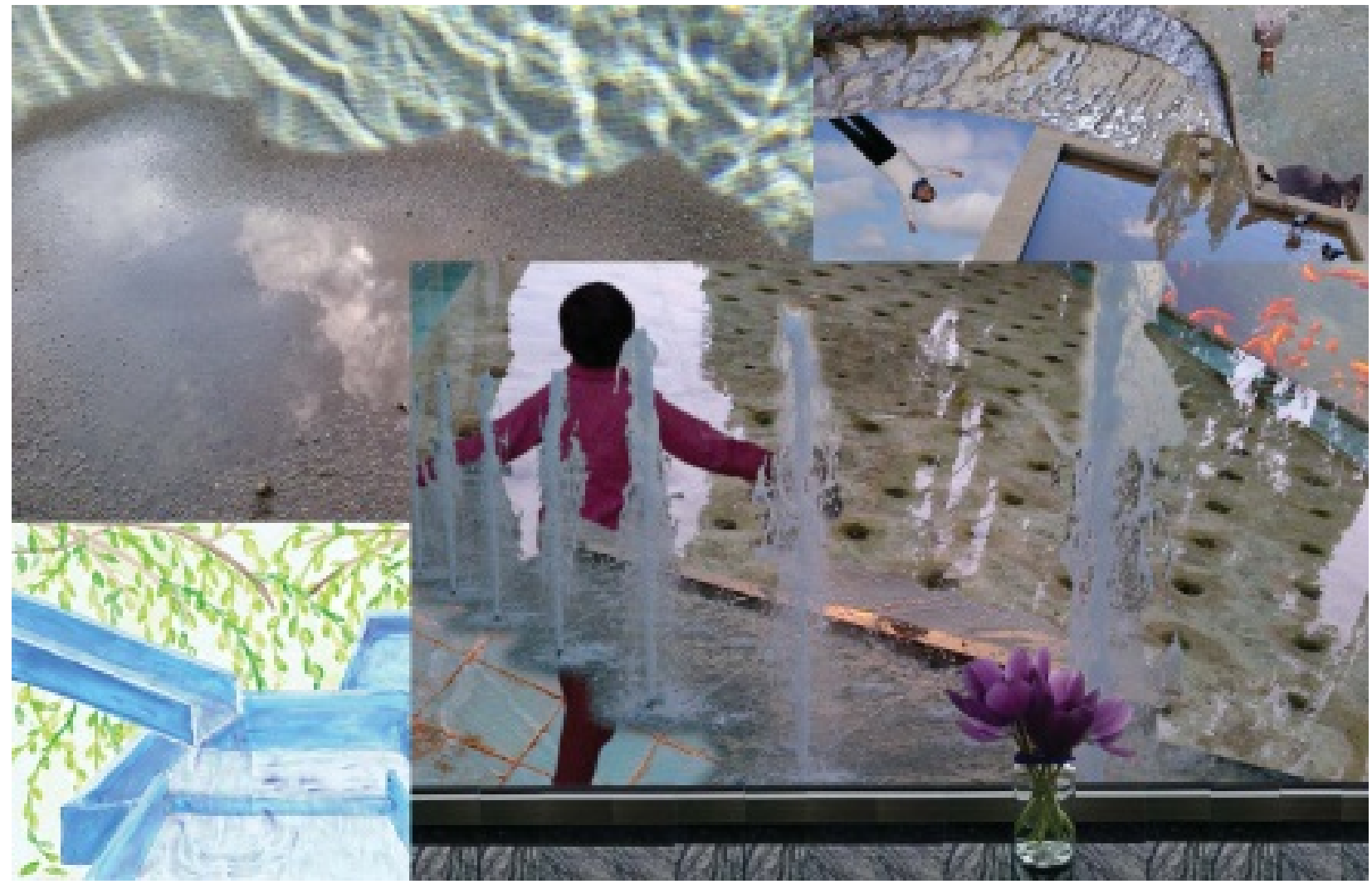

The architectural language of water is a mbiguous - because of its ma lleability and the multiplic ity of its states. The water dreams address this changing nature of water, depic ting many of its physic al possibilities. Reflection and opacity, movement and stasis, flow and stillness are depicted. Ultimately, the joy and innocence of the children inhabiting the dream speaks to water as the source of life, while the reflections of clouds, sky and trees are reminders of its etemal nature impervious to our own finite tenure. 
TEXTURE

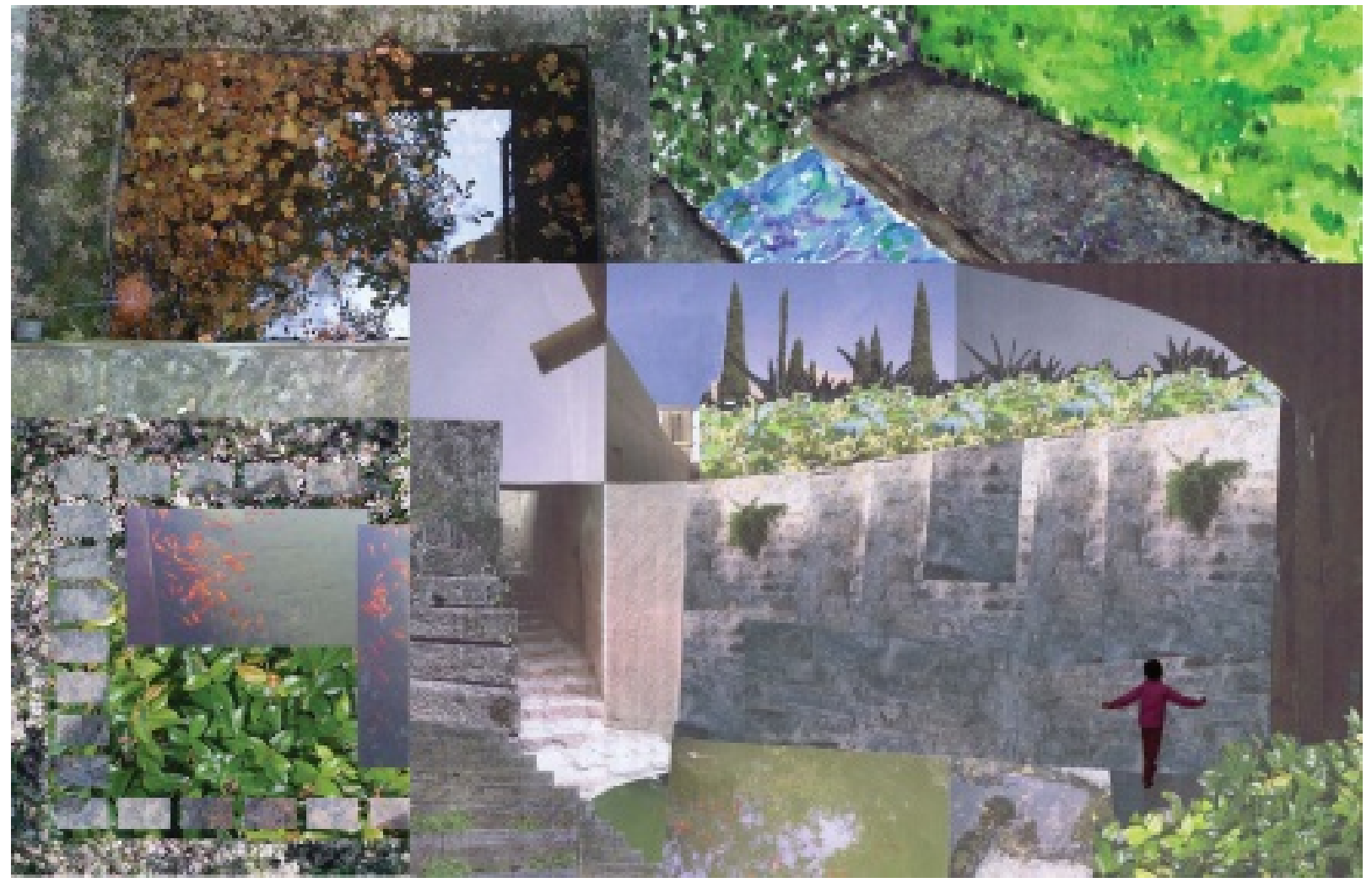

The dream of texture speaks to enclosure and focus, the astonishing detail which renders and defines each physic al being. Pla nes and surfaces expressed through minute and tactile textural components are used to delineate an enclosed space. The eye is directed to look inward and marvel at the miraculous and painstaking construction of the vessels that conta in life. 


\section{SHADOWS}

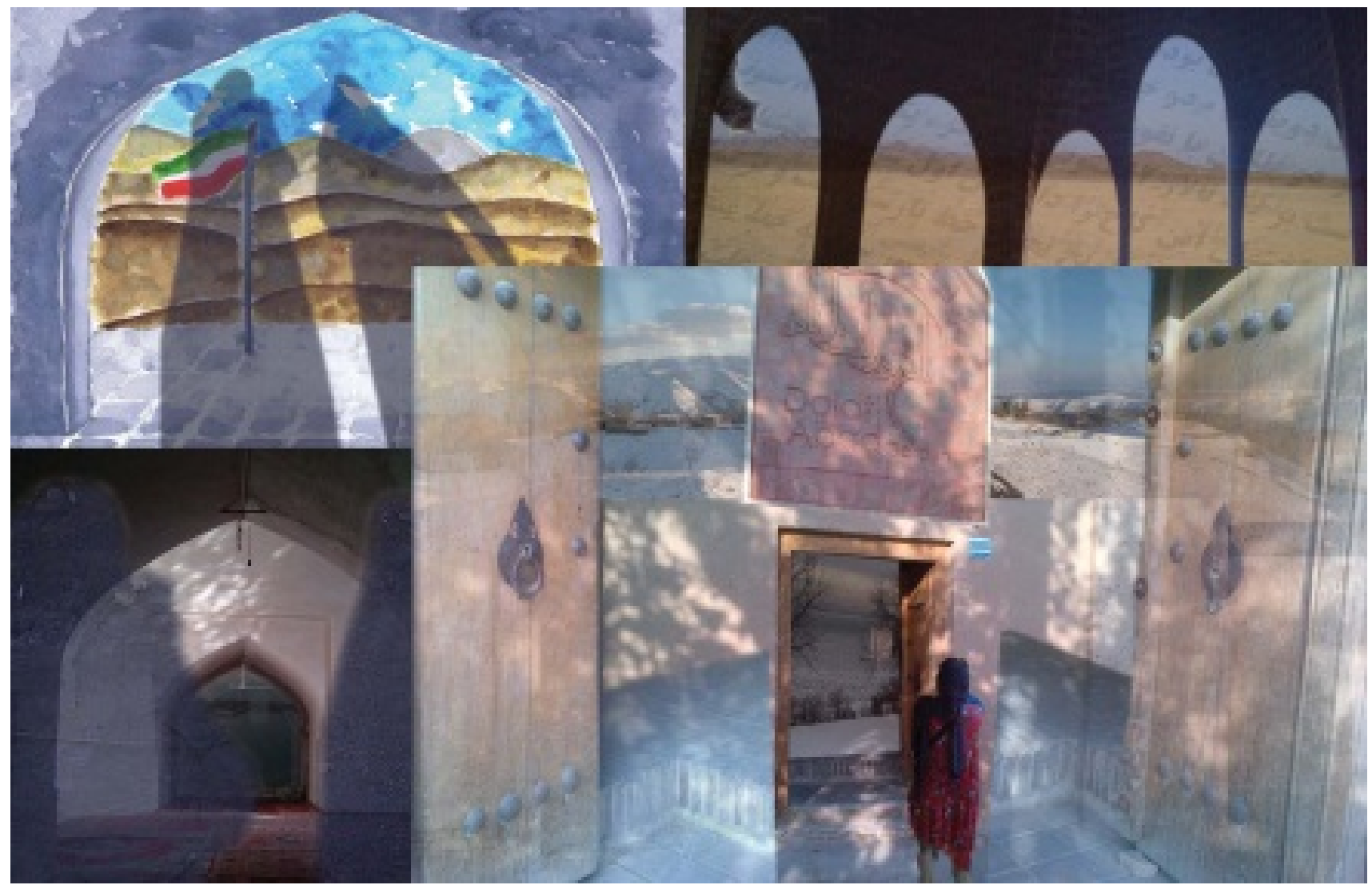

If shadows are about darkness, they cannot exist without light. The light in this dream series not only casts shadows, it illuminates the spaces they occupy. There is repeated use of arches and doorways to express the threshold of memory, the framed opening through which we can look back, the possibility to choose a direction of movement. The views framed by the archways and doorways fluc tuate between different worlds the world of sand and dust or the world of water and green, the world of the past or the world of the future. The twin shadows evoke parallels, as well as divergences - the choices we make along the joumey of life. 


\section{SCREENS}

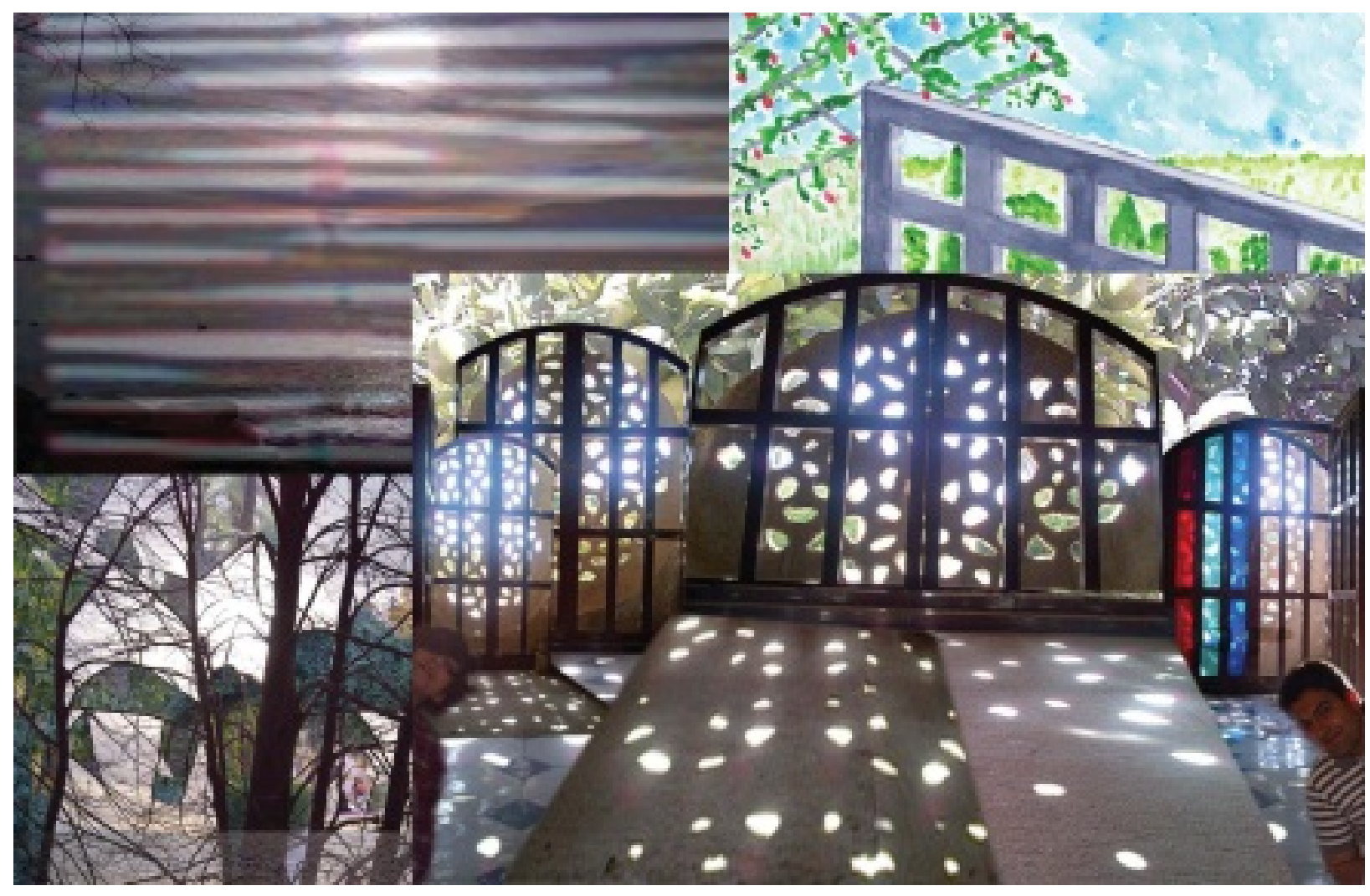

Planar and layered, the snatches of altemate rea lities revealed by sc reens illuminate illic it desires and anxieties for the other, and the yeaming nature of what it is to be human. Peeling back one reality to reveal another in search of the answer to which world to occupy, which reality to seek? 


\section{COLOUR}

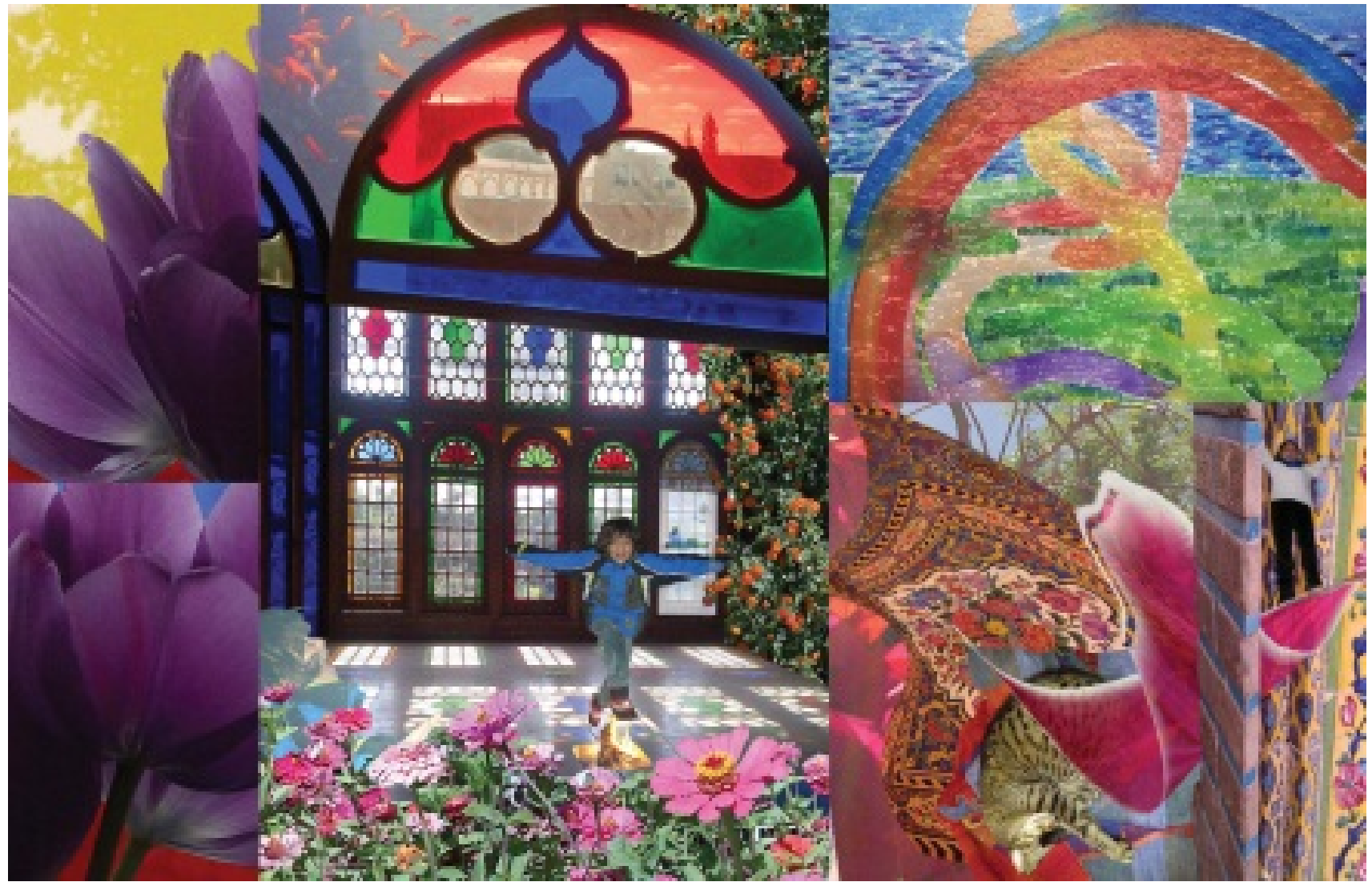

Colour is high energy, sinuous in the forms employed. A joyful dance camied out across meadows and through walls. The consistent use of intense, bright hues, the repeated arches and curving shapes, and the joyful innocence of the children exulting in the dreams among riots of colour are expressions of the excited delinum of exultation. 


\section{FOOD}

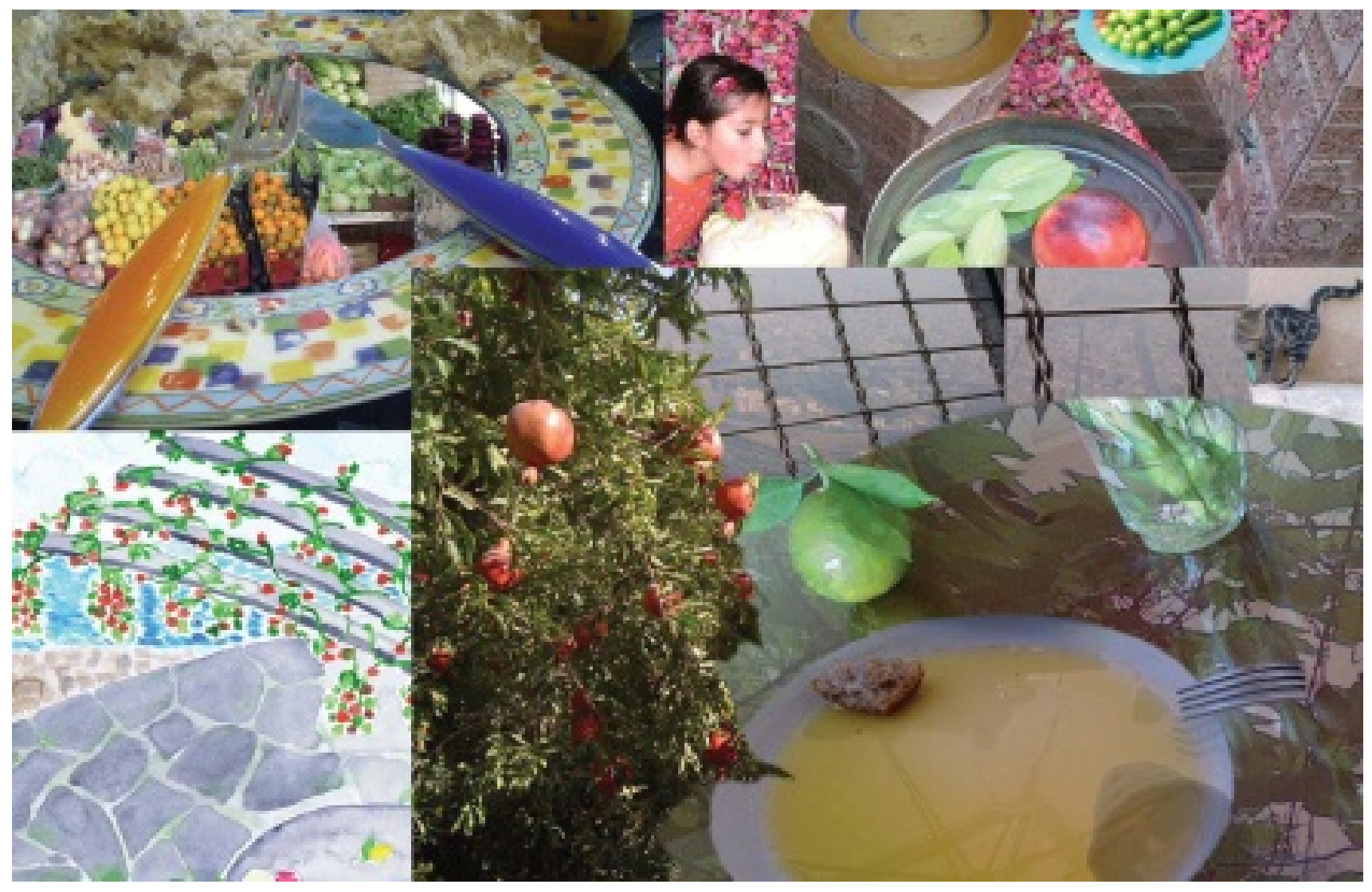

Rounded curves of plates, terraces, bowls and tables express the circular, cyclic al nature of food. Bounty, the celebratory and holy aspects of food, and the quiet contentment of sustenance are expressed through the architecture of the dreams. The final vision is a semi-enclosed meal setting which overlooks a lakeside metropolis. It speaks to the balance between feeding the body and nourishing the soul. 


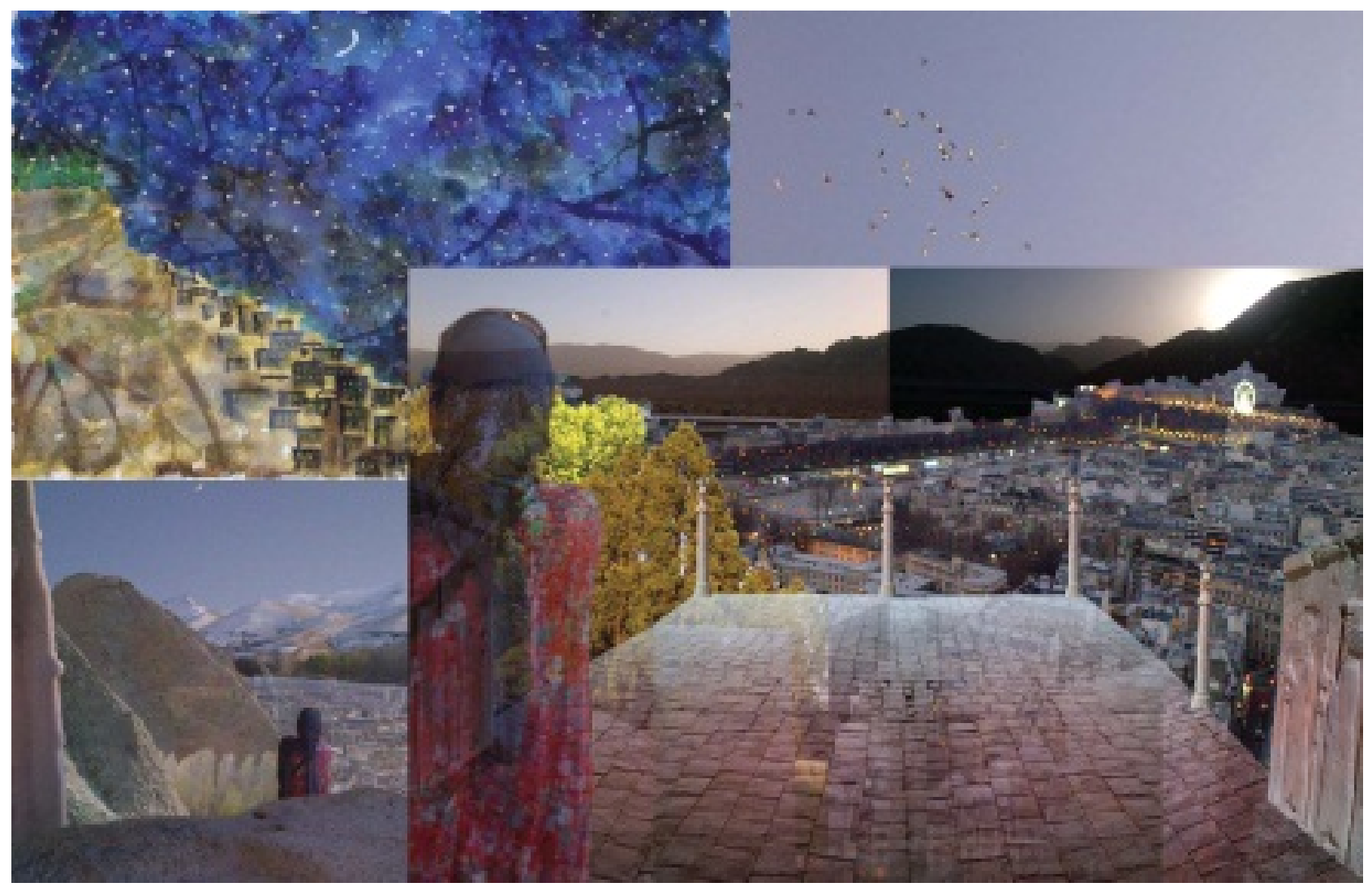

The unguarded posture of throwing the head back to gaze upward, the open hilltop, the unbounded plinth projecting from the side of a mounta in express the vulnerability of exposure together with the physical tension of reaching for something not quite within grasp. Birds circling overhead, the inky softness of sky spilling tiny seeds of bright white light, a pale sliver moon floating above mountains - are all expressions of a mbition, aspiration, longing. In the final vision, the tension between two worlds is expressed in the juxtapositions of the architec ture which takes shape within it, as well as the division of the horizon into contrasts of dark and light. 
As a joumey comprised of many adventures, this dream cycle speaks to parallels between a personal joumey - migration of an individual, and that of paradise migration of a construct, while referencing the greater joumey of life.

As paradise transfomed from a garden to a projected ideal, so have the marks of its passage enabled a transformation of memory into dreams which vision possibilities.

The project site is the nebulous perimeter between perception and rea lity, between the interio rity of a personal a rc hitec ture and the exterionity of other.

Simulta neously, the site is the mundane, repetitive joumey of every day - which is paralleled, yet transcended by the contrast of the dreams of possibilities.

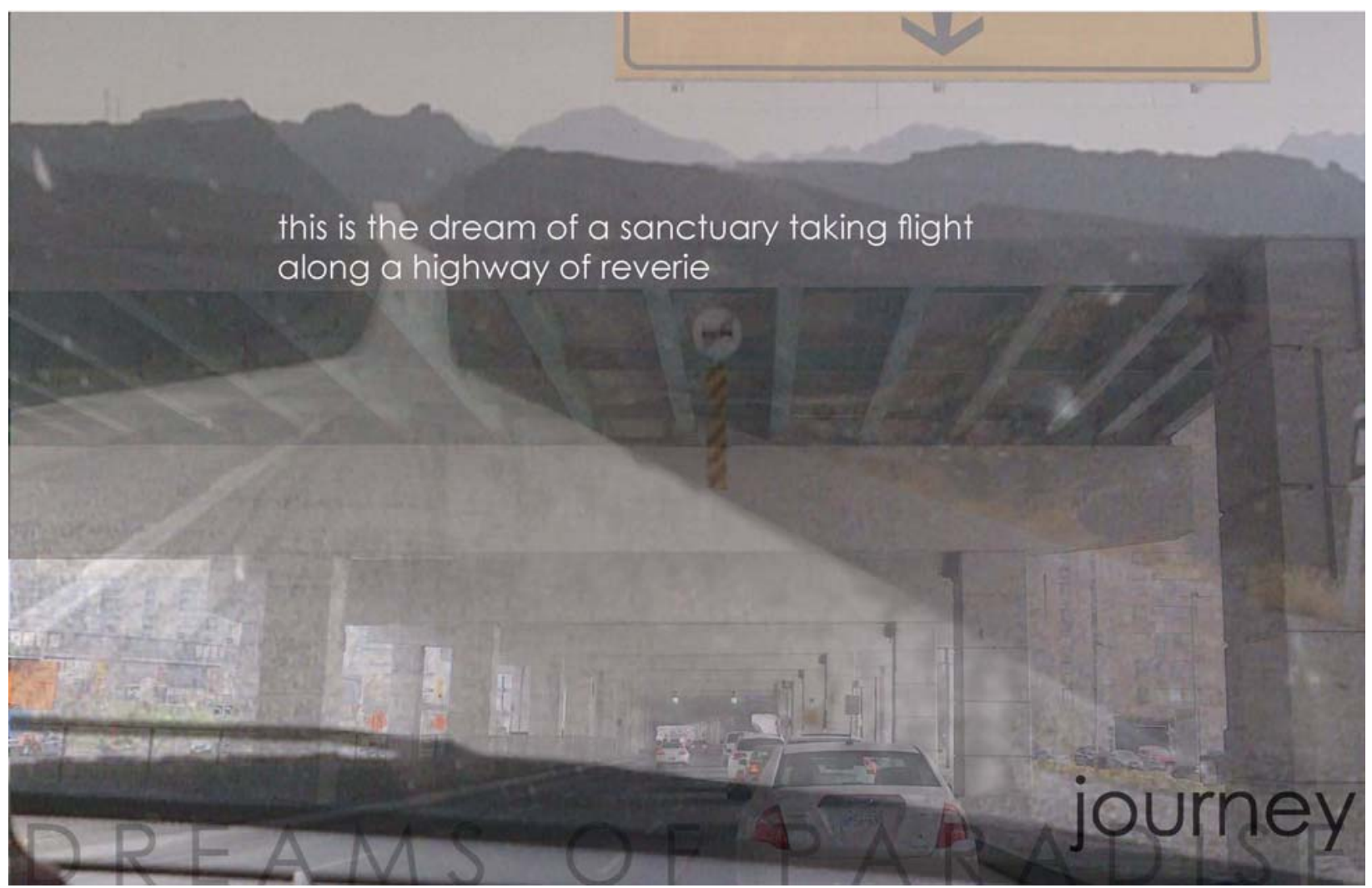

The Gardiner is my quotidian joumey. 
The film which concludes the design is intended to bring the viewer along on this joumey, the mundane nature of the physical trip along the Gardiner freeing the imaginations to roam memory and formulate desire. Altemating between the speed and mythm of the quotidian seen in fla shes of black and white, the dreams intervene as colourful visions of possibilities. The speeds, mythms, sounds and visions of one joumey serve to cast into relief and amplify the other. While the Gardiner segments are loud with the noises of the roadway and speed, the dream visions are set to the sounds of water and narrated with poems that offer some possible interpretations of their architecture.

The folowing pages are intended to simulate the experience of the film. 

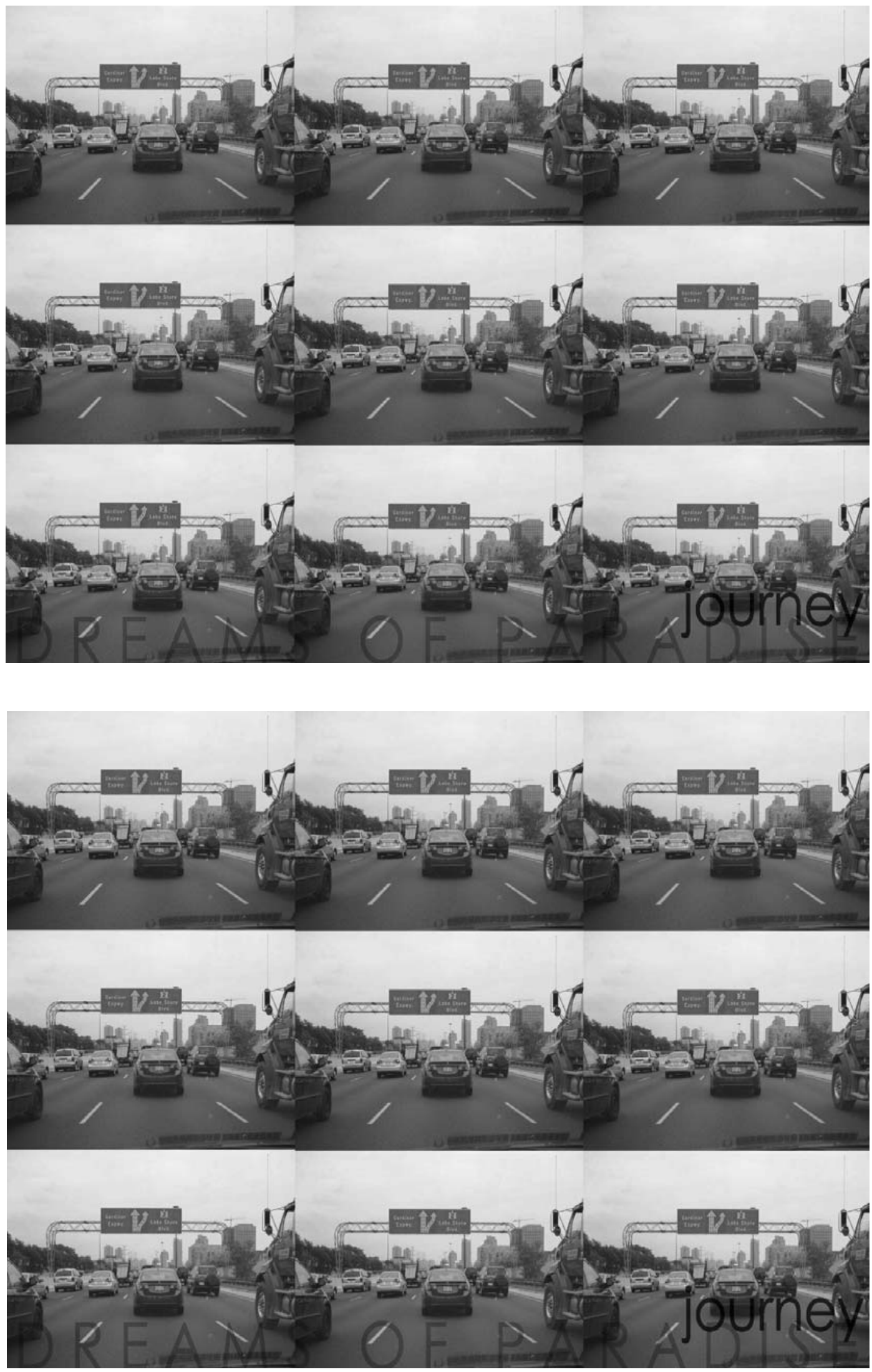

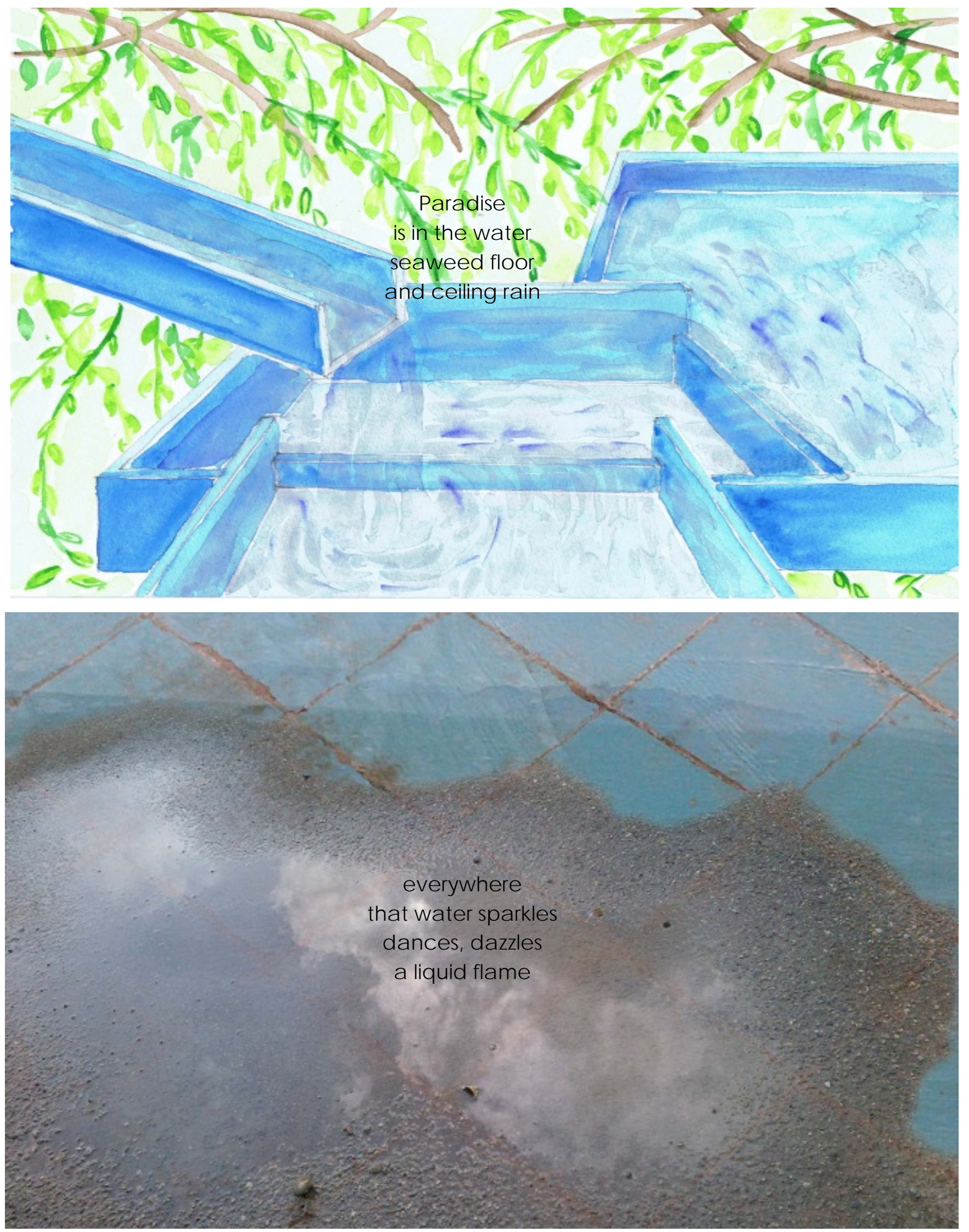

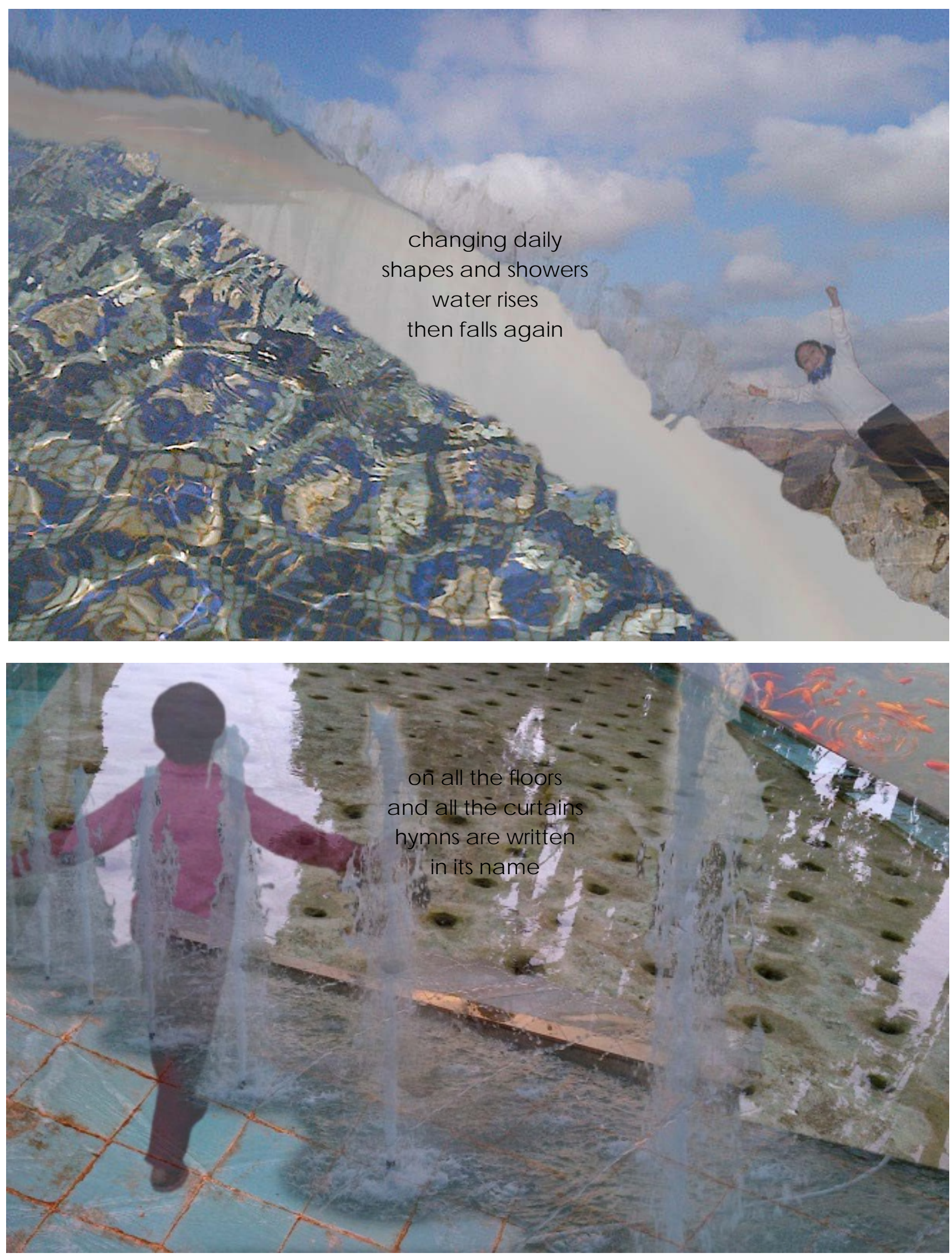

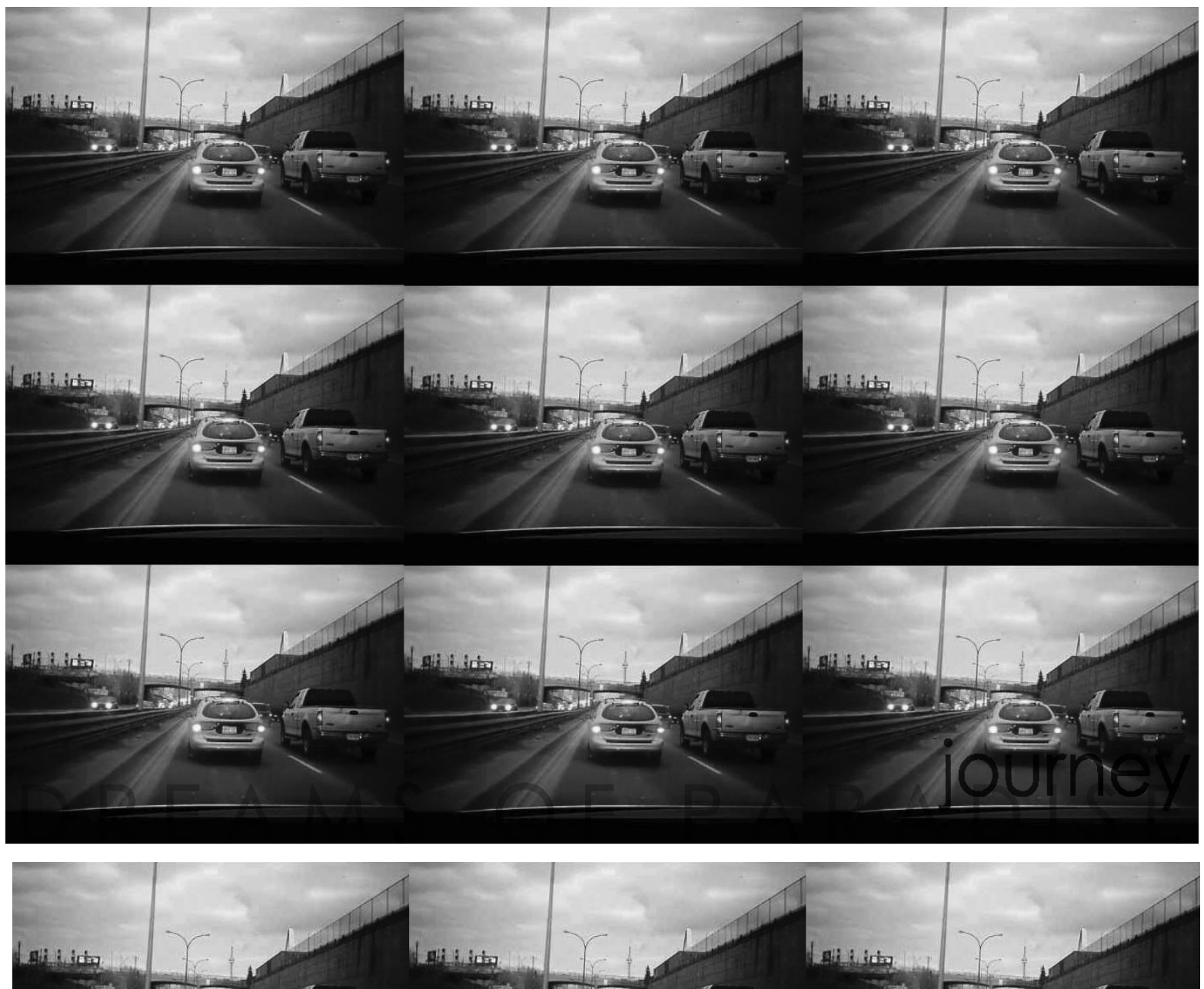

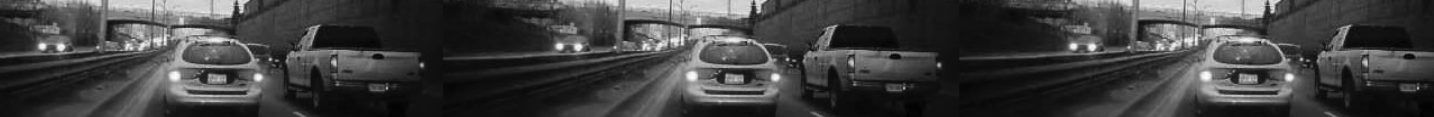

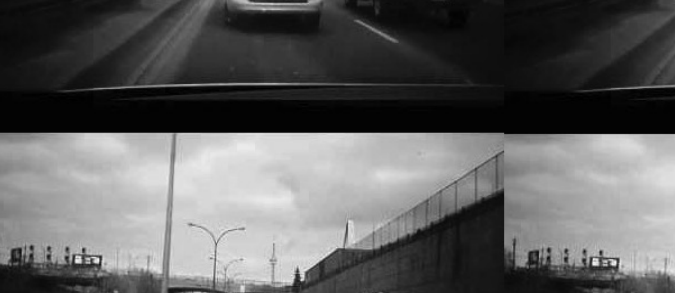

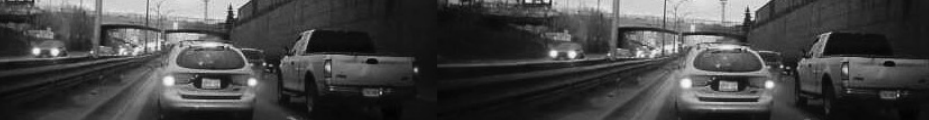

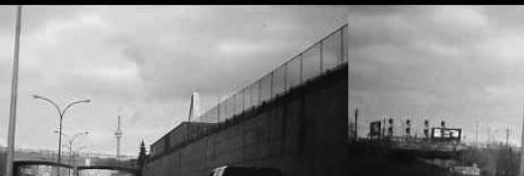
20

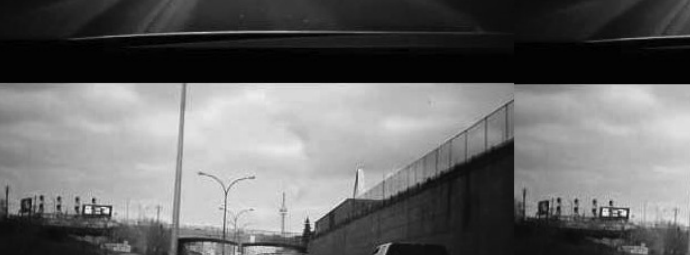

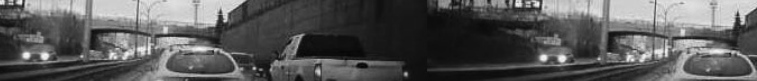

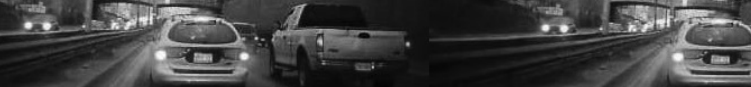



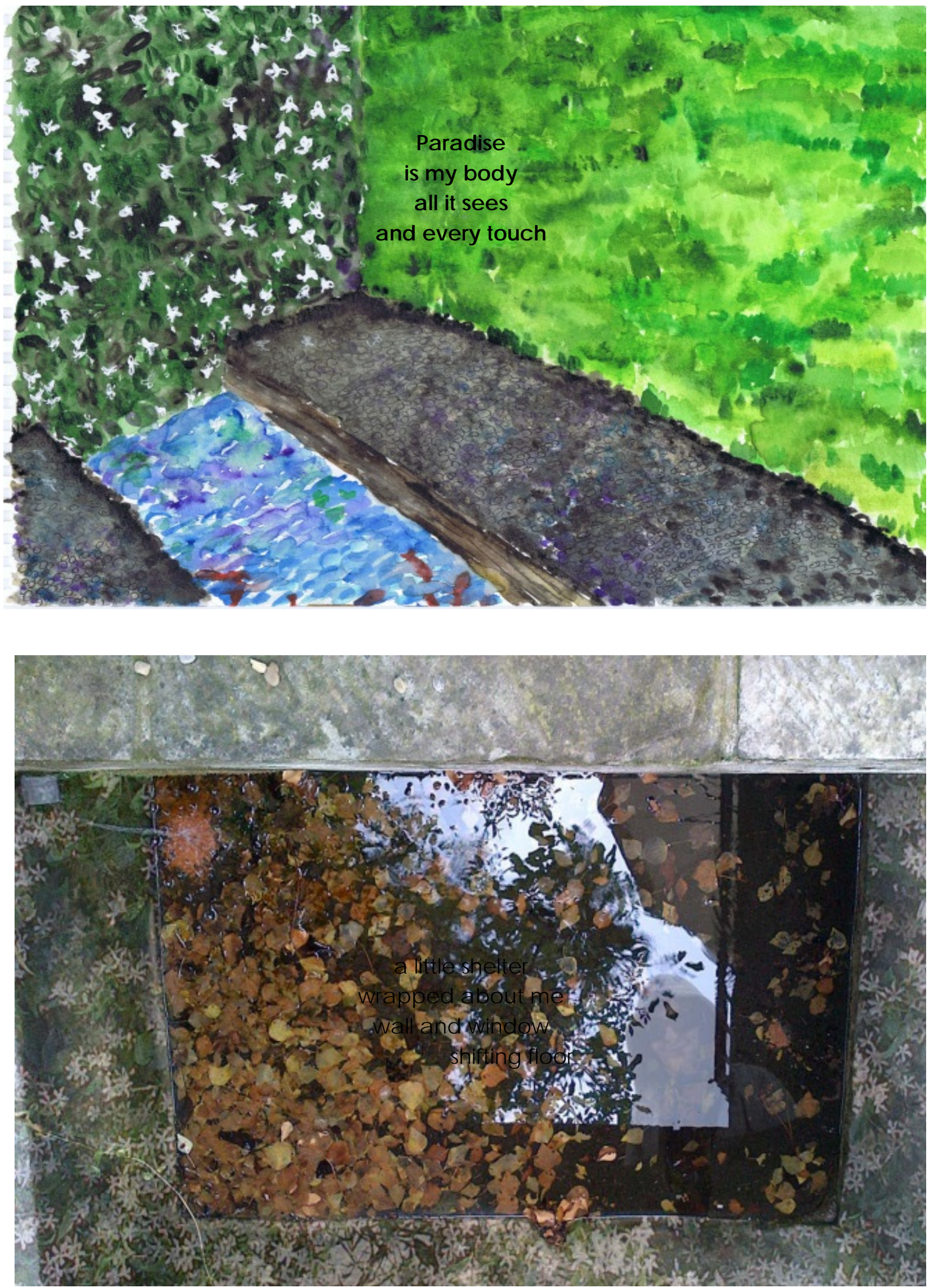

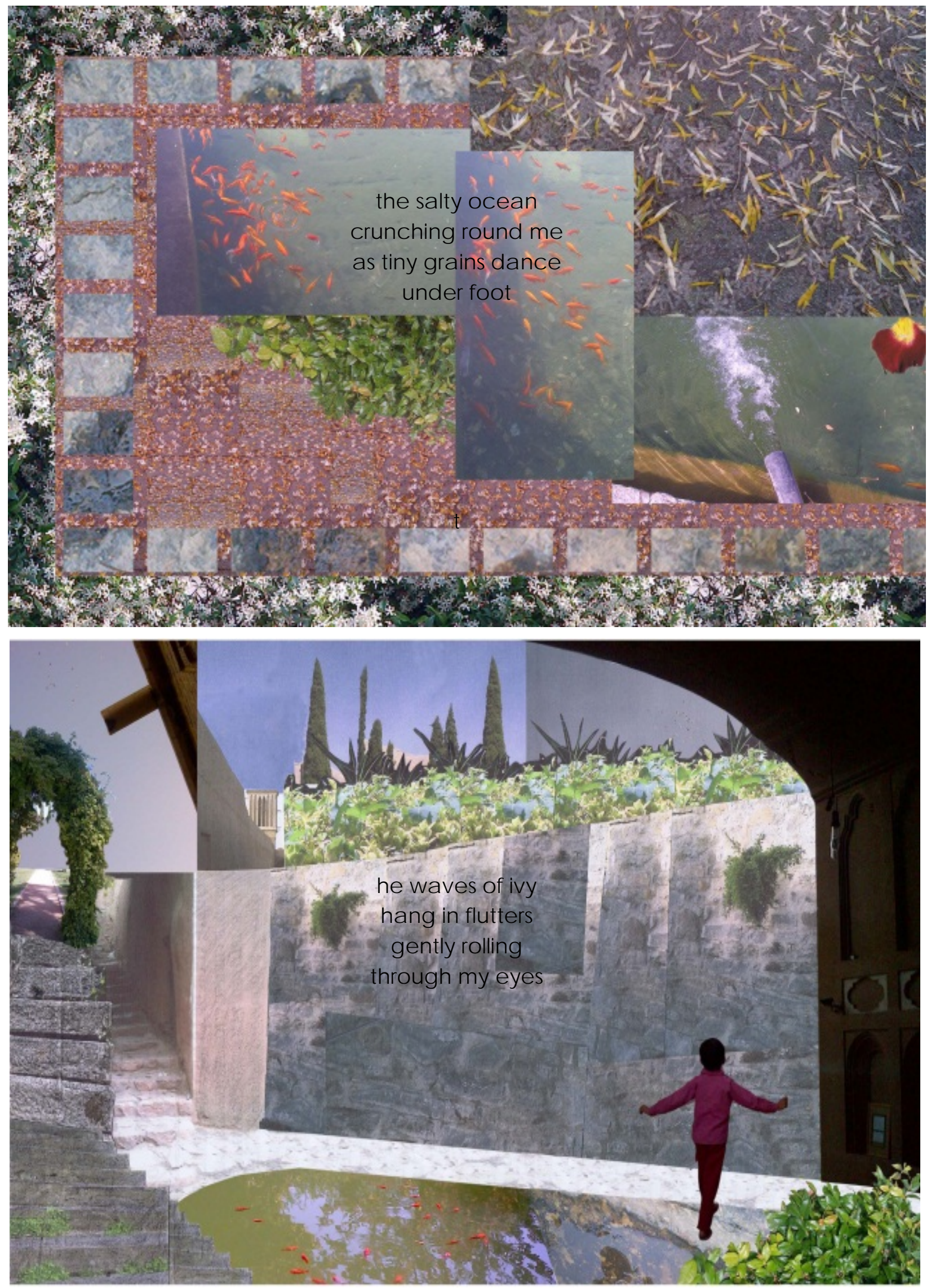

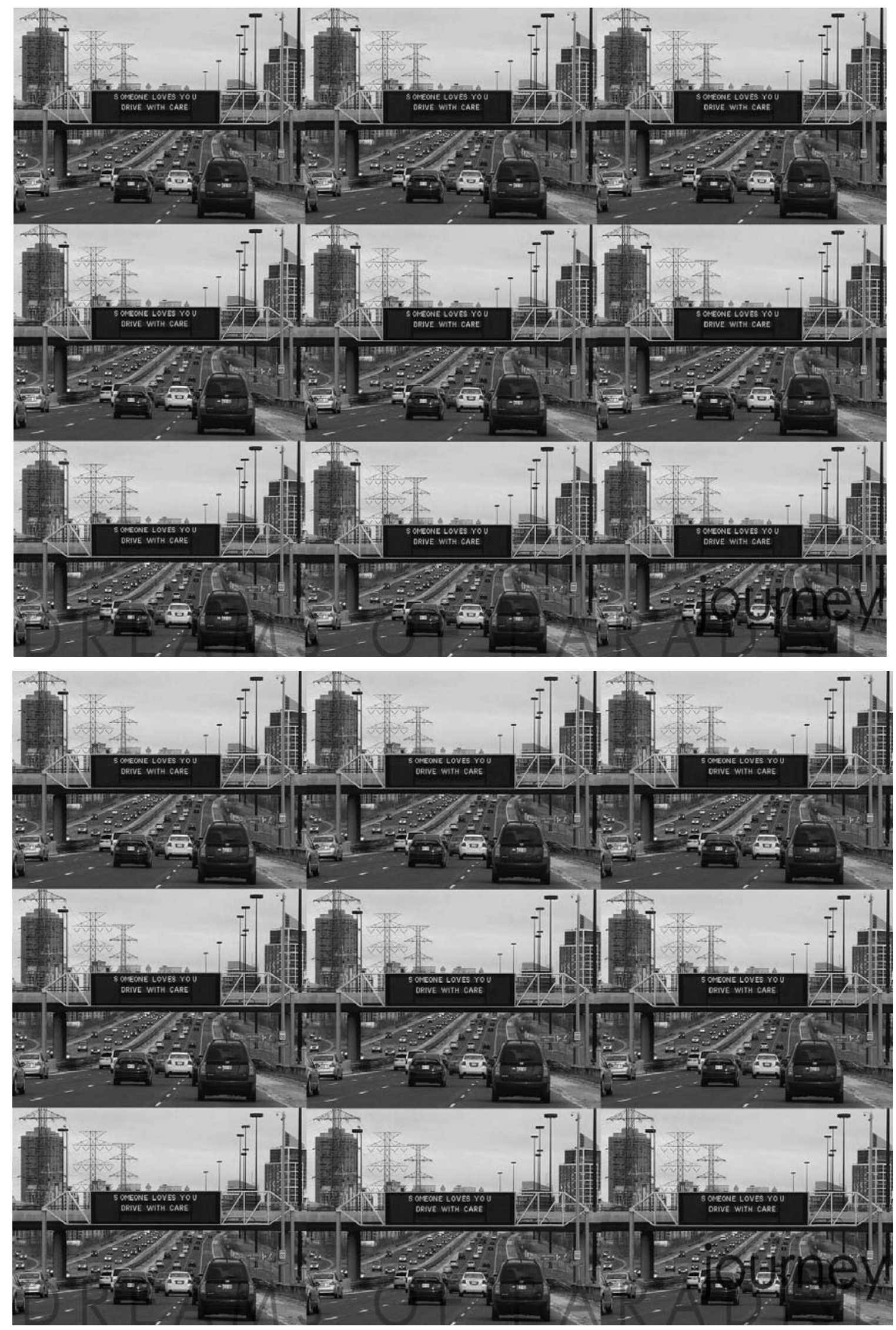

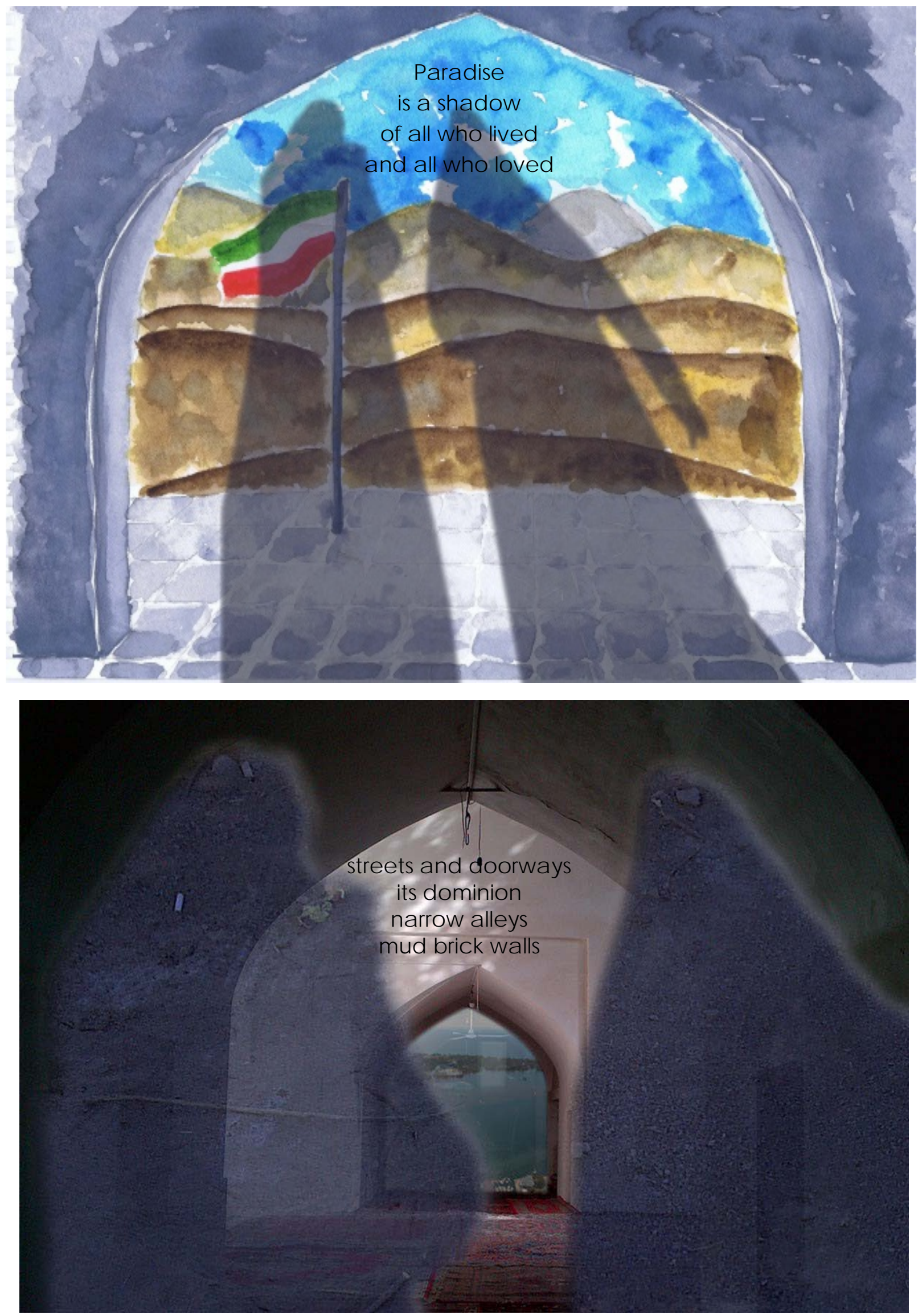

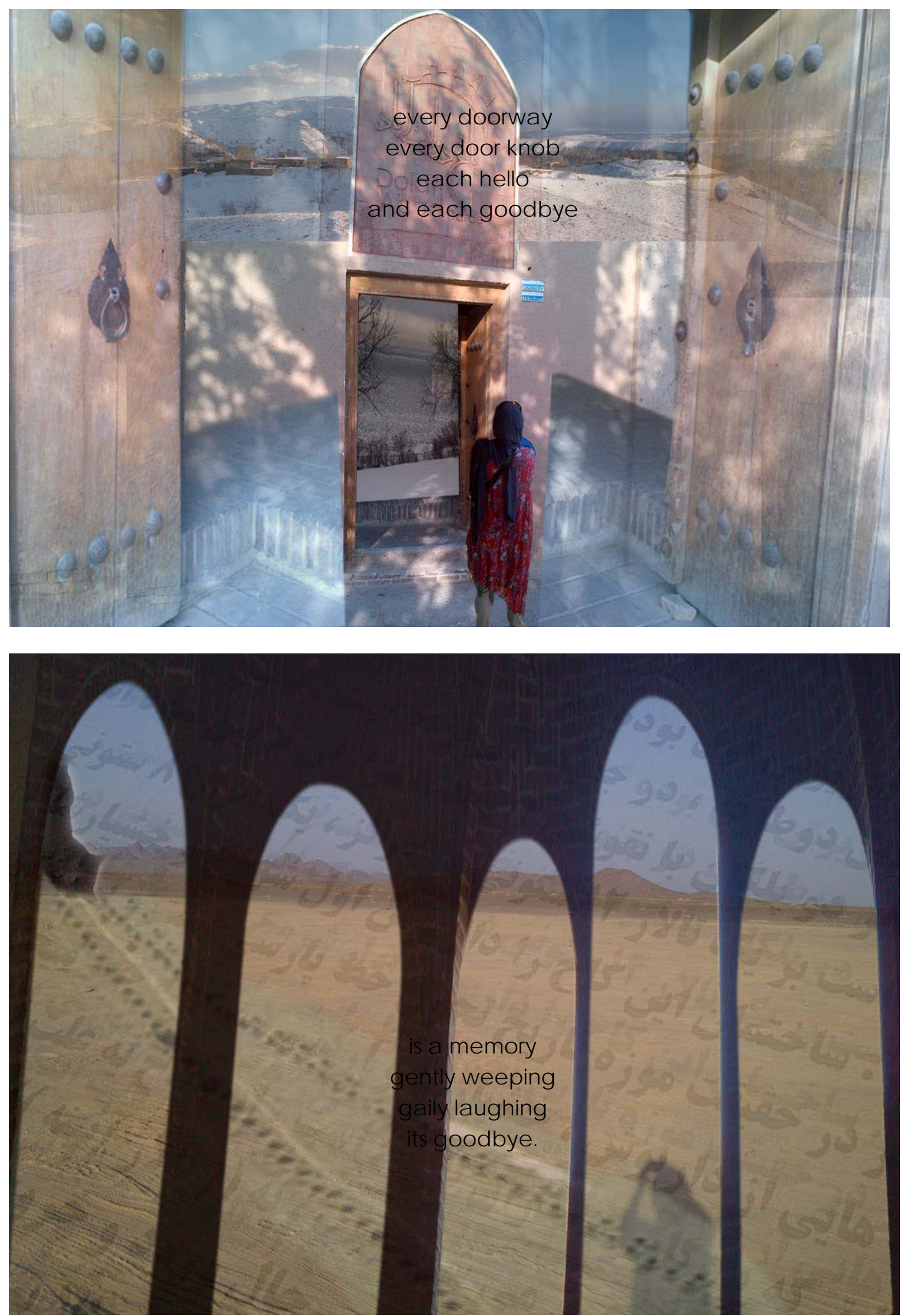

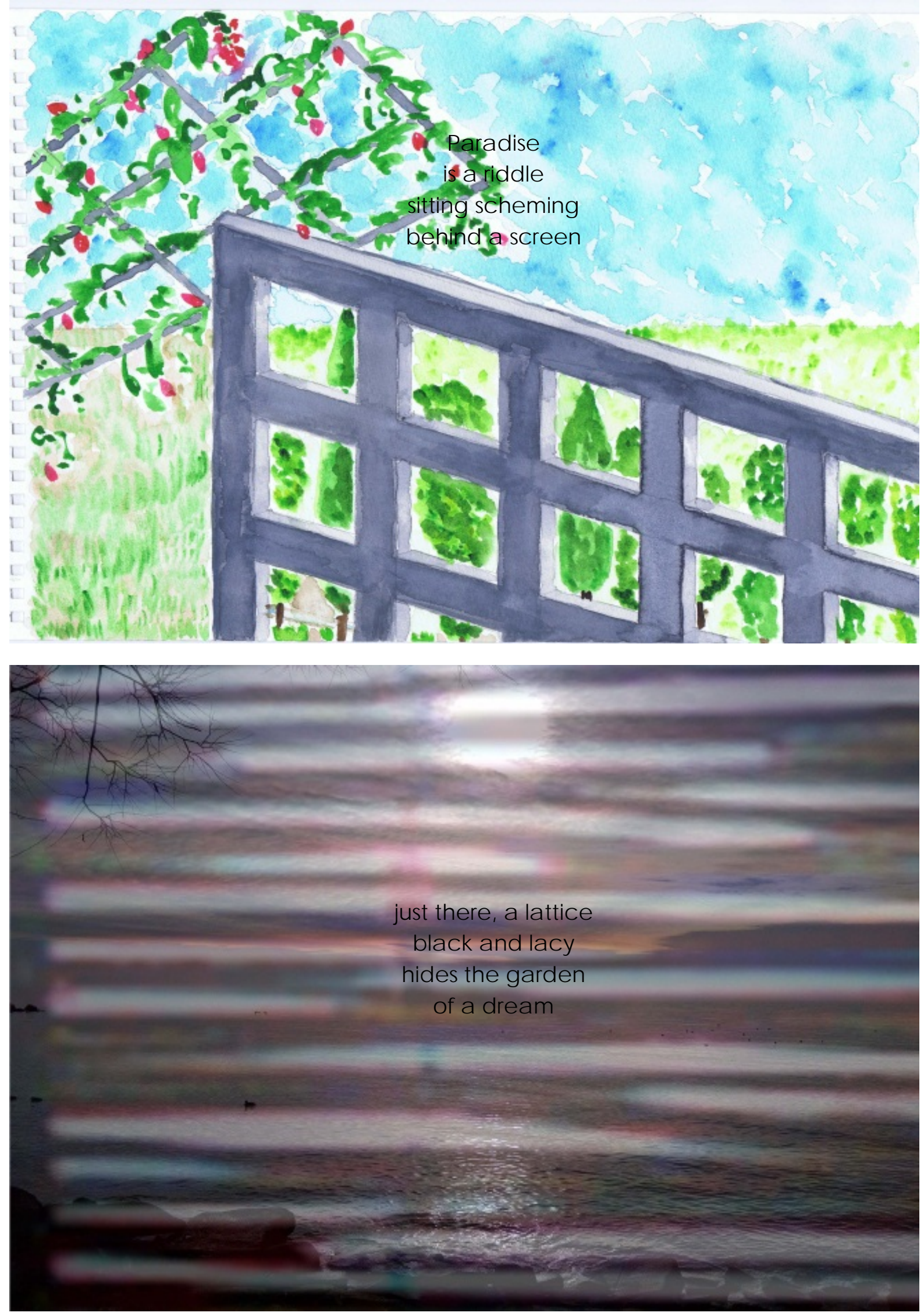

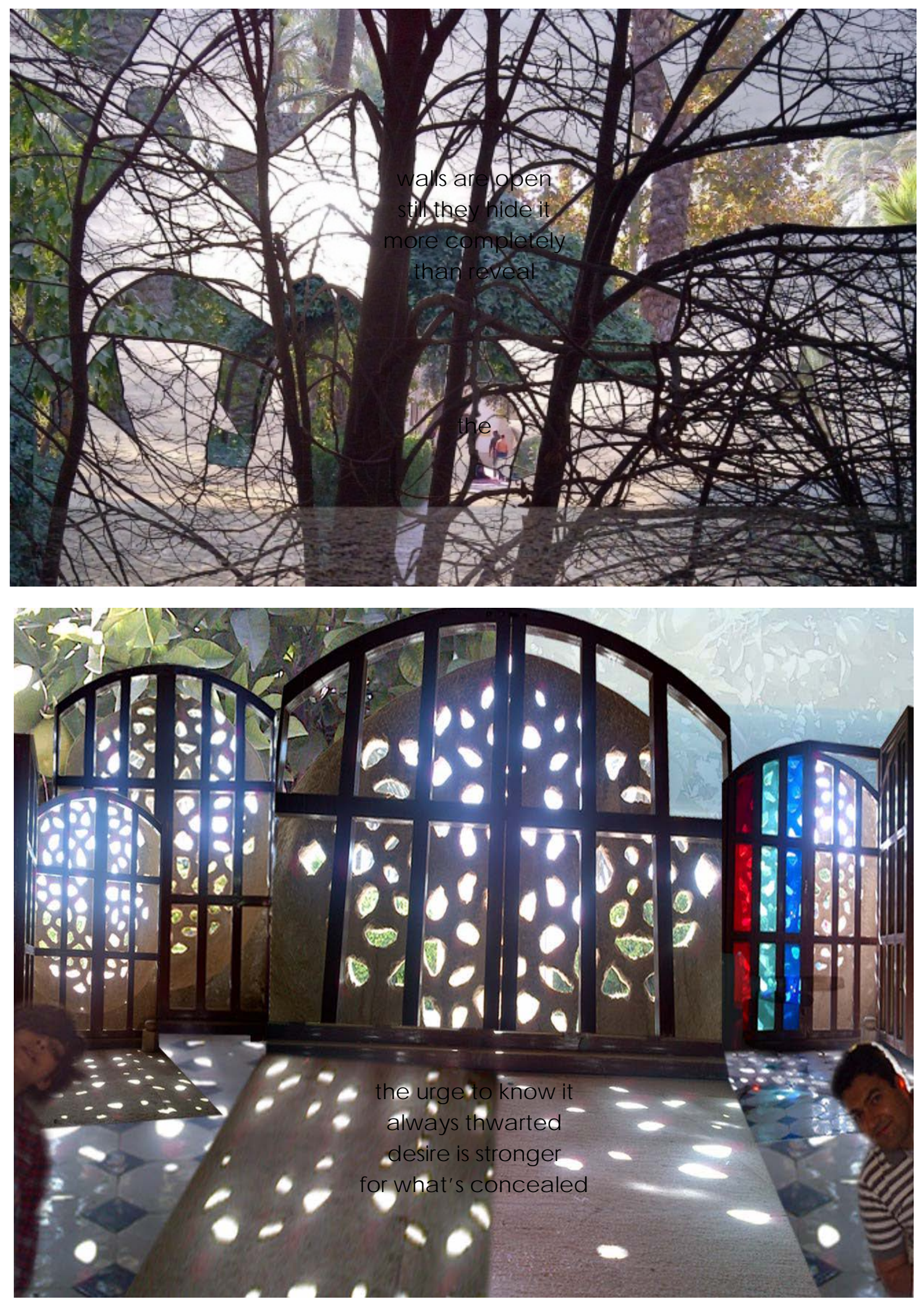


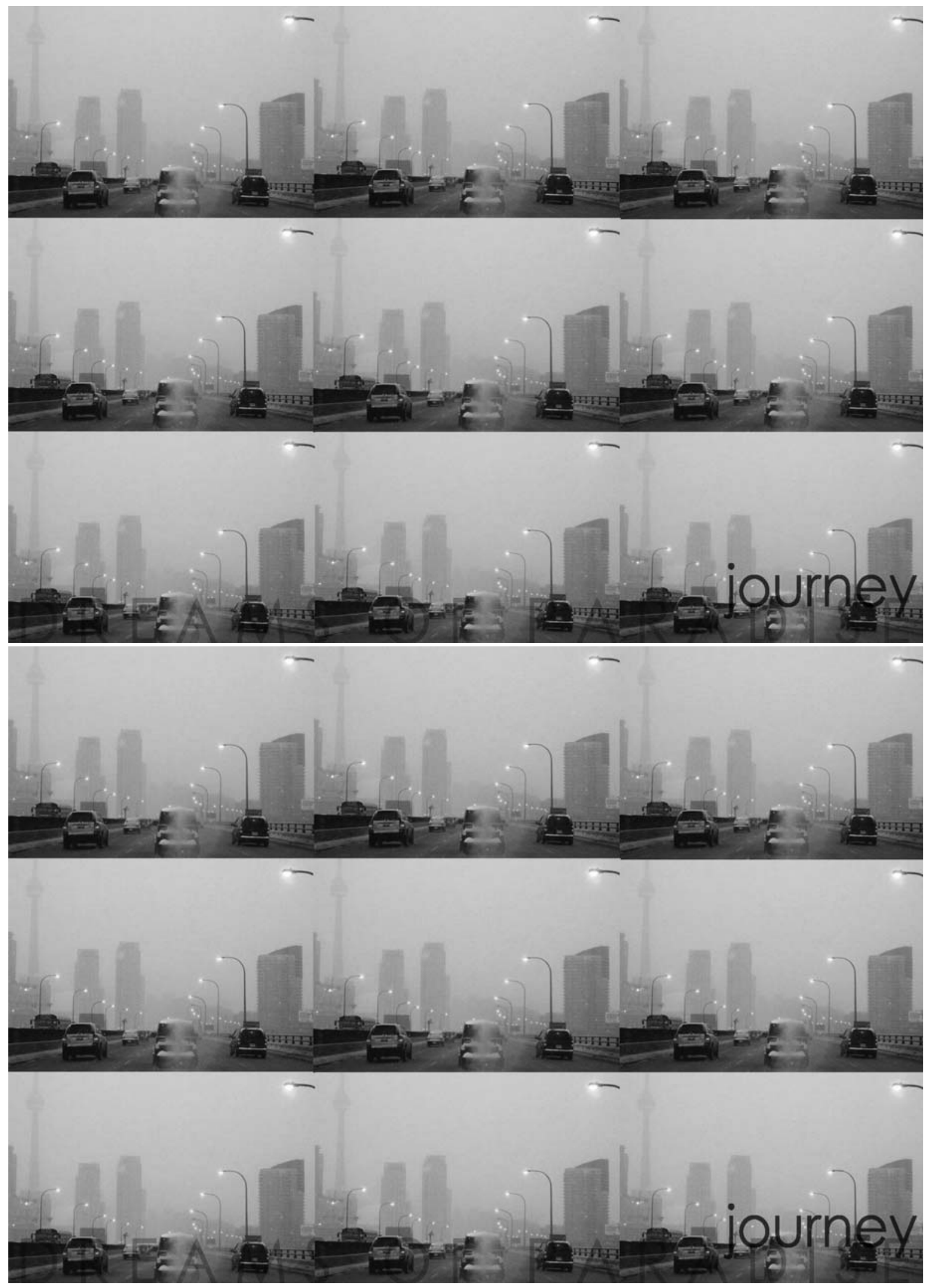



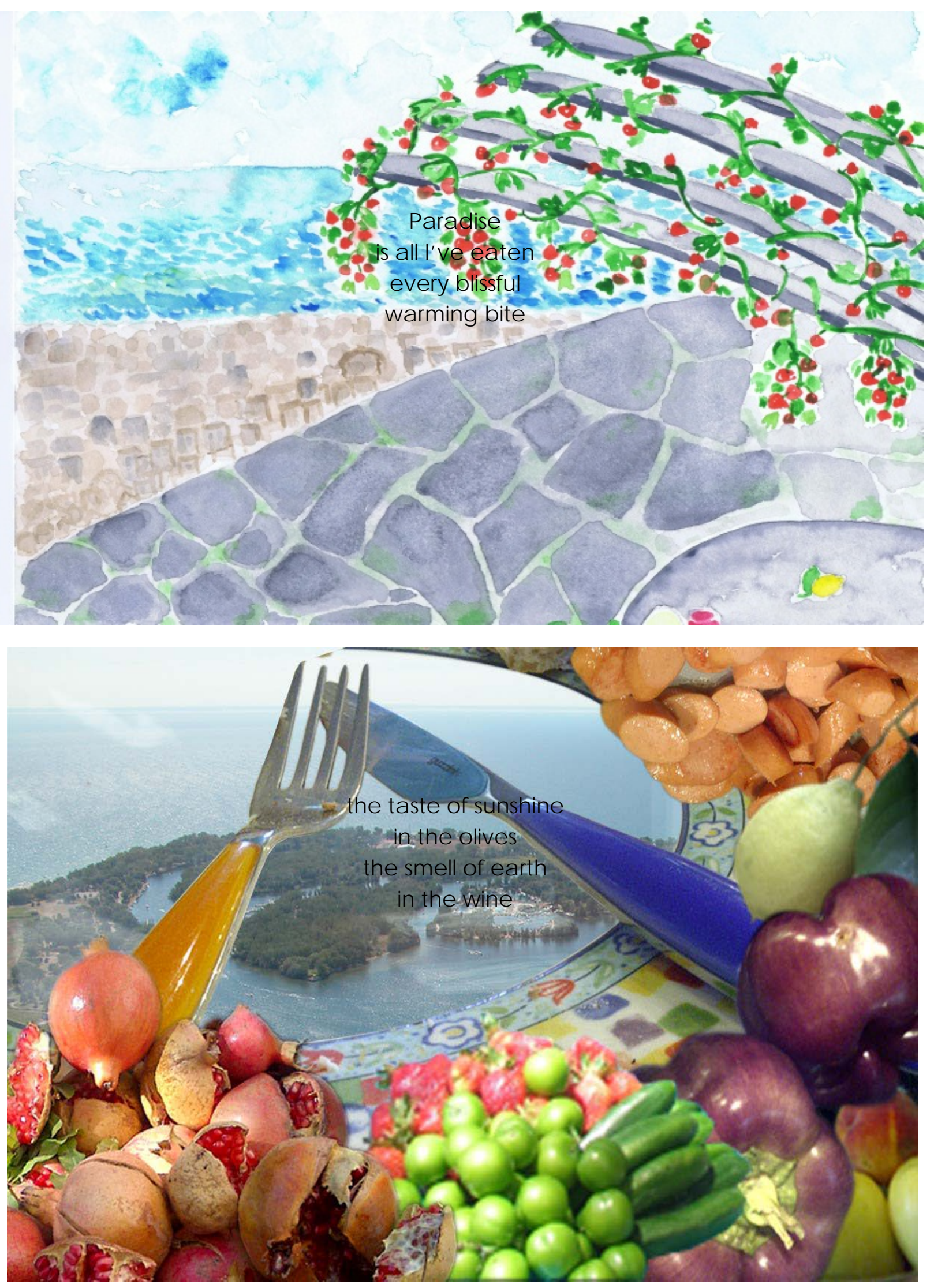

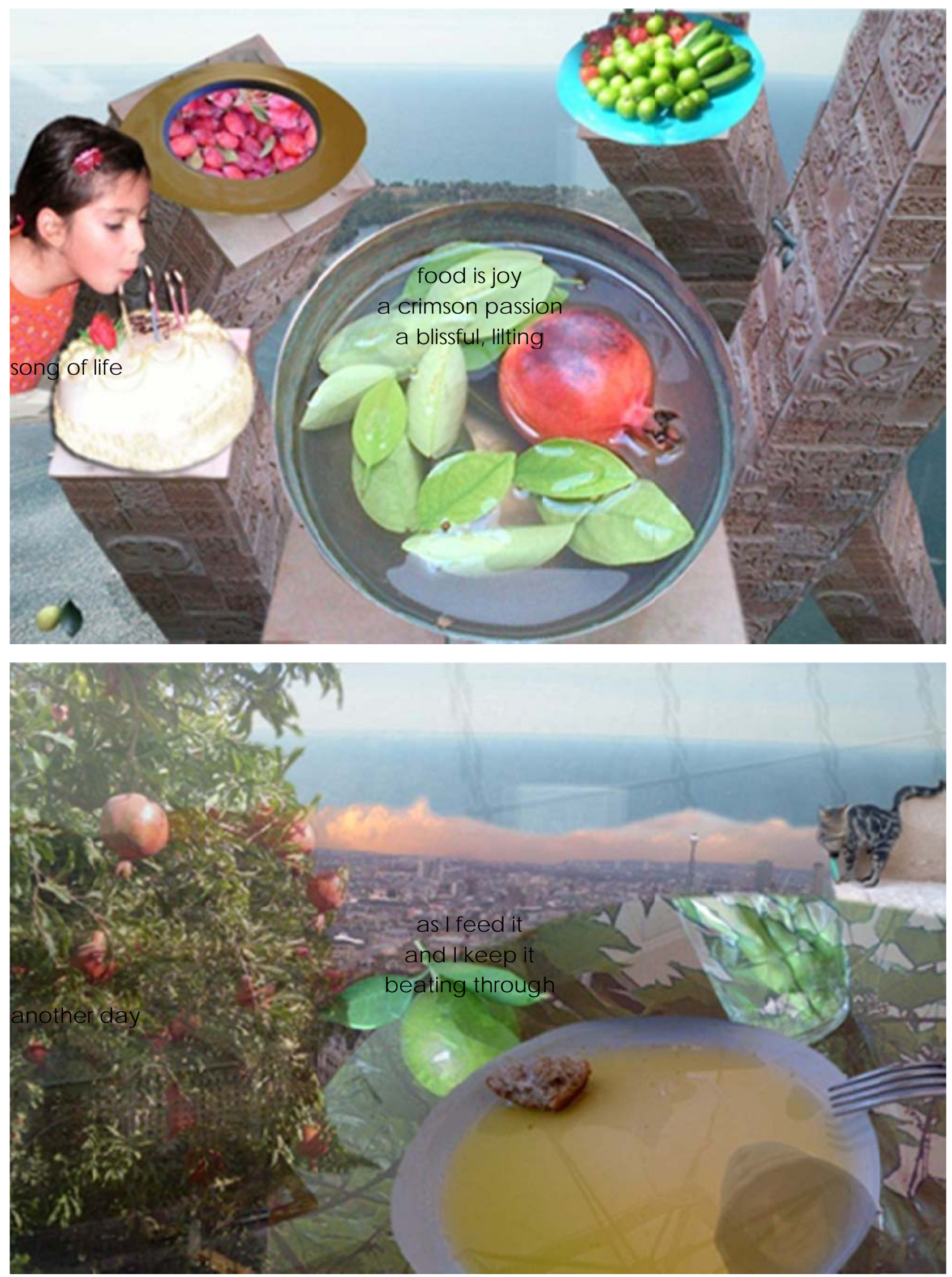

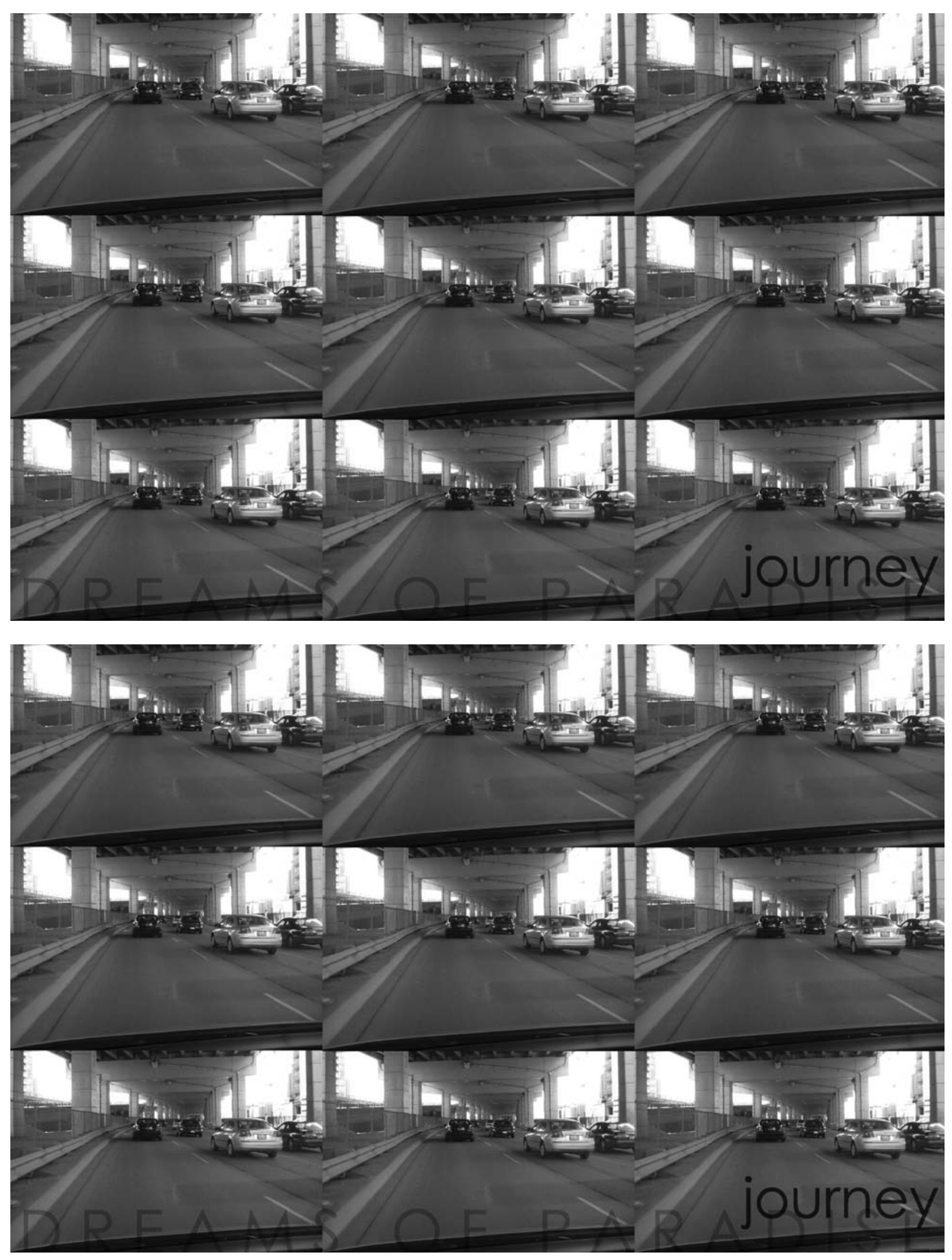

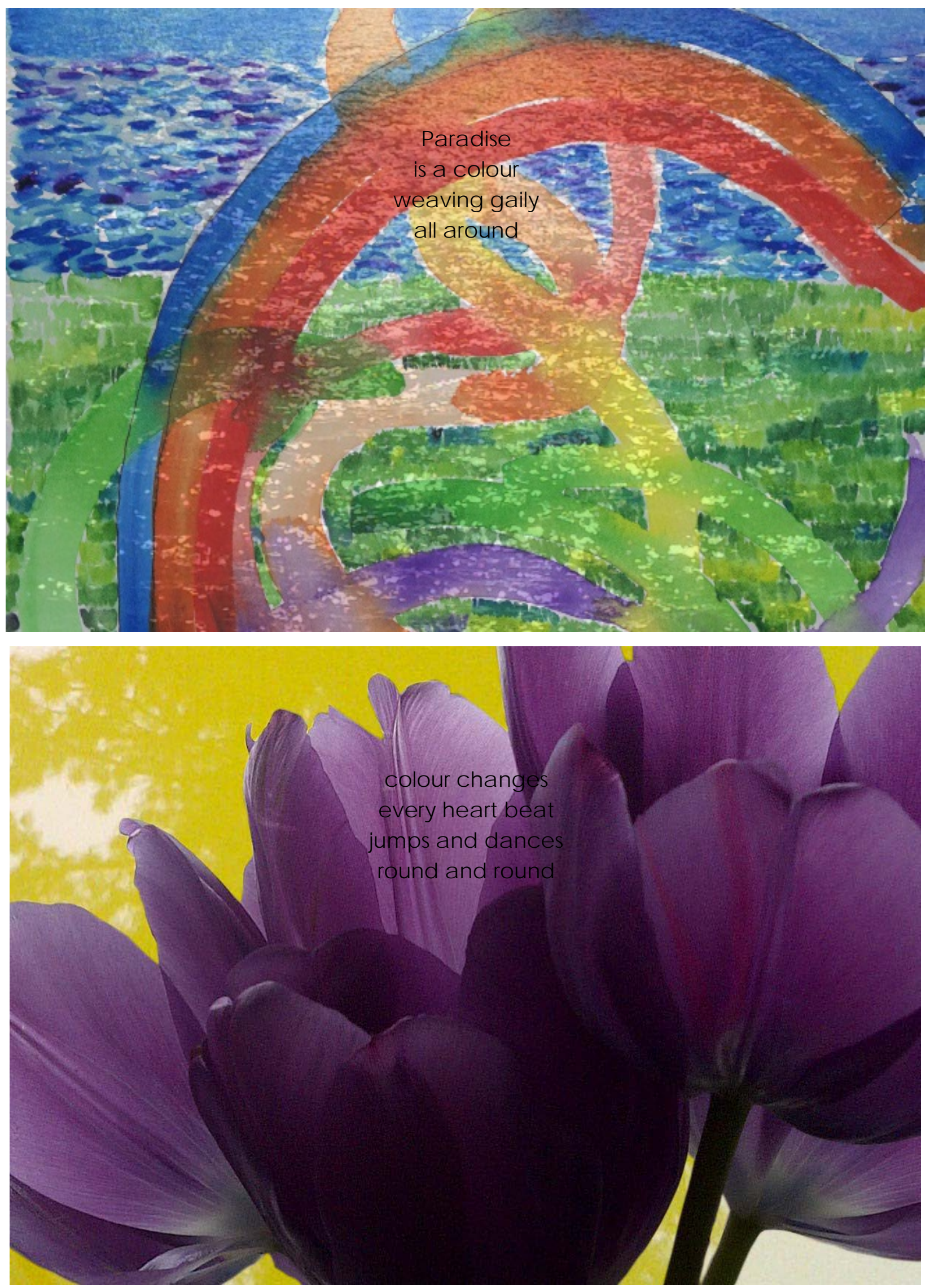

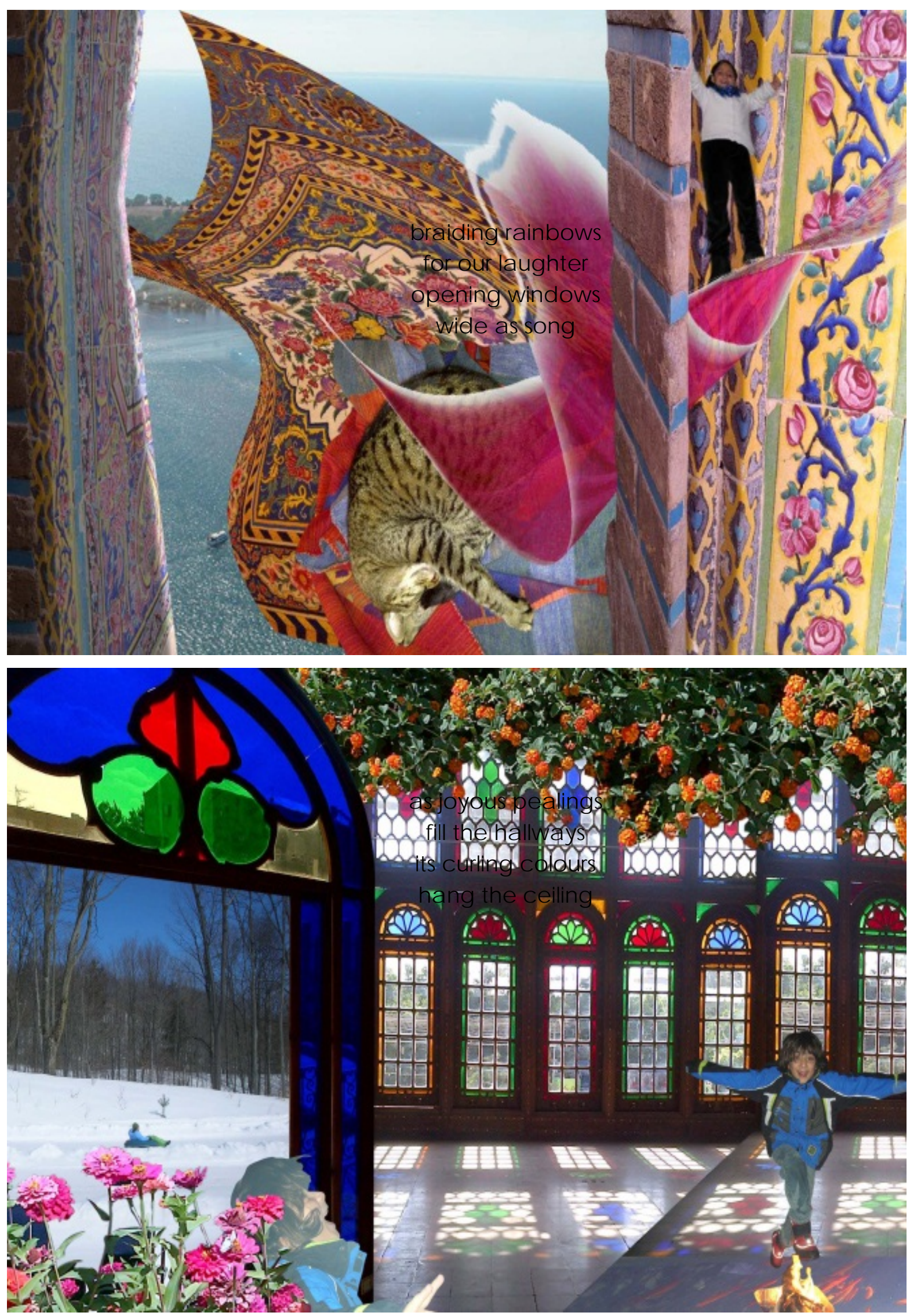

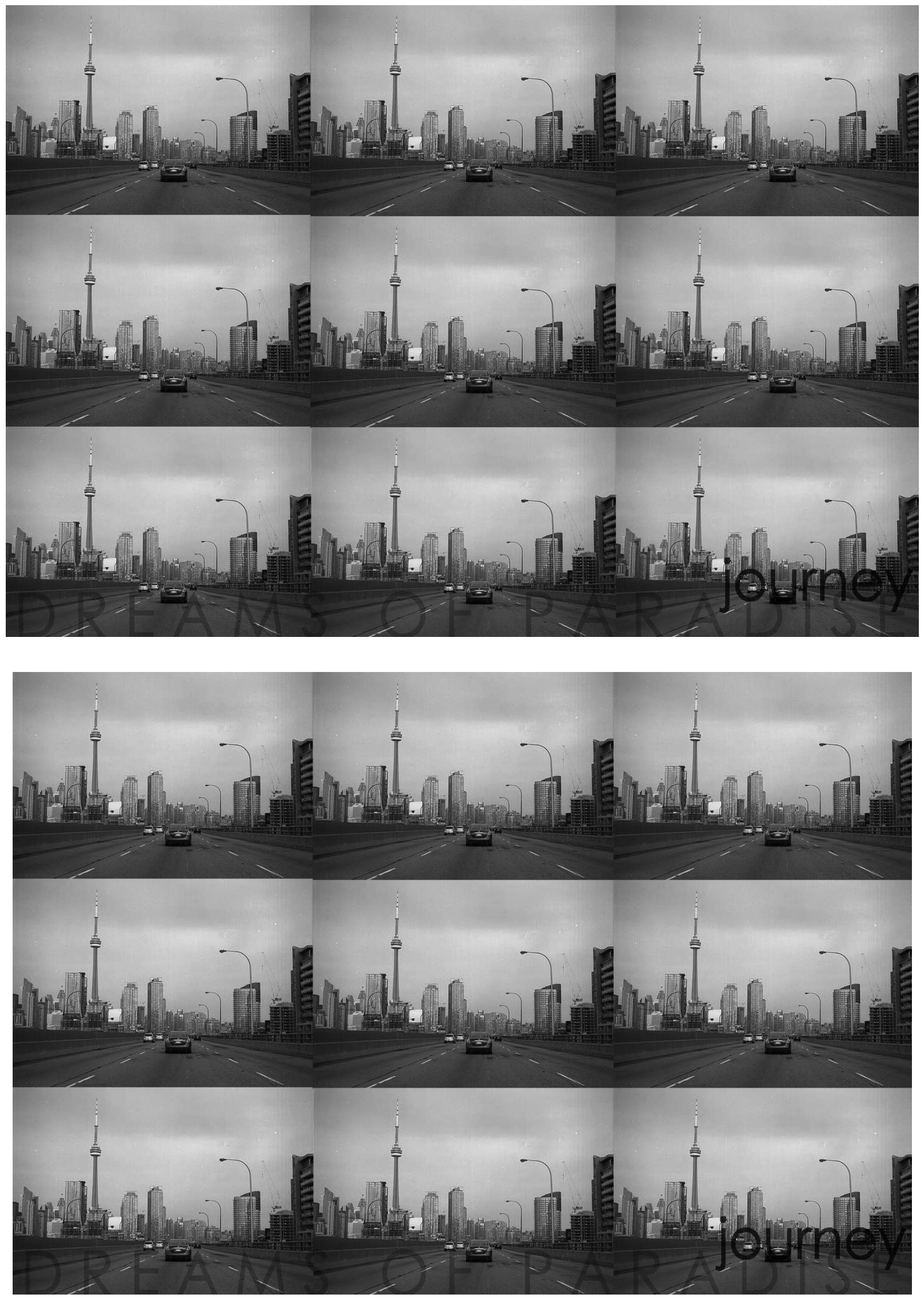

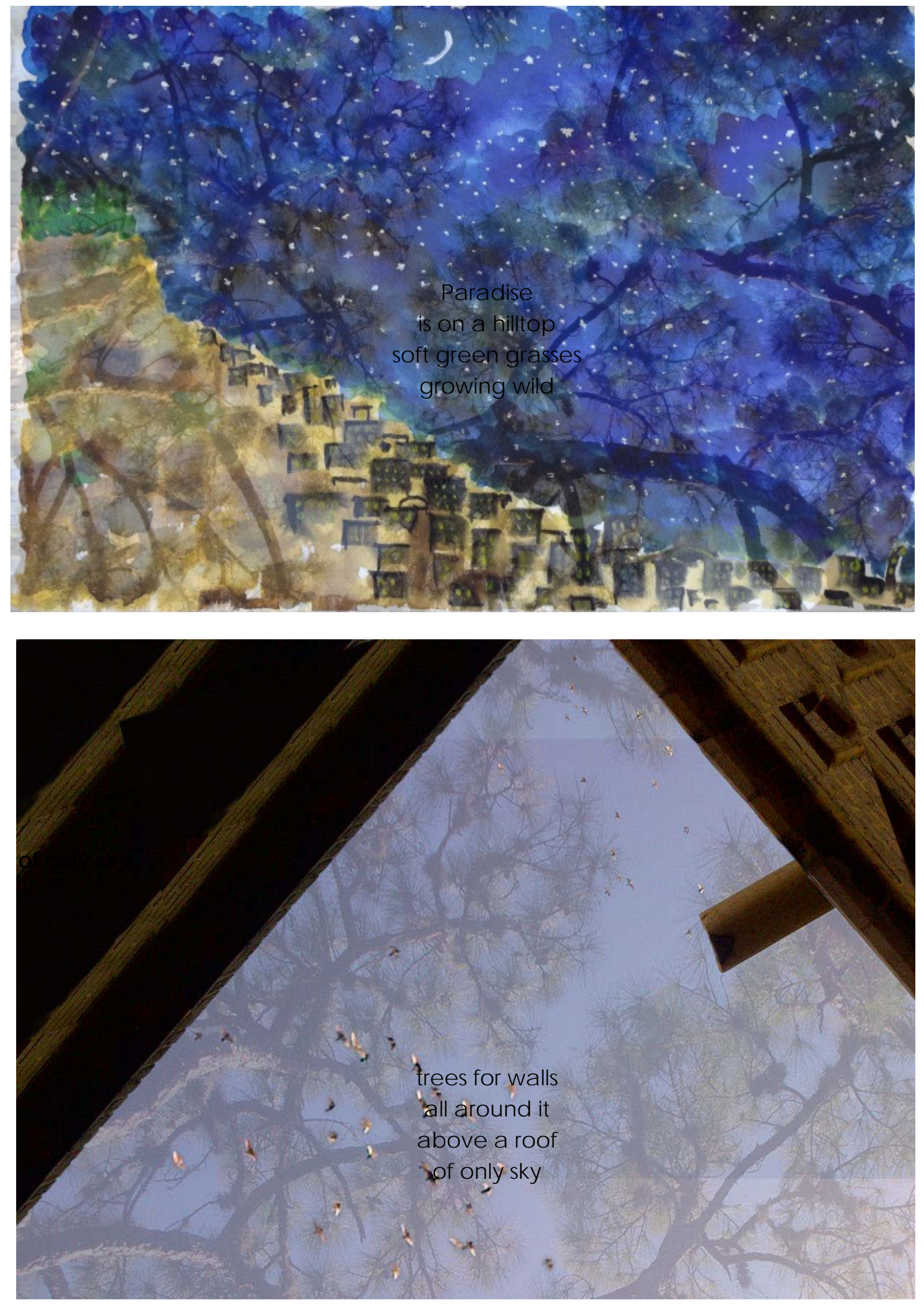

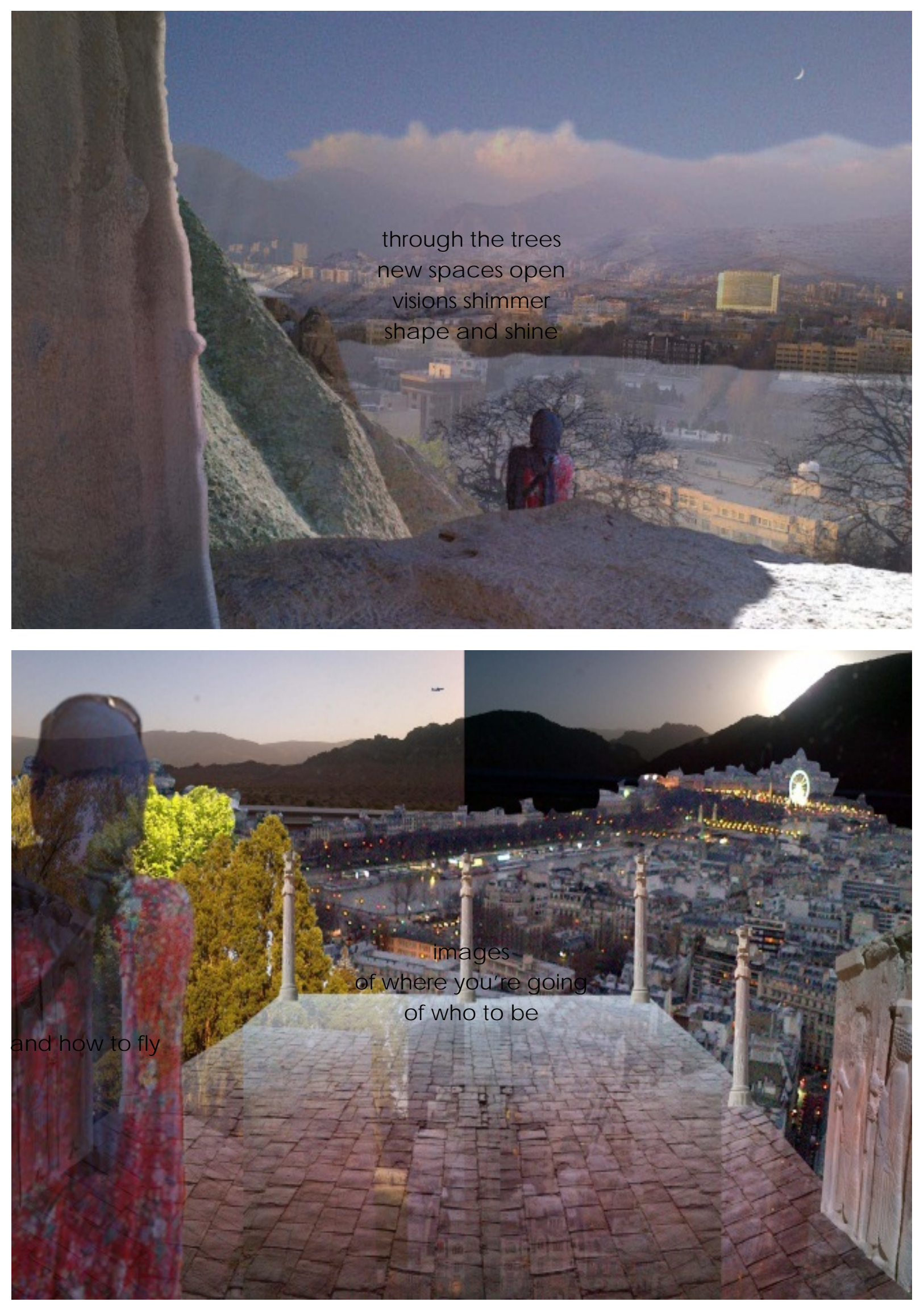

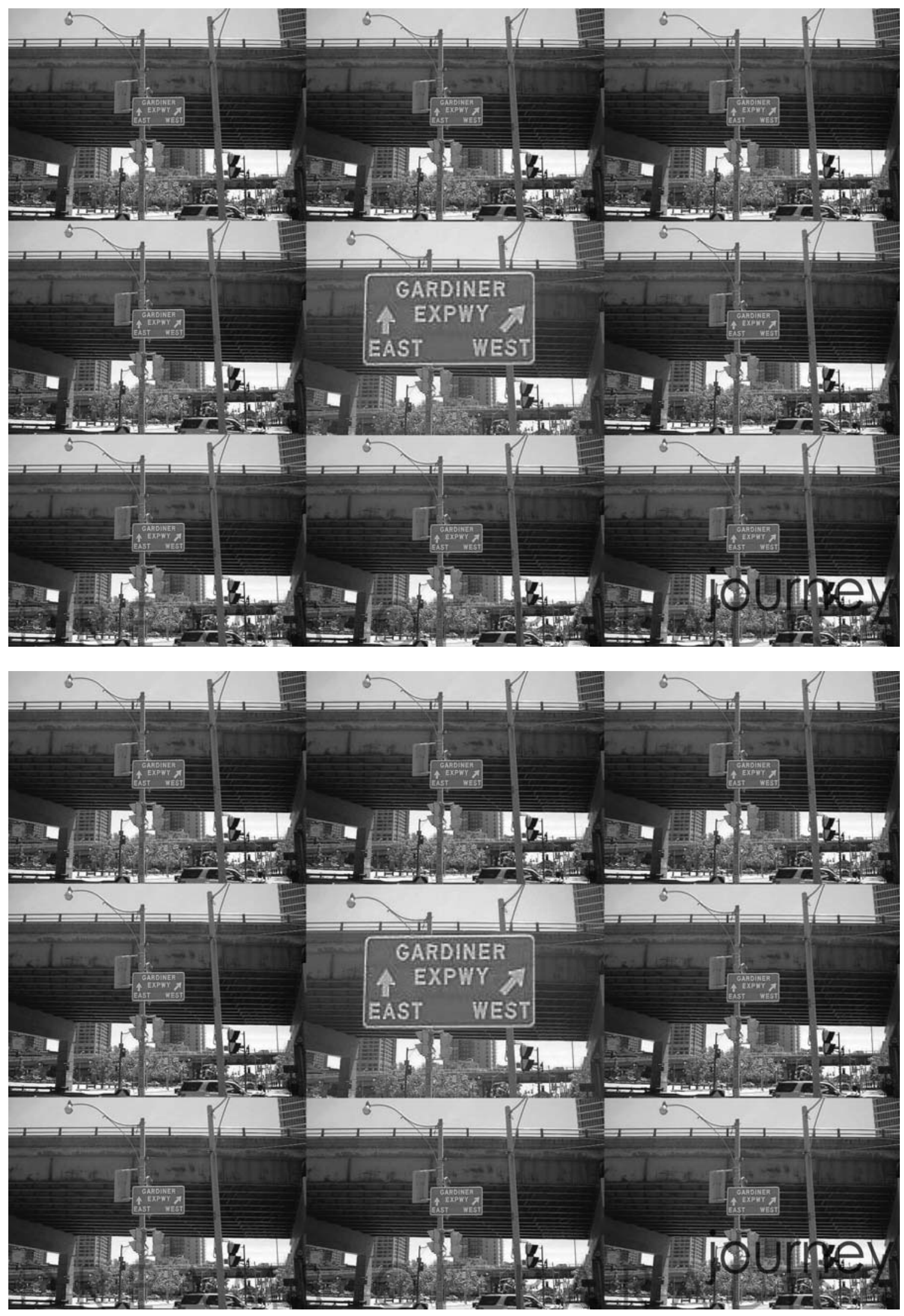


\section{THE MEDIUM IS THE MESSAGE}

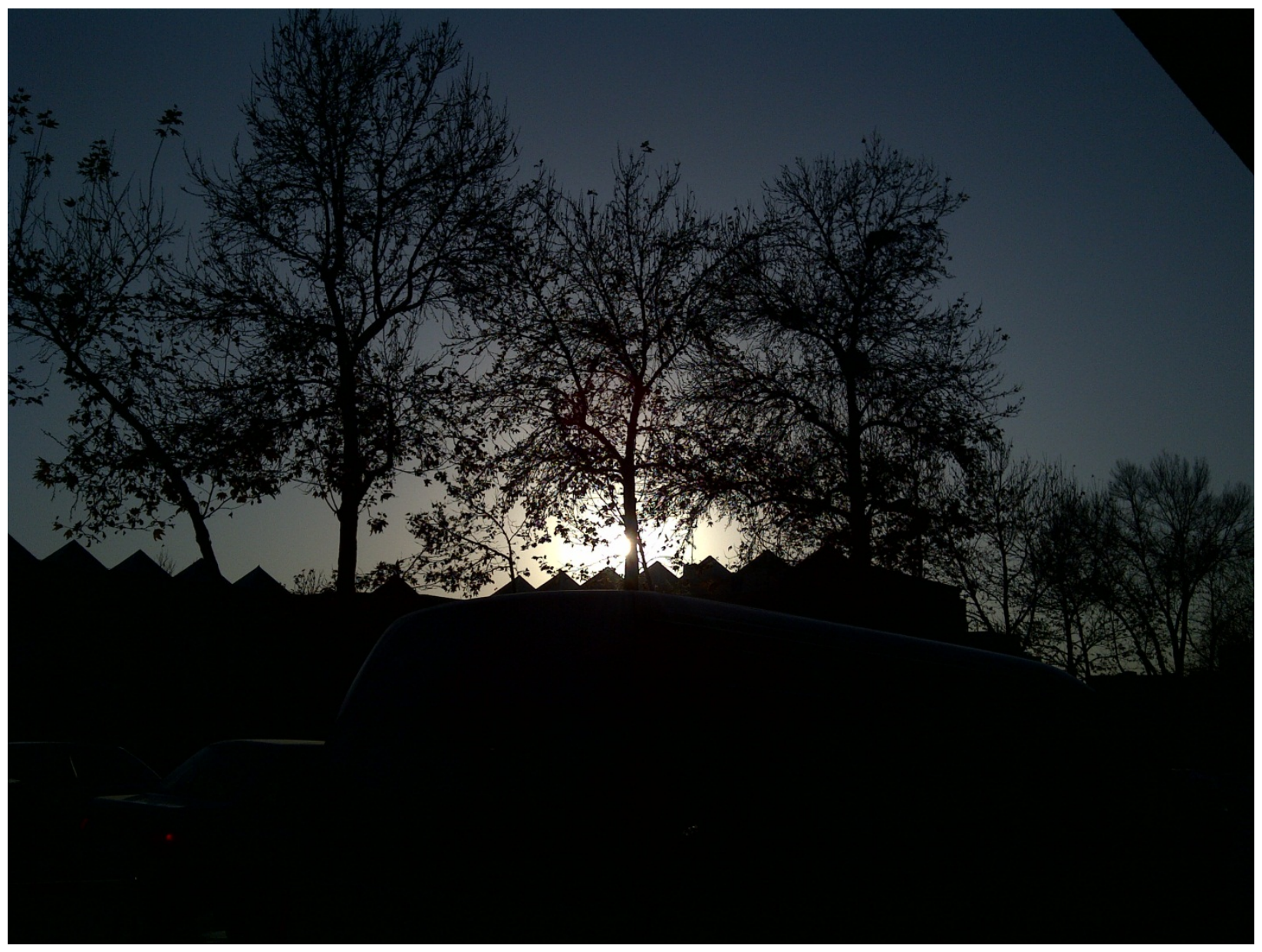


"Media come in pairs, one "containing" the other. The contained medium is the message of the containing one, but the effects of the latter are obscured for the user, who focuses on the former. Because those effects are so powerful, any message, in the ordinary sense of "content" or "information," has far less impact than the medium itself. Thus, "the medium is the message"."

(McLuhan, 1964. p. xv)

"My purpose... has been to dramatize and illustrate the ways in which memory func tions through asso c ia tions, leaps, or other disloca tions out of time or space and how the more profound of these occurencescan give us a new understanding of our relation to the world." (Kuberski, 1992. p.2) 
There has been a kind of heart-brea king comfort in sitting 10,000 kilometers a way and being able to navigate my country with the flex of a fingervia Google Maps - the scale expanding and contracting like a beating heart. Now seeing the green of North America, Russia, China and Europe contrasting with the dun of the Middle East and North Africa, now finding the house I spent childhood vacations in lingering by the desert.

The odyssey of the search for paradise has been a joumey with parallels, its resolution a metaphor for a personal resolution. As I travelled thousands of years back in time to understand the origins, so did I attempt to make sense of my own crossing from Iran to Toronto. Both joumeys were burdened by decisions, choic es, and consequences. Both had migration as their impetus, and memory as their agent of transformation.

Memory has been the magic al elixir enabling the alchemy of hope, from whose nebulous surface visions of promises shimmer. Signific antly, even as the memories transformed into visions of new possibilities, they have reta ined their identity as imprints of what has passed. Conta inment of the design investigation within the realm of memory-collage honours those images that made its architecture possible while validating their dominion through the fid elity of the medium.

I have memories of commonplace trips within Toronto duning the years before travel back home and elsewhere in the world became a beacon illuminating and clarifying the landscape of what was ostensibly my home. A walk to the store in which I would suddenly and acutely become a ware of my displacement. Where the ache of where I found myself placed had no rhyme or reason, where the sense of alienation from my immediate physic al surround ings transported me to a purgatory of permanent placelessness, the displacement of not belonging anywhere.

J oumey, the accretion of memory, and its transformation through desire have been the agents of moving from the purgatory of placelessness to the paradise of possibilities. This project has served to illustrate how the act of migration, of travel to new locations, with new ways of understanding the world and my place in it, has enabled a transition from 
displacement to sanc tuary. This is my architec ture of the heart - memory transformed into vision through the joumey of desire.

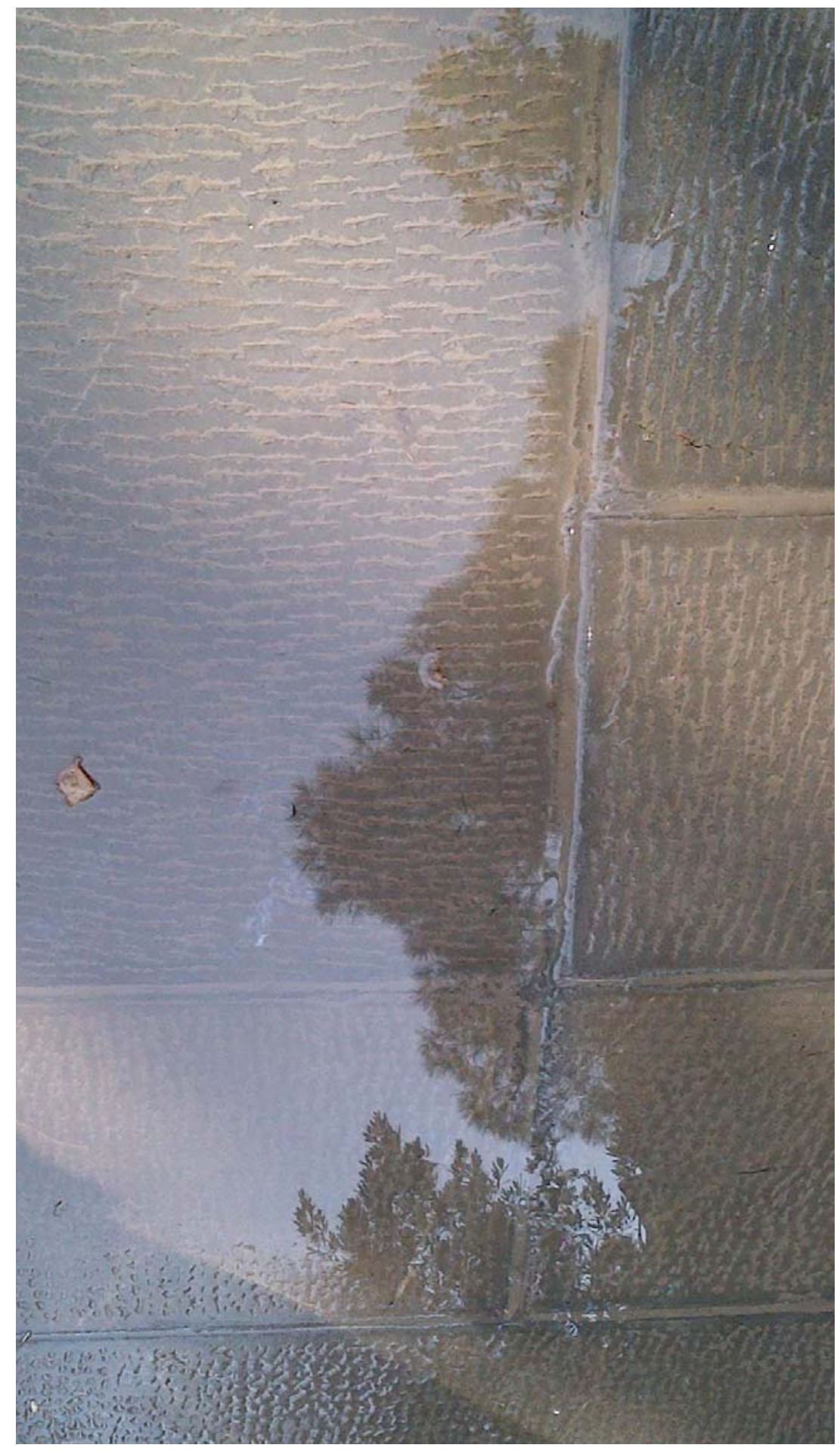




\section{BIBUOGRAPHY}

Aciman, A., \& New York Public Library. (1999). Letters of transit: Reflections on exile, identity, language, and loss. New York: New Press.

Allsen, T. T. (2006). The royal hunt in Eurasian history. Phila delphia: University of Pennsylvania Press.

Ba khtiari, S. (2010). Road Atlas of Iran. Tehran, Iran : Gita shenasi Geographic and Cartographic Foundation.

Ba hloul, J . (1996). The architecture of memory: A J ewish-Muslim household in colonial Algeria, 1937-1962. New York: Ca mbridge University Press. Bastéa, E. (2004). Memory and architecture. Albuquerque: University of New Mexic o Press.

Bastani Parizi, M. E. (1978) Epic of the Desert.Tehran, Iran : Sepehr Publishing.

Bastéa, E. (2004). Memory and arc hitecture. Albuquerque: University of New Mexico Press.

Beazley, E. and Harverson, M. (1982). Living with the Desert : [Working Buildings of the Iranian Plateau]. Warminster, England : Aris \& Phillips Ltd.

Bloomer, K. C., \& Moore, C. W. (1977). Body, memory, and architecture. New Haven: Yale University Press.

Burke, A. and Elliott, M. (2008). [Lonely Planet] Iran. O akland, CA : Lonely Planet Public a tions Pty Ltd.

Calvino, I. (2002). Invisible Cities. Toronto : Vintage Canada.

Canepa, M. P. (2009). The two eyes of the Earth: Art and ritual of kingship between Rome and Sasanian Iran. Berkeley: University of Califomia Press.

Cura tola, G and Scarcia, G. Shore, M. trans. (2007). The Art and Architecture of Persia. New York: Abbeville.

De Bella igue, C. (2005). In the rose garden of the martyrs: A memoir of Iran. New York: HarperCollins.

Delumeau, J. O'C onnell, M. trans. (1995). History of Paradise : the Garden of Eden in myth \& tradition. New York : Continuum.

Etymonline

http://www.etymonline.com/index.php? search=paradise\&searchmode=none accessed J une 27, 2011 
Ferd owsi, A. (orig.1021, curr. 2007). Book of Kings. Tehran, Iran : Sayeh Nima.

Google Maps

http://maps.google.ca/maps? q=iran+map\&oe=utf-8\&rls=org.mozilla :enUS: offic ia I\&c lient=firefox-a \&um $=1 \& i e=U \pi$ -

8\&ei=192qT_vWDIS49Q S3oa DOAQ \&sa =X\&oi=mode_link\&ct $=$ mode $\& c d=3 \& v e d=0$ C BIQ_A $\mathrm{UoAg}$ accessed December 2011

Hay, E. (2007). Late nights on air: A novel. Toronto, ON: McClelland \& Stewart.

Hoad, T. F. (1986). The Concise Oxford dic tionary of English etymology. Oxford: Oxford/Clarendon Press.

Hobhouse, P. (2004). Gardens of Persia. Carlsbad, CA : Kales.

Homstein, S. (2011). Losing Site : [Architecture, Memory and Place]. Surrey, England : Ashgate.

Kasrain, N. and Naderi, K. A. (2003). Iranian Architecture. Tehran : Agah Publishing House.

Khansari, M., Moghta der, M. R., \& Yavari, M. (1998). The Persian garden: Echoes of paradise. Washington, DC: Mage Publishers.

Kuberski, P. (1992). The persistence of memory: Organism, myth, text. Berkeley, Ca lif: University of Califomia Press.

McLuhan, M. (1964). Understanding media: The extensions of man. New York: McG rawHill. Moynihan, E. B. (1979). Paradise as a Garden in Persia and Mughal India. New York: Braziller.

Nasr, T. (S). (2010). The Manifestation of Wisdom in Persian Gardens. Shiraz, Iran : Rokhsid.

Pimia, H. and Ashtiani, A. (2007). History of Iran : [a Comprehensive History of Iran]. Tehran, Iran : Behzad Publications.

Pollan, M. (2008). A place of my own: The architecture of daydreams. New York: Penguin Books.

Rykwert, J . (1972). On Adam's house in Paradise ; the idea of the primitive hut in architec tural history. New York: Museum of Modem Art.

Sassen, S. (1998). Globalization and its discontents: [essa ys on the new mobility of people and money]. New York: New Press.

Sackville-West, V. (2008). Passenger to Teheran. London: Ta unis Parke Pa perbacks. 
Schacter, D. L. (2001). The seven sins of memory: How the mind forgets and remembers. Boston: Houghton Mifflin.

Seven Wonders of the World

http://en.wikipedia.org/wiki/Wonders_of_the_World

accessed April 16, 2012

Sha hbazi, A. S. (2005). Illustrated guide to Takhte J a mshid. Tehran, Iran : Sa firan.

The Architecture of Memory

Google Book Reviews

http://books.google.ca/books? id =K359yB3AFTYC \&dq=isbn\%3A0300021429\&q= accessed May 2, 2012

The Circle of Ancient Iranian Studies

http://www.cais-soas.com/CAIS/Images2/Maps/Large_Iran.jpg

accessed December 1, 2011

Wikipedia

http://en.wikipedia .org

accessed May 2012

IMAGES

Photographs by author unless otherwise noted 